\title{
Encuesta Nacional
}

de Salud y Nutrición 2018

Presentación de resultados 


\section{Introducción}

- La Secretaría de Salud, el Instituto Nacional de Salud Pública (INSP) y el Instituto Nacional de Estadística y Geografía (INEGI), llevan a cabo el levantamiento de la Encuesta Nacional de Salud y Nutrición (ENSANUT) 2018, con el objeto de conocer el estado de salud y las condiciones nutricionales de la población en México.

- Los Programas Sectoriales de Salud y de Desarrollo Social requieren de indicadores para el seguimiento y evaluación, siendo referente básico de información la ENSANUT. 


\section{Antecedentes}

1986 La Secretaría de Salud crea el Sistema Nacional de Encuestas de Salud (SNES).

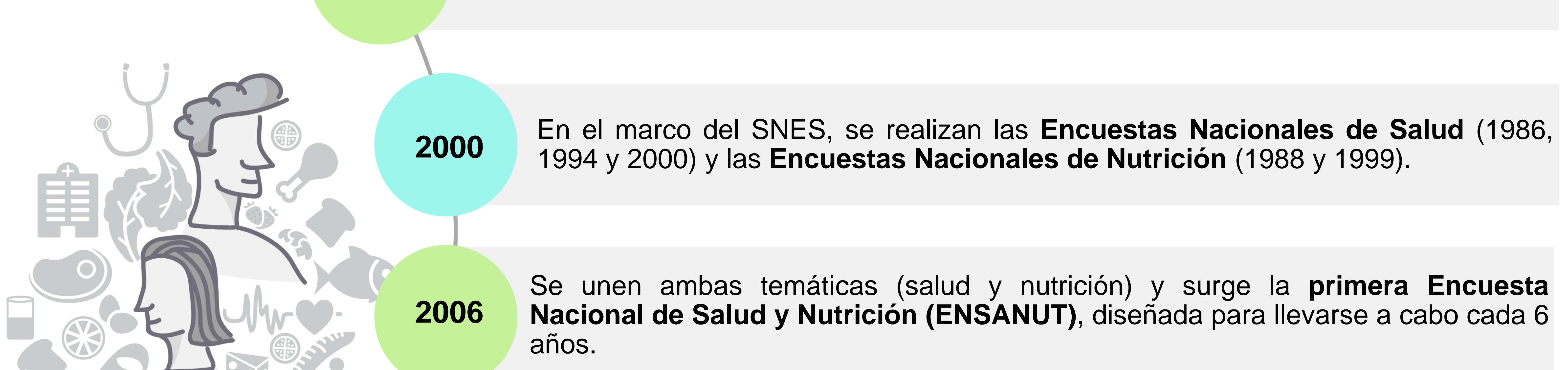

Segunda ENSANUT, que da continuidad a lo reportado en la encuesta del 2006, permite evaluar avances y resultados. 


\section{Objetivos generales}

\section{ENSANUT 2018}

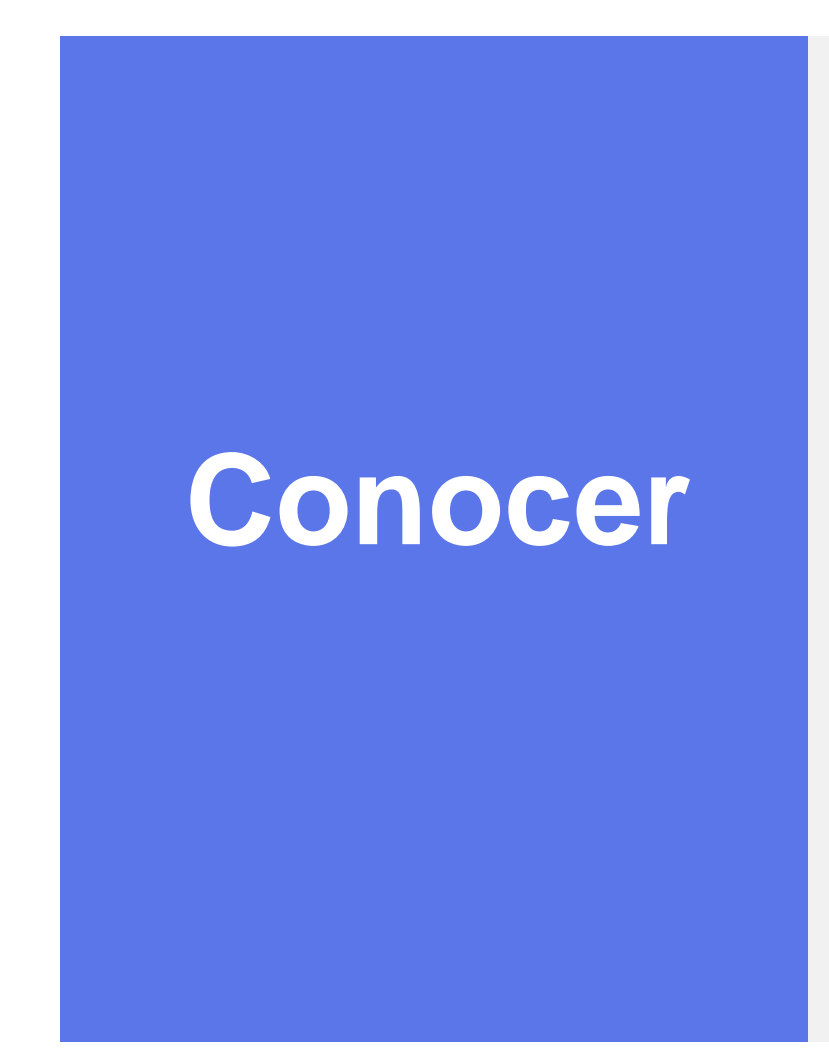

- Condiciones de salud y nutrición.

- Prevalencias y distribución de enfermedades agudas y crónico degenerativas.

- Sobre población con anemia o deficiencias de los micronutrimentos.

- Sobre población con problemas de desnutrición y obesidad.

- Información sobre el desarrollo infantil temprano y las prácticas de alimentación infantil.

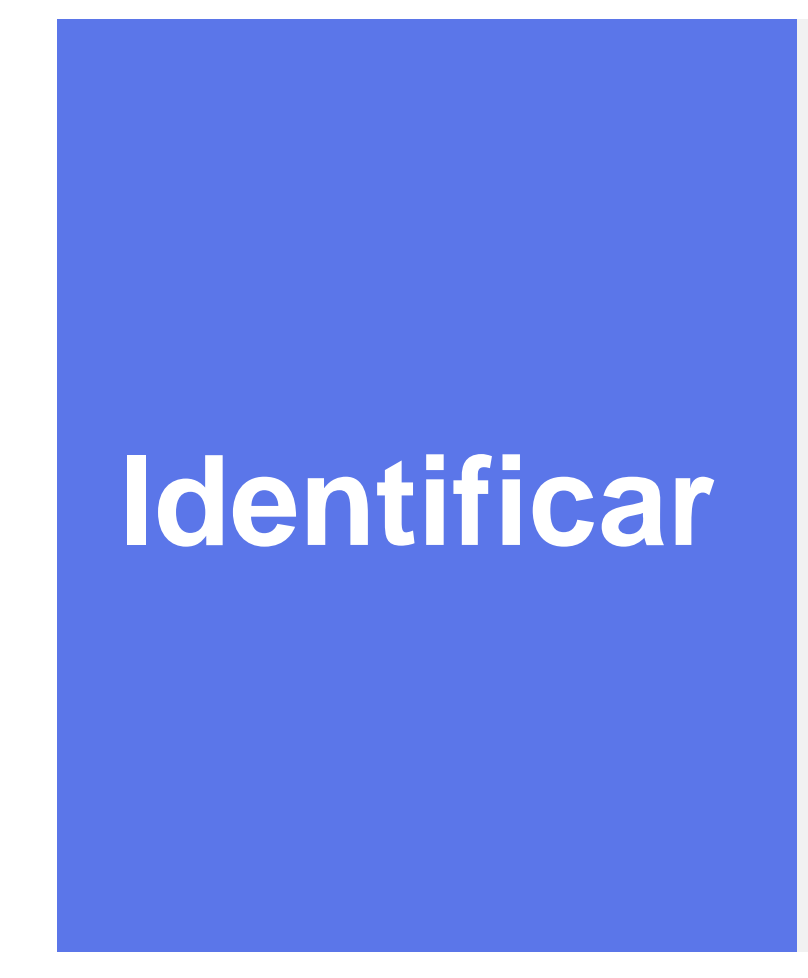

- Cobertura, calidad, accesibilidad y utilización de programas de salud y nutrición.

- Gastos personales y familiares para salud.

- Factores ambientales, socioeconómicos y culturales determinantes del proceso salud-enfermedad. 


\section{Aspectos metodológicos}

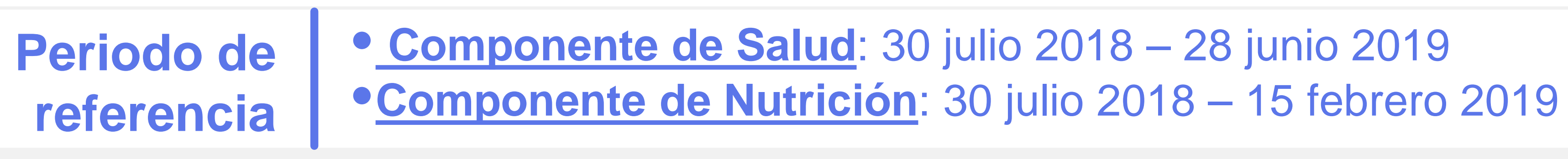

Unidades de observación

- Vivienda

- Hogares

- Población de estudio:

$\checkmark$ Niñas y niños de 0 a 4 años

$\checkmark$ Niñas y niños de 5 a 9 años

Adolescentes de 10 a 19 años

$\checkmark$ Adultos de 20 y más años

Utilizadores de servicios de salud

\section{Método de recolección}

Entrevista cara a cara con cuestionario electrónico:

- informante adecuado

- informantes seleccionados*

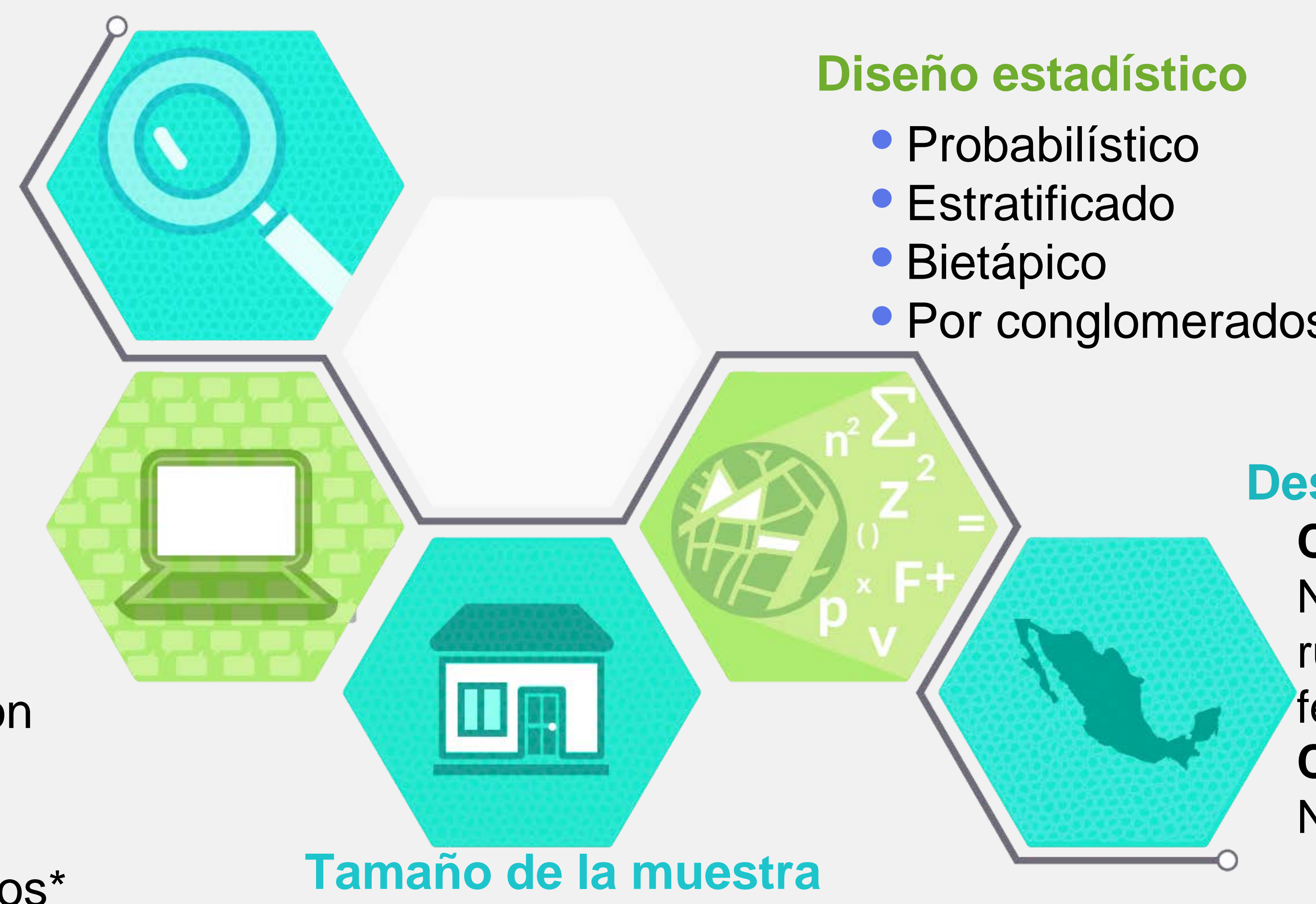

Desglose geográfico

Componente de Salud

Nacional, Nacional urbano-

rural, regional y entidad

federativa

Componente de Nutrición

Nacional y por regiones

50000 viviendas Componente Salud

32000 viviendas Componente Nutrición

que representan a $\mathbf{1 2 6 . 5}$ millones de habitantes 


\section{Colaboración Interinstitucional}

La ENSANUT 2018 tuvo un costo de 196.4 millones, de los cuales el INEGI aportó el 71 por ciento.

\section{Responsabilidades del INSP y el INEGI para el desarrollo del}

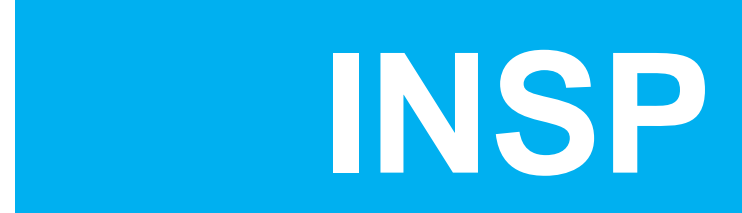

Diseño conceptual

Instrumentos de captación y Manuales

Capacitación conceptual y Estandarización del Personal (Criterios Internacionales)

Protocolos Comités de Bioética, Bioseguridad e Investigación

Monitoreo y verificación calidad de levantamiento de componente de Nutrición

\section{programa}

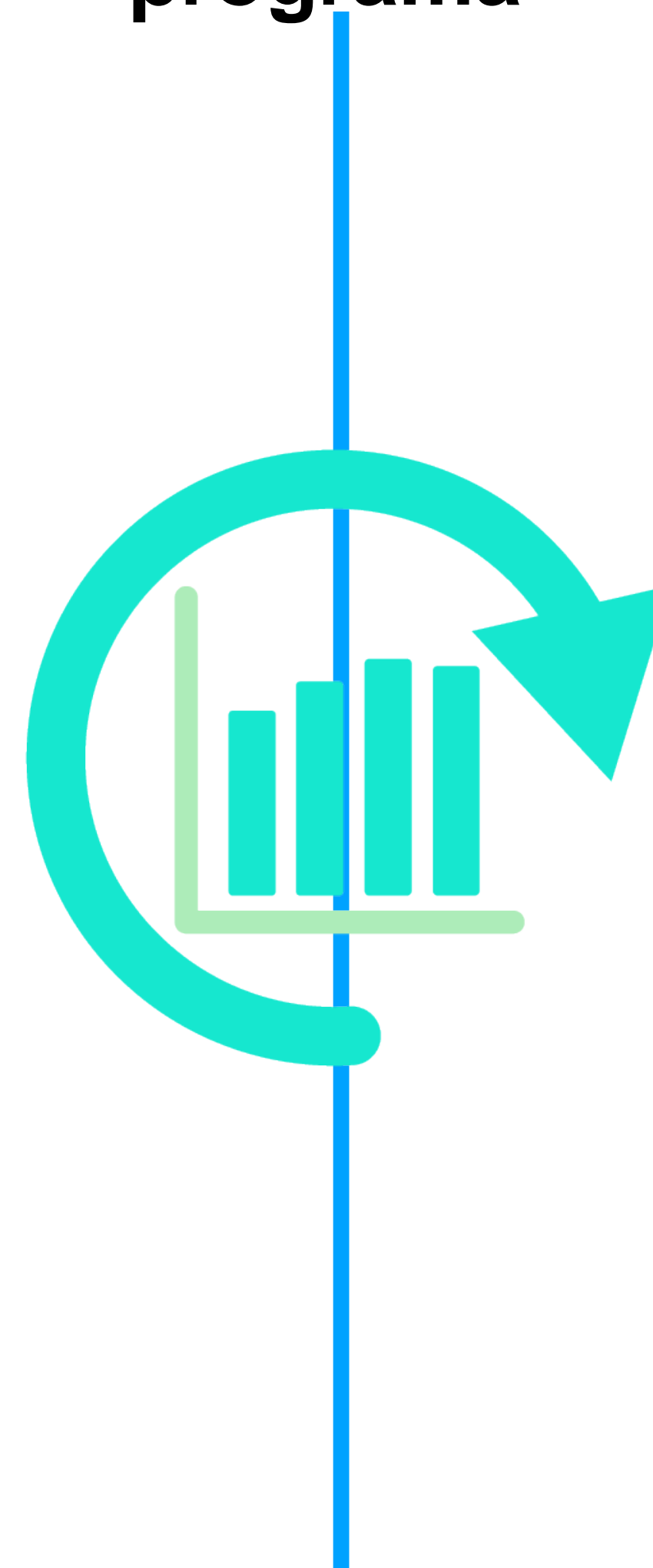

\section{INEG|}

Diseño estadístico

Diseño operativo y levantamiento en campo

Sistema de captura e integración base de datos

Integración y procesamiento de información

Compartir la información al Sistema Nacional de Información Estadística y Geográfica 


\section{Instrumentos de captación}

En total, 18 cuestionarios, 10 aplicados por equipo de entrevistadores (Componente Salud), 8 cuestionarios aplicados por equipo de especialistas: nutriólogos y enfermeras (Componente Nutrición).

\section{Cuestionarios del Componente Salud}

$\frac{1}{2}$
$\frac{0}{\frac{0}{0}}$
$\frac{0}{0}$
$\frac{0}{0}$
$\frac{.0}{0}$
$\frac{0}{4}$

1. Cuestionario del Hogar

2. Cuestionario de programas de ayuda alimentaria*

3. Cuestionario de seguridad alimentaria*
4. Cuestionario de 0 a 9 años

5. Cuestionario de Salud de Adolescentes (10 a 19 años)

6. Cuestionario de Salud de Adultos (20 años o más)

7. Actividad física en niños (10 a 14 años)

8. Actividad física en adolescentes y adultos (15 a 69 años)

9. Cuestionario de Utilizadores de Servicios de Salud

10. Cuestionario de etiquetado frontal de alimentos (20 y más años) *

* Estos cuestionarios refieren a temáticas de nutrición.

\section{Cuestionarios y pruebas de Componente Nutrición}

11. Lactancia materna y prácticas de alimentación complementaria (0 a 36 meses)

12. Frecuencia de consumo de alimentos de preescolares (1 a 4 años)

13. Frecuencia de consumo de alimentos de escolares (5 a 11 años)

14. Frecuencia de consumo de alimentos de adolescentes y adultos (12 años o más)

15. Estudio de niveles de plomo en niños y mujeres embarazadas (Temática nueva) ${ }^{\star \star}$

16. Antropometría y tensión arterial**

17. Formato de muestras sanguíneas**

18. Desarrollo infantil temprano (Temática nueva)

** Incluyen toma de muestras de sangre capilar y venosa, así como mediciones antropométricas. 


\section{Algunos temas específicos:}

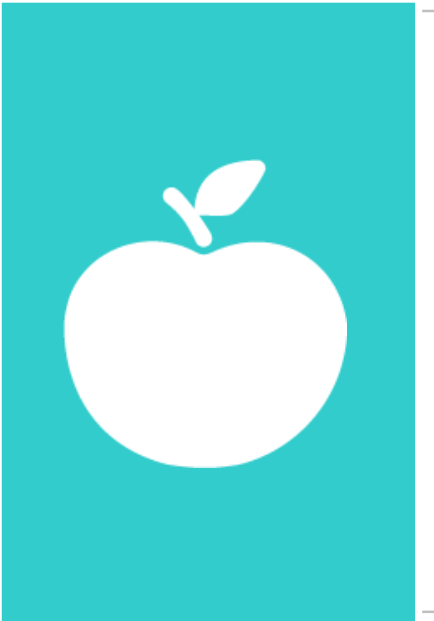

Consumo de alimentos de niños, adolescentes y adultos.

Derechohabiencia y uso de servicios de salud

(ambulatorio y hospitalario)

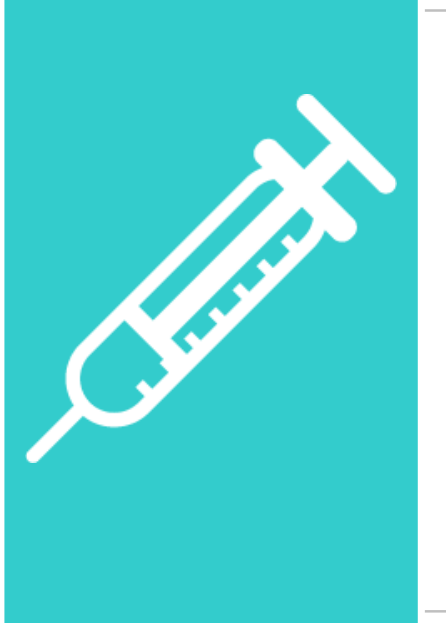

Vacunación en menores de 5 años

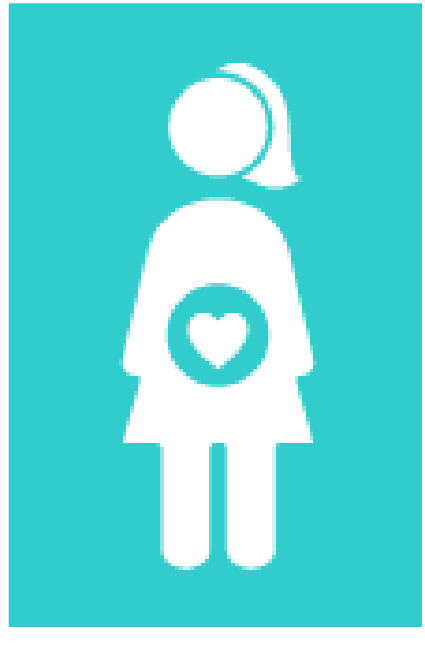

Enfermedades crónicas

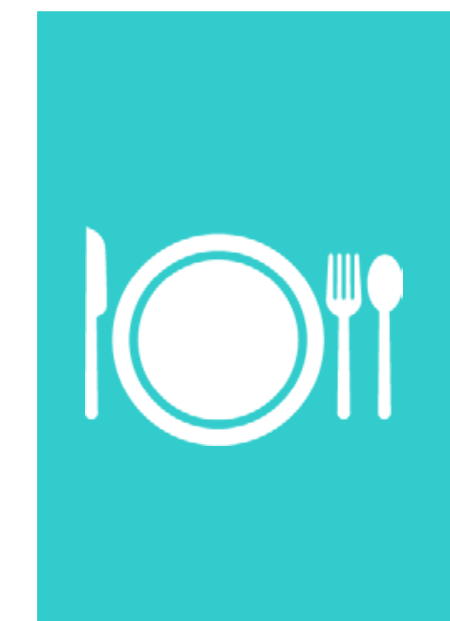$$
\text { Salud reproductiva }
$$

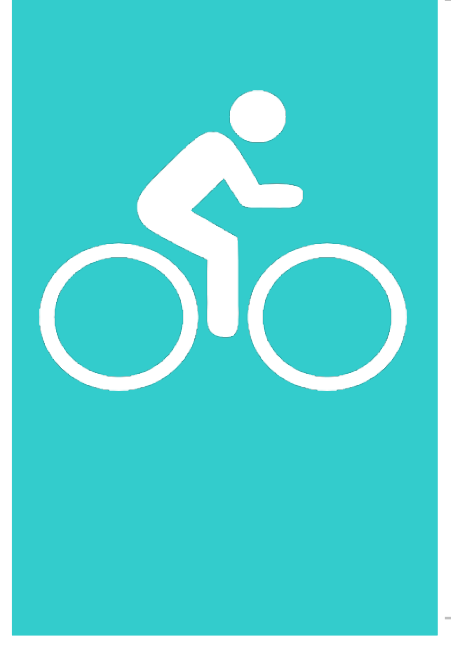

\section{Actividad física}

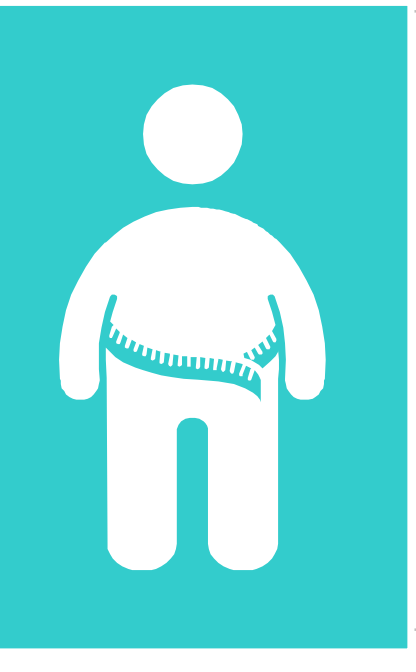

\section{Salud reproductiva}

Prácticas de alimentación infantil (lactancia)

(diabetes, hipertensión,

dislipidemias), por diagnóstico previo.

Anemia en niños y mujeres

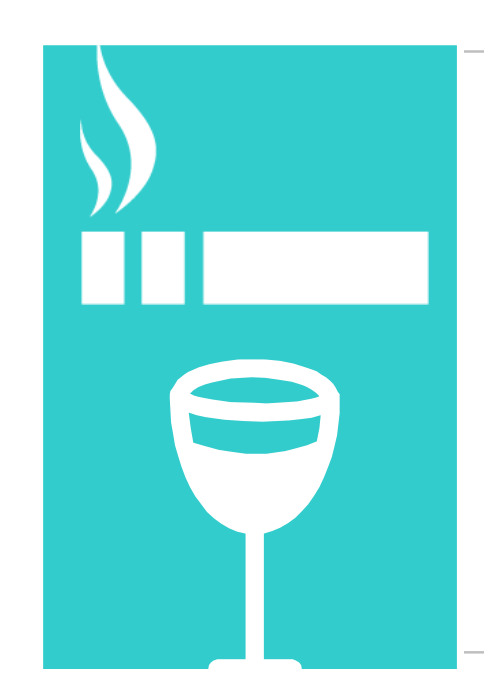

Consumo de tabaco y alcohol en adolescentes y adultos

Sobrepeso y obesidad

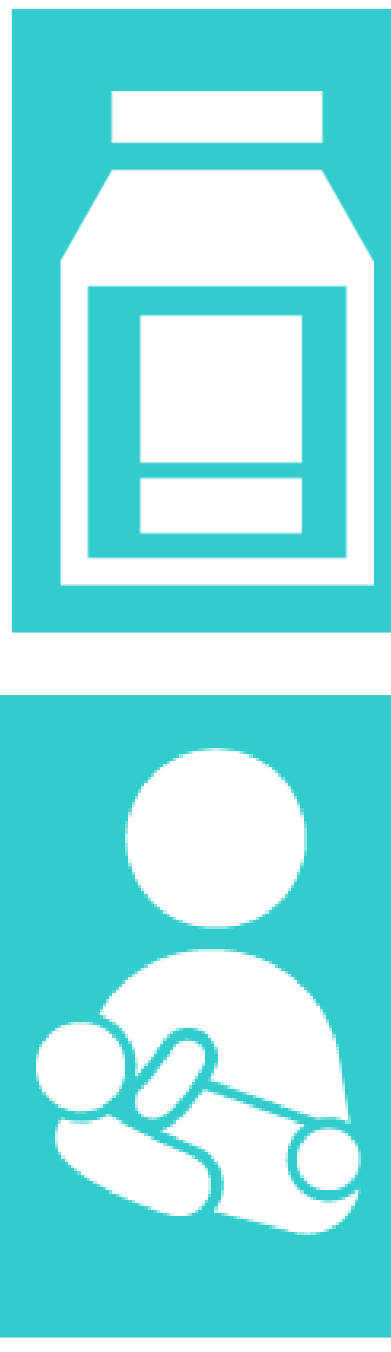

Etiquetado de alimentos

Lactancia materna 


\section{Instrumentos por población de estudio:}

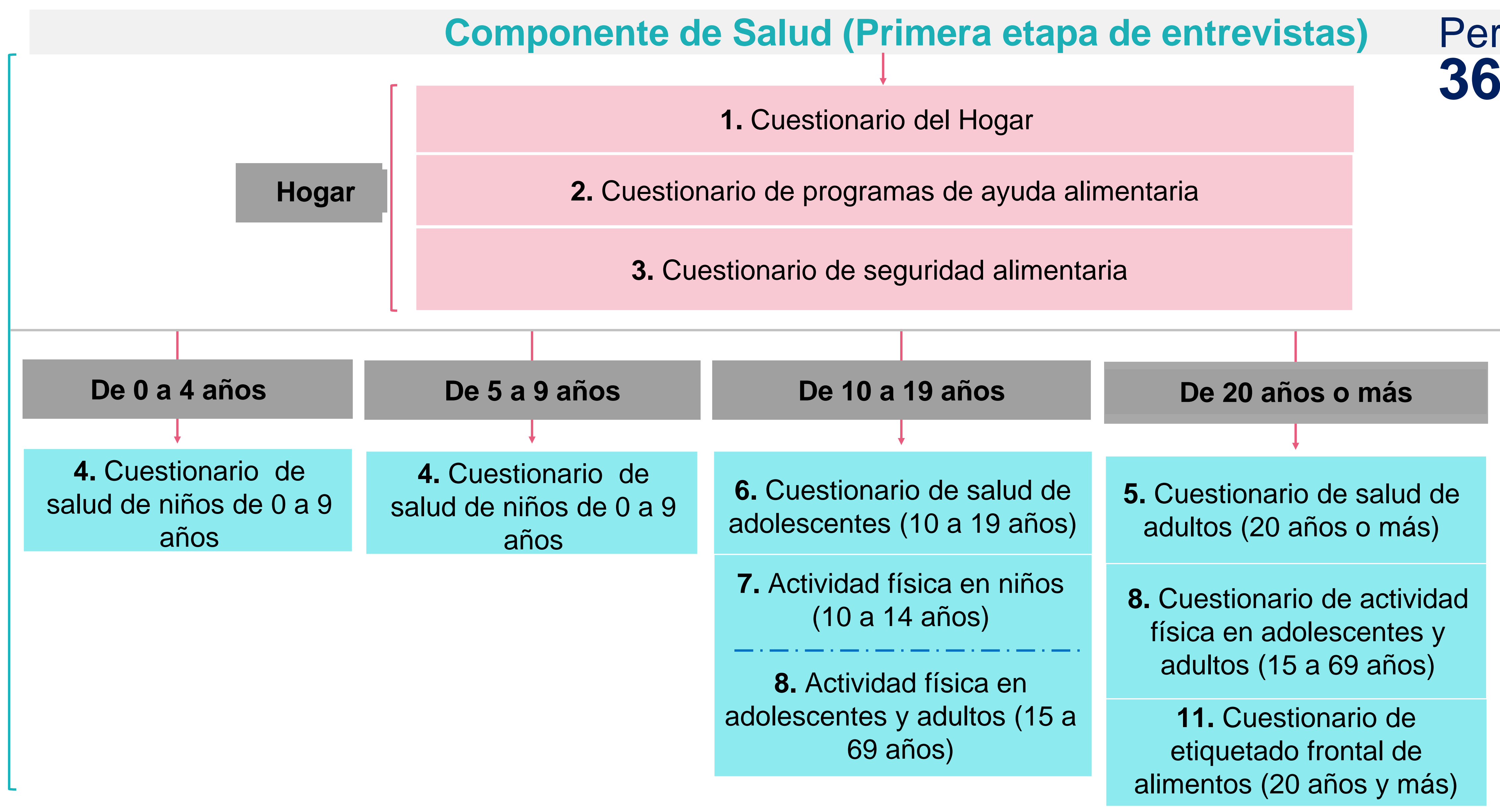

Utilizadores de servicios de salud

9. Cuestionario de utilizadores de servicios de salud (Cualquier edad) 


\section{Instrumentos por población de estudio:}

Componente Nutrición (Segunda etapa de entrevistas)

Cuestionarios aplicados por enfermera(o)

Cuestionarios aplicados por nutrióloga(o)

De 0 a 4 años
16. Antropometría y
tensión arterial
17. Formato de
muestras sanguíneas

15. Estudio de niveles de plomo en niños y mujeres embarazadas

11. Lactancia materna y prácticas de alimentación complementaria (0 a 36 meses)

12. Frecuencia de consumo de alimentos de preescolares (1 a 4 años)

18. Desarrollo Infantil Temprano

De 5 a 9 años
16. Antropometría y
tensión arterial
17. Formato de muestras
sanguíneas

16.

\section{De 10 a 19 años}

16. Antropometría y tensión arterial

17. Formato de muestras sanguíneas

15. Estudio de niveles de plomo en niños y mujeres embarazadas
13. Frecuencia de consumo de alimentos de escolares (5 a 11 años)

\section{:\$:ஃ:|NEG|}

13. Frecuencia de consumo de alimentos de escolares ( 5 a 11 años)

14. Frecuencia de consumo de alimentos de adolescentes y adultos (12 años o más)
De 20 años o más

16. Antropometría y tensión arterial

17. Formato de muestras sanguíneas

15. Estudio de niveles de plomo en niños y mujeres embarazadas

14. Frecuencia de consumo de alimentos de

adolescentes y adultos (12 años o más) 


\section{Principales resultados}

ENSANUT 


\section{Población de estudio}

\section{Población total por grupos de edad y su distribución porcentual}

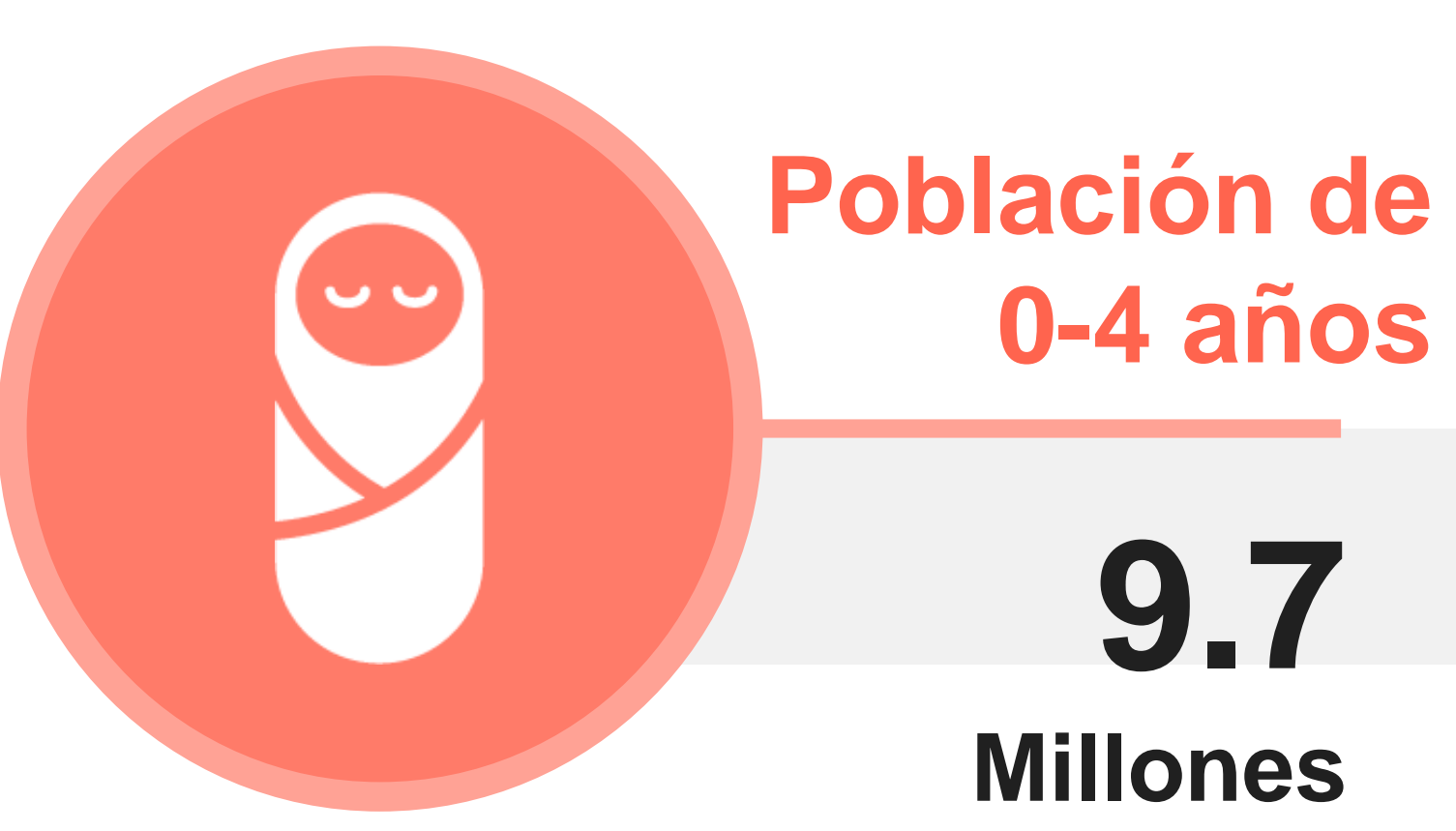

$7.7 \%$

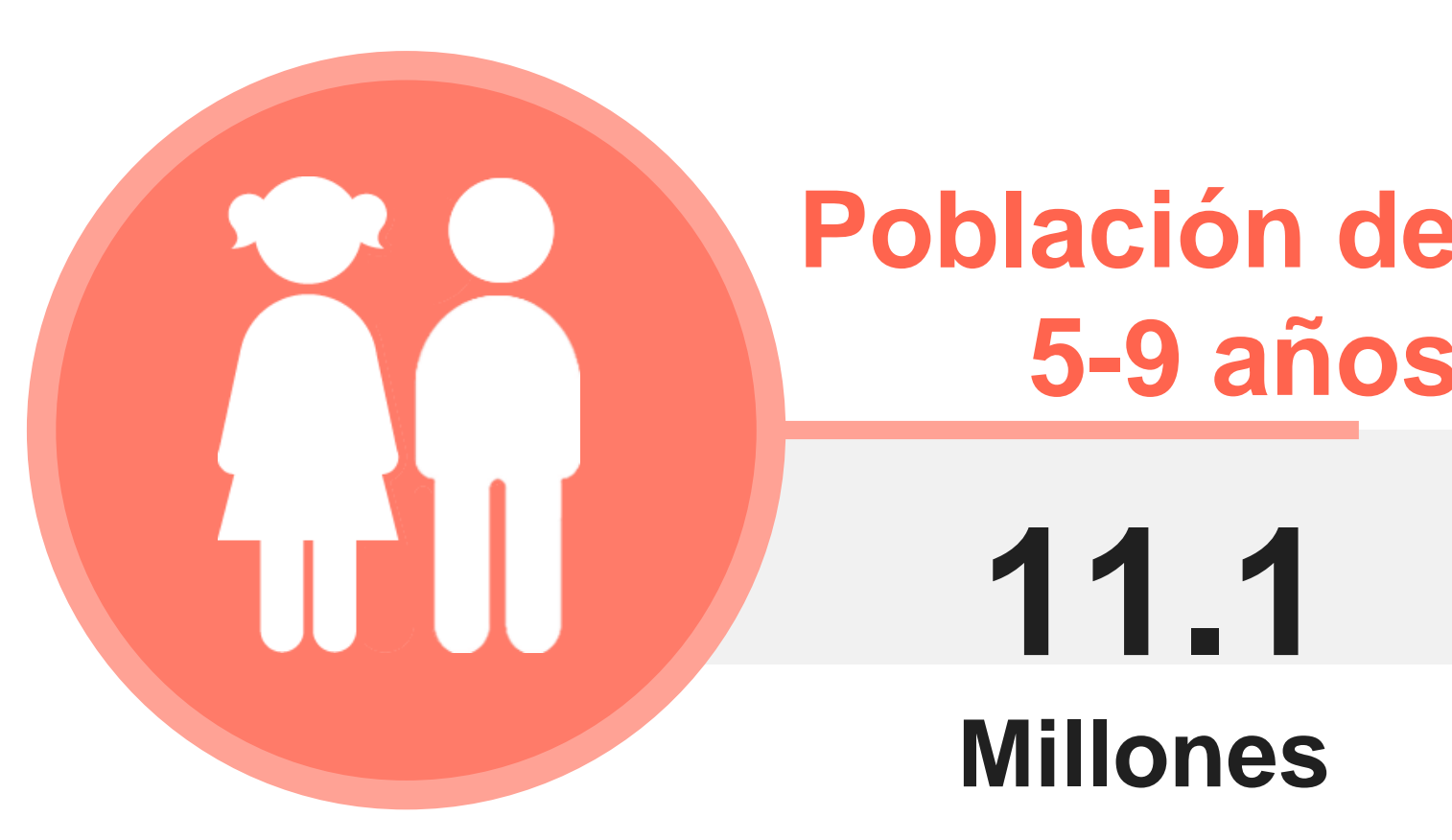

$8.8 \%$

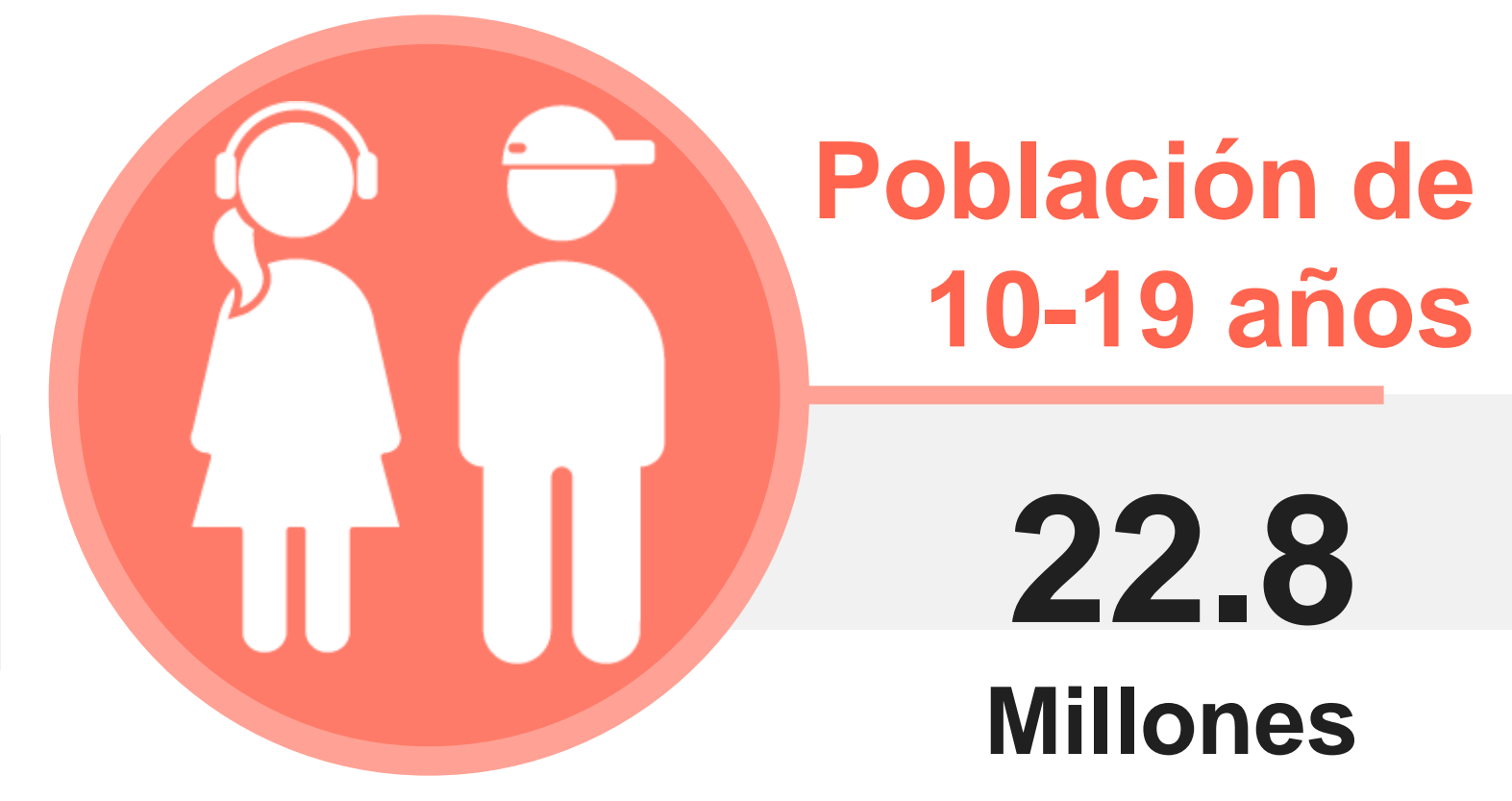

$18.1 \%$

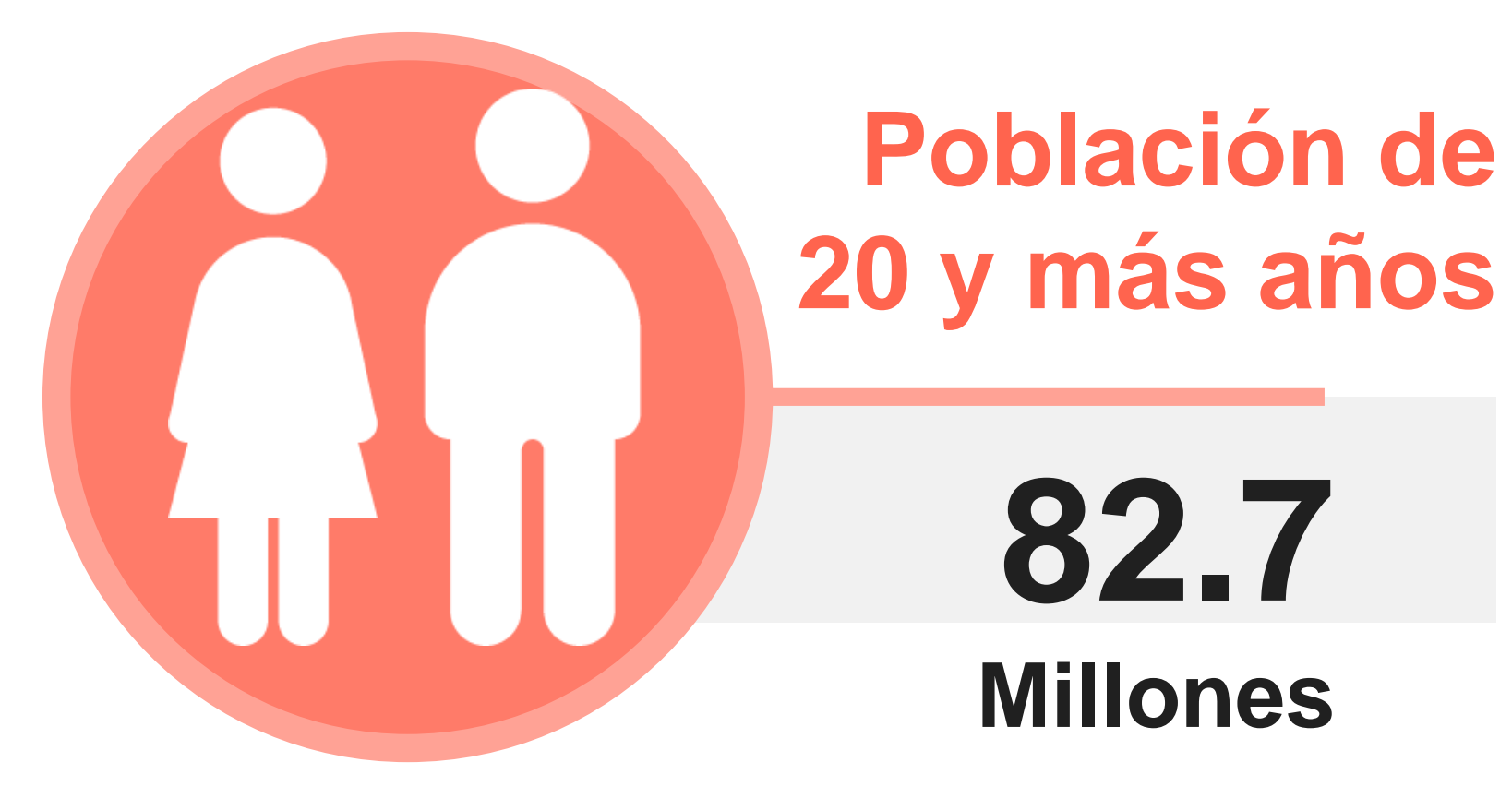

$65.4 \%$ 


\section{Salud}




\section{Derechohabiencia a servicios de salud}

Ocho de cada 10 personas en el país declaran tener derecho a servicio médico (102.3 millones). La cobertura más baja es para la población joven (20 a 29 años).

Porcentaje de población derechohabiente a servicios de salud, por sexo y grupos de edad

\begin{tabular}{|c|c|c|c|c|}
\hline $\begin{array}{c}54.3 \\
\text { Millones }\end{array}$ & $83.2 \%$ & 0 a 9 años & $82.1 \%$ & $\begin{array}{c}48.0 \\
\text { Millones }\end{array}$ \\
\hline \hline 8 & $81.2 \%$ & 10 a 19 años & $80.3 \%$ & \\
\hline $83.0 \%$ & $88.4 \%$ & 20 a 29 años & $70.6 \%$ & \\
\hline & $83.9 \%$ & 30 a 59 años & $77.4 \%$ & $78.8 \%$ \\
\hline $87.6 \%$ & 60 y más años & $86.5 \%$ & \\
\hline
\end{tabular}




\section{Uso de servicios de salud}

Son las mujeres quienes tienen la tasa más alta de uso de servicios de salud, tanto ambulatorios como hospitalarios.

Tasas de uso de servicios de salud ambulatorios y hospitalarios por sexo 2012 y 2018

\begin{tabular}{|c|c|c|c|c|}
\hline & Servicis & ulatorio & \multicolumn{2}{|c|}{ Servicio hospitalario } \\
\hline 트ㄹㅡㅡ & & & & \\
\hline & 2012 & 2018 & 2012 & 2018 \\
\hline Mujeres & $9.6 \%$ & $7.6 \%$ & $4.9 \%$ & $5.8 \%$ \\
\hline Hombres & $6.6 \%$ & $5.1 \%$ & $2.6 \%$ & $3.3 \%$ \\
\hline Total & $8.2 \%$ & $6.4 \%$ & $3.8 \%$ & $4.6 \%$ \\
\hline
\end{tabular}

$56.6 \%$

población se atiende en los servicios públicos (IMSS, ISSSTE, SS etc); para ENSANUT 2012, esta porcentaje fue de 61.1. 


\section{Enfermedades diarreicas en población de 0 a 4 años}

Porcentaje de población de 0 a 4 años de edad que presentó diarrea en las dos semanas previas a la entrevista, por sexo

2006-2018

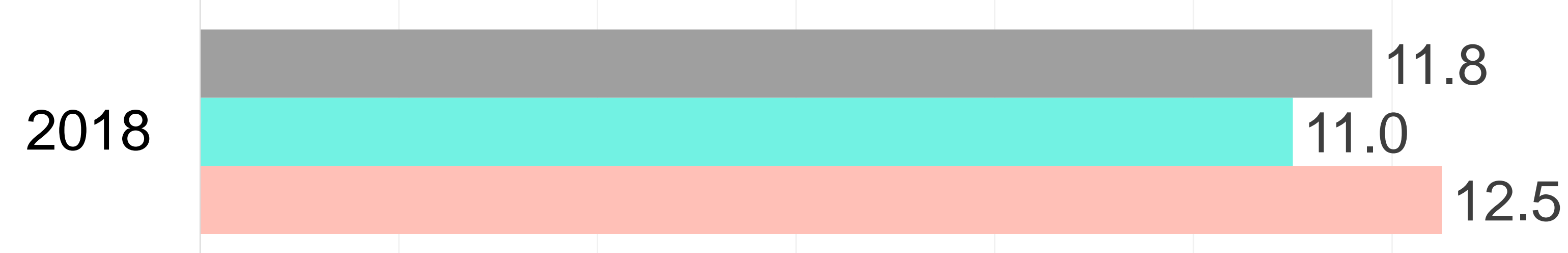

2012
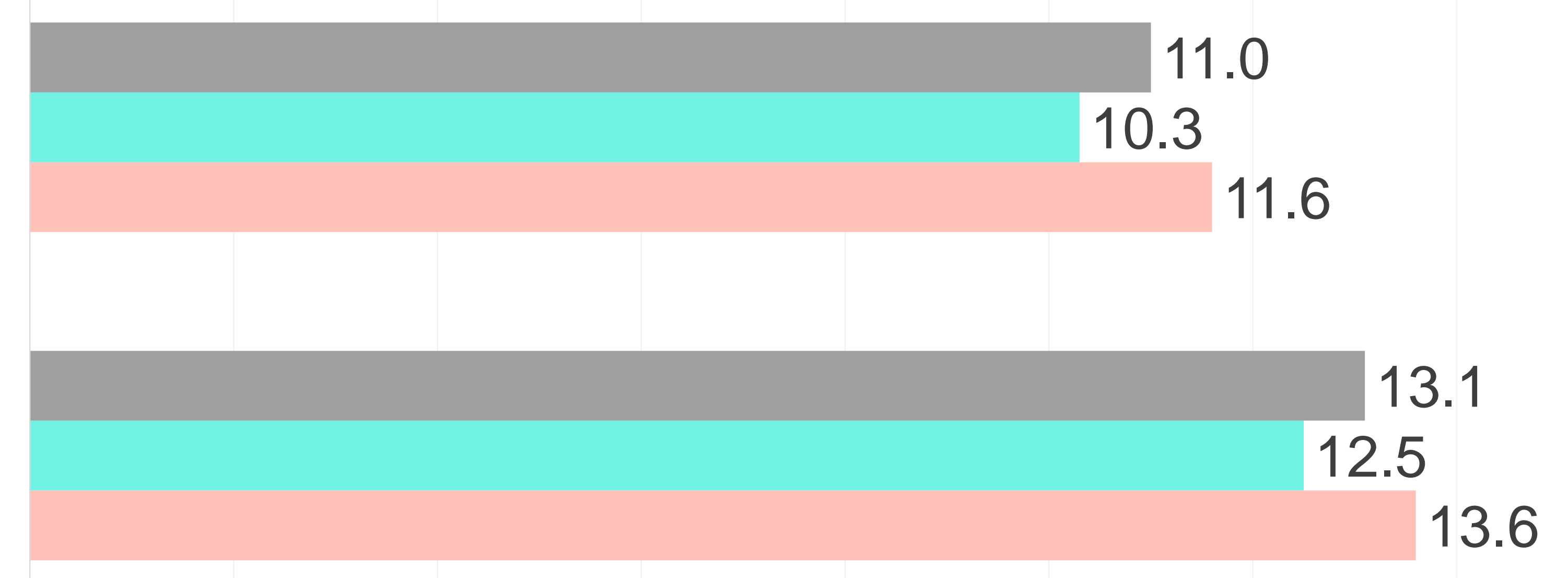

$\square$ Total $\quad$ Mujeres $\quad$ Hombres

En el $\mathbf{5 2 \%}$ de los casos de niños con diarrea se reportó haber administrado Suero, porcentaje mayor al registrado en el 2012 (40\%). 


\section{Enfermedades respiratorias en población de 0 a 4 años}

Para 2018, el porcentaje de población de 0 a 4 años de edad que presentó enfermedad respiratoria en las dos semanas previas a la entrevista fue del 32.1 por ciento.

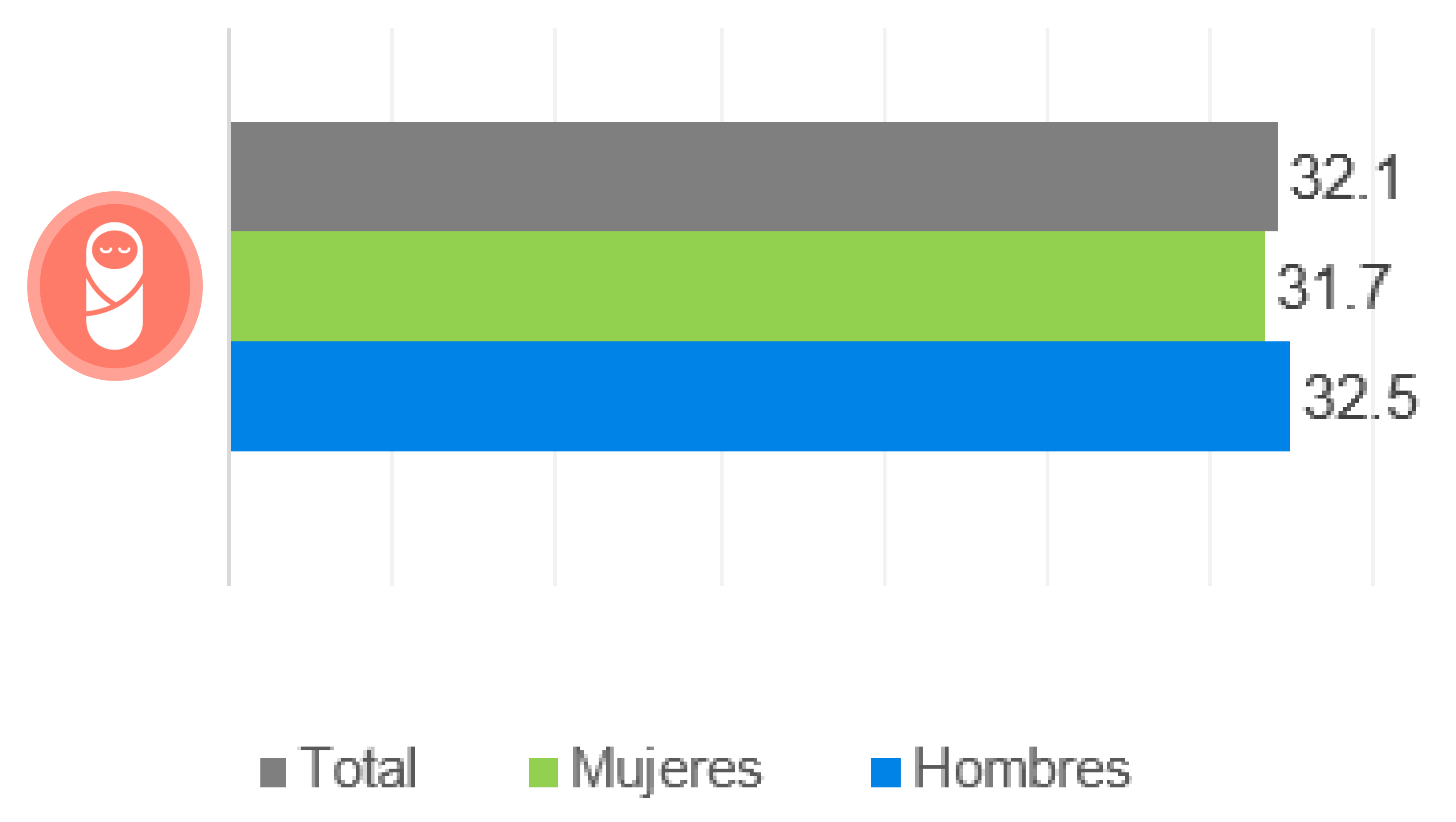




\section{Diabetes en población de 20 años y más años}

Porcentaje de la población de 20 años y más con diagnóstico médico previo de diabetes, por sexo

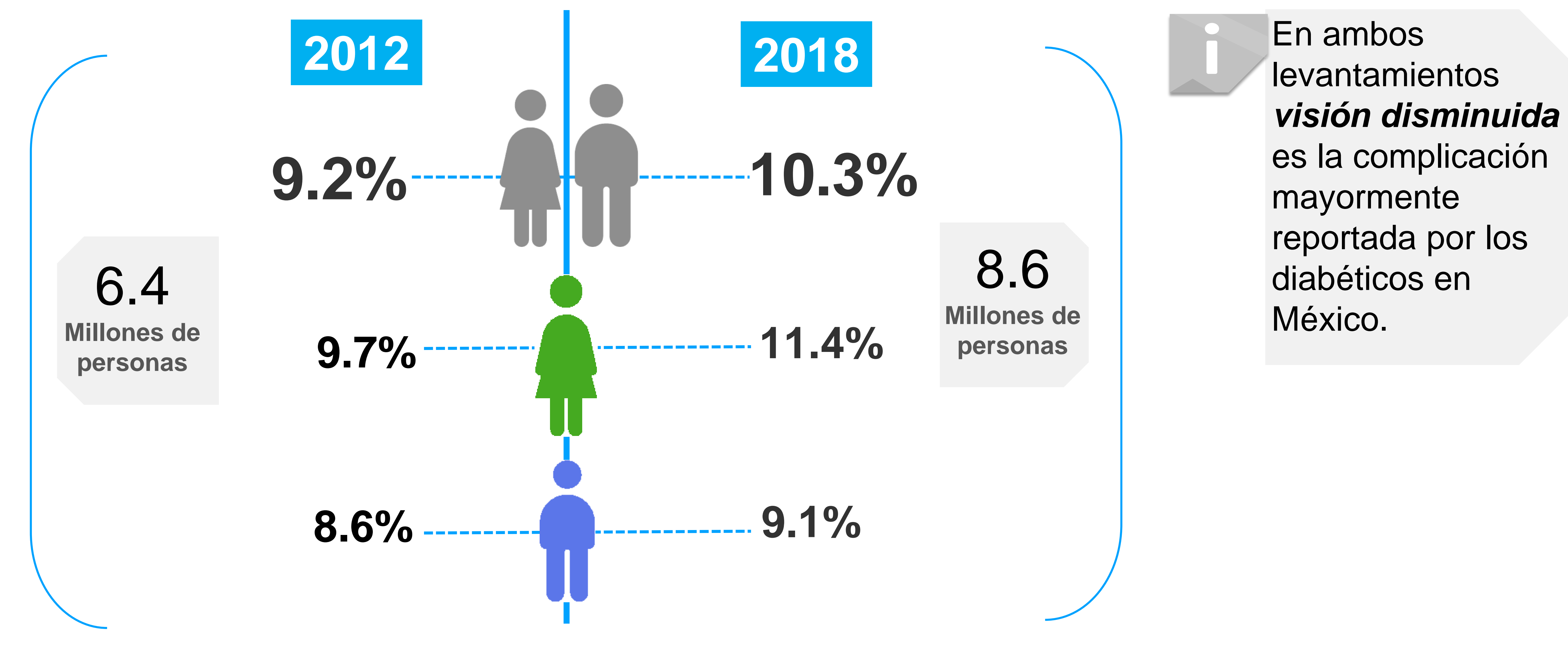




\section{Diabetes en población de 20 años y más años}

Porcentaje de la población de 20 años y más con diagnóstico médico previo de diabetes, por entidad federativa

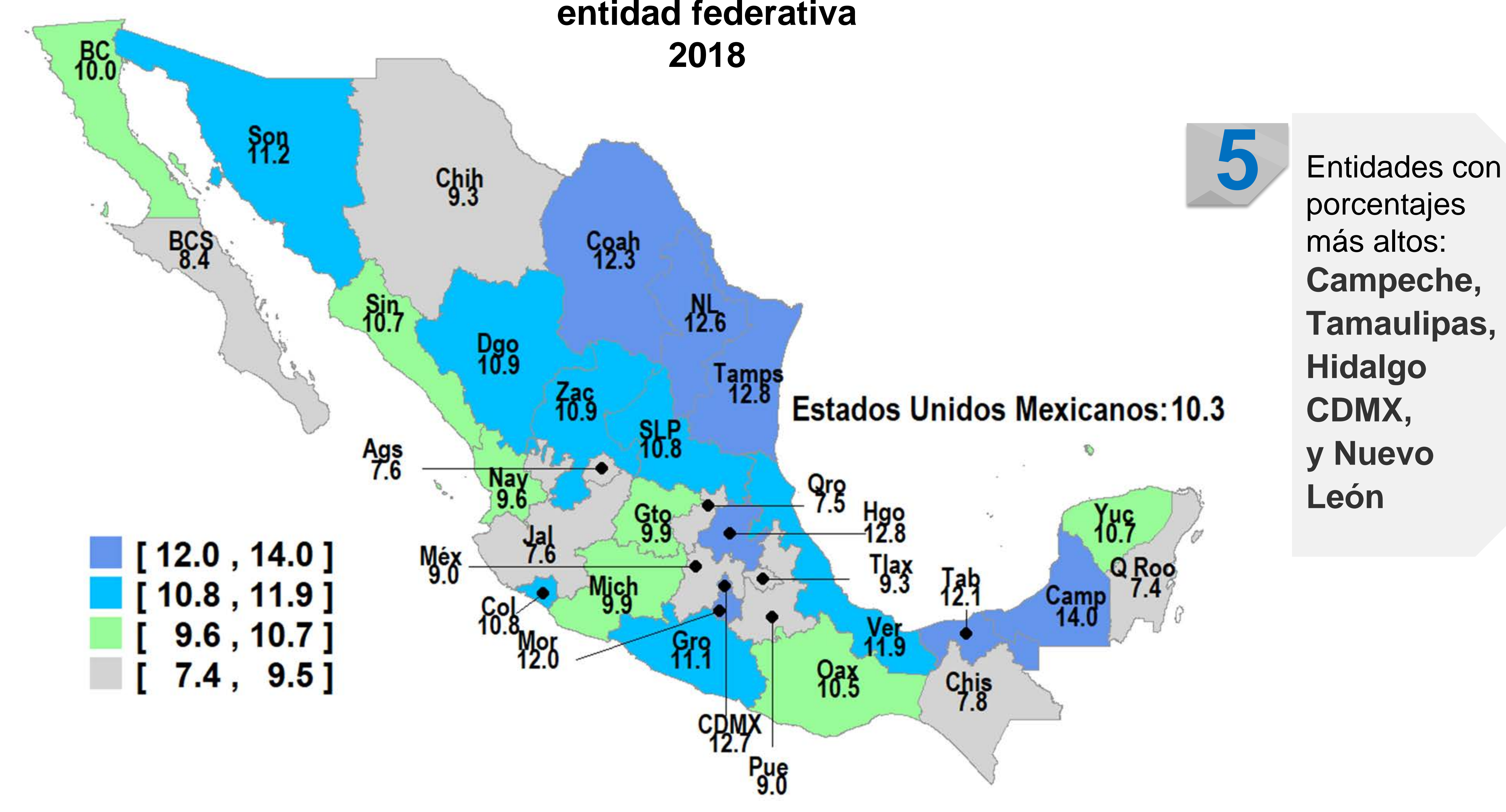




\section{Hipertensión en población de 20 años y más años}

Porcentaje de la población de 20 años y más con diagnóstico médico previo de hipertensión, por sexo
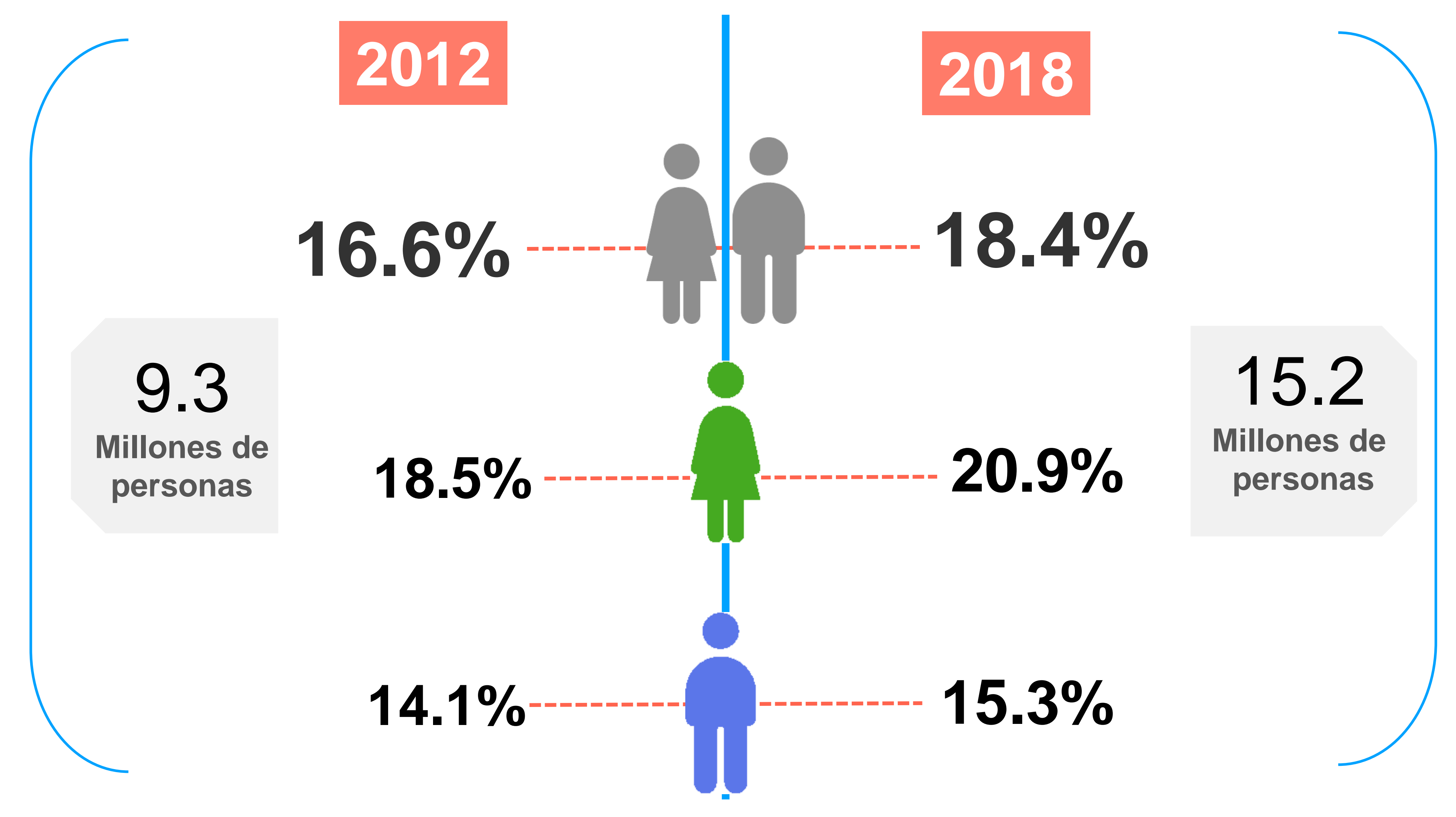

Conforme se incrementa la edad, crece el porcentaje de población con diagnóstico previo de hipertensión, principalmente a partir de los 50 años, llegando al $\mathbf{2 6 . 7 \%}$ en el grupo de 70 a 79 años en 2018. 


\section{Hipertensión en población de 20 años y más}

Porcentaje de población de 20 y más años de edad con diagnóstico médico previo de hipertensión por entidad federativa

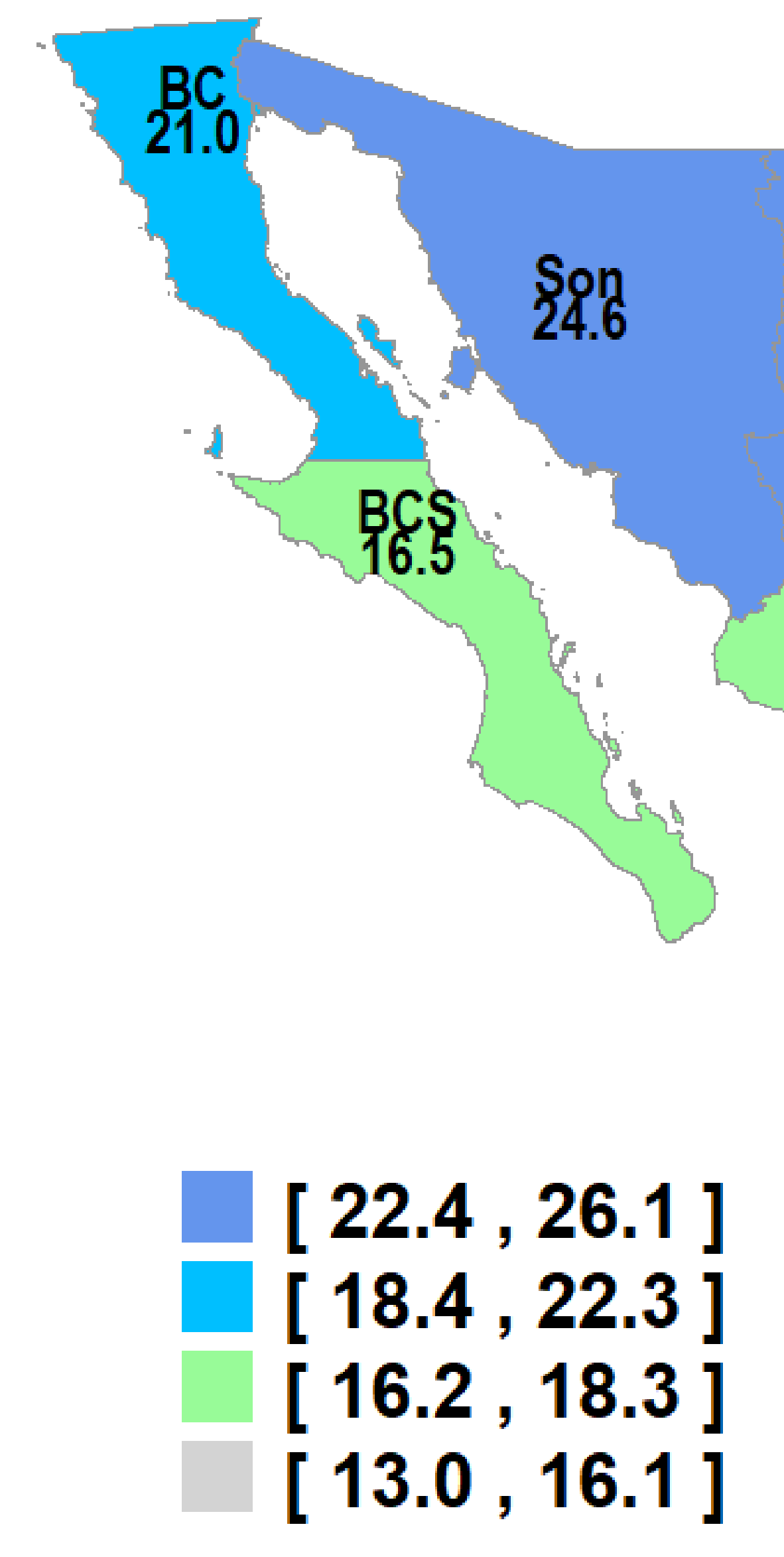
2018

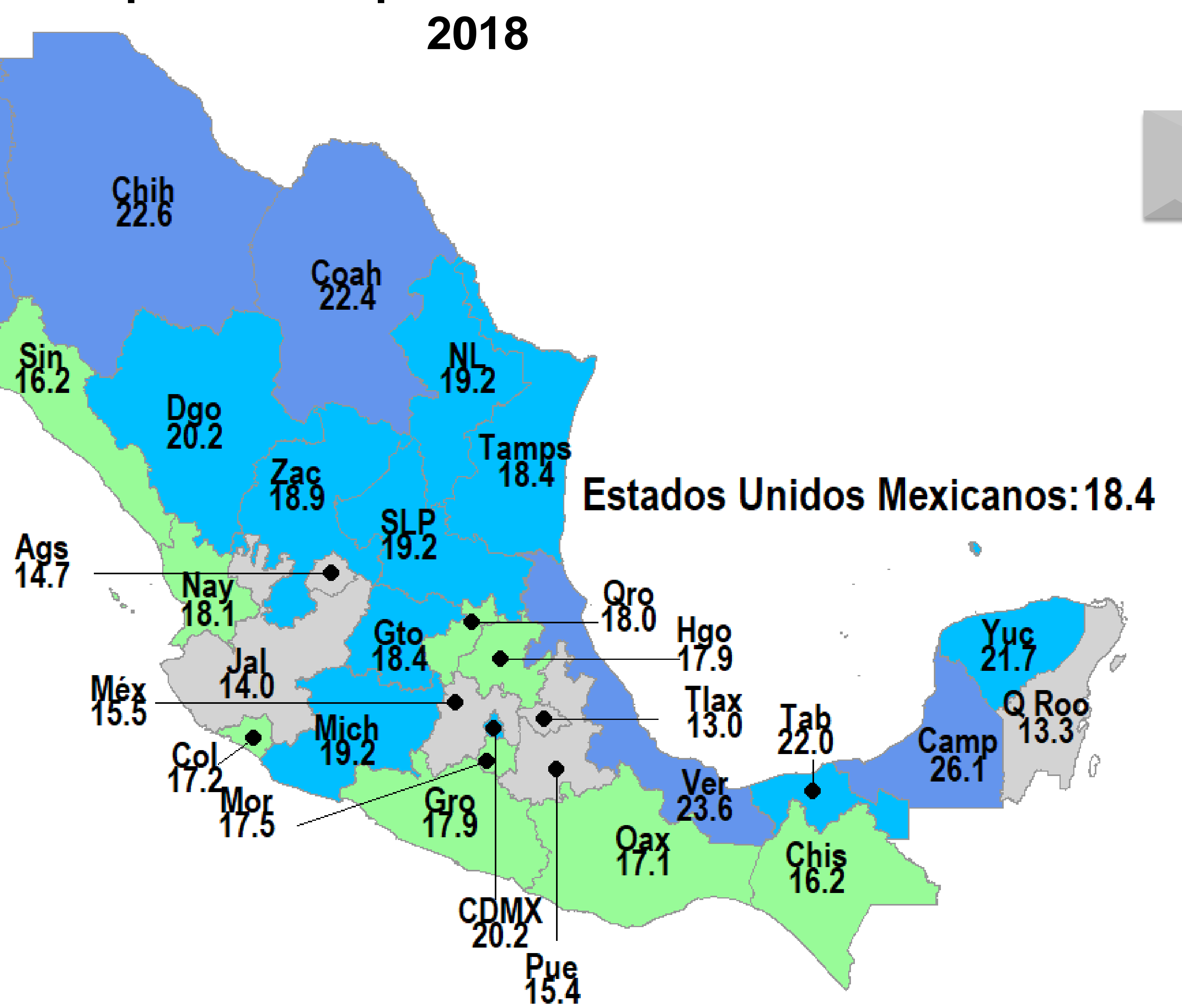

Entidades con porcentajes más altos: Campeche, Sonora, Veracruz, Chihuahua y Coahuila 


\section{Colesterol y triglicéridos en población de 20 y más años}

Distribución porcentual de la población de 20 y más años de edad según condición de reporte de medición de colesterol y triglicéridos y su resultado, por sexo 2012 y 2018

\begin{tabular}{|c|c|c|c|c|c|}
\hline $\begin{array}{l}\text { Medicion de } \\
\text { colesterol y } \\
\text { triglicéridos }\end{array}$ & 2012 & 2018 & 2012 & 2018 & 2012 \\
\hline Sí, normal & $37.0 \%$ & $32.7 \%$ & $38.6 \%$ & $34.8 \%$ & $35.1 \%$ \\
\hline Sí, alto & $13.0 \%$ & $19.5 \%$ & $14.1 \%$ & $21.0 \%$ & $11.7 \%$ \\
\hline No & $50.0 \%$ & $47.7 \%$ & $47.3 \%$ & $44.2 \%$ & $53.2 \%$ \\
\hline
\end{tabular}




\section{Consumo de alcohol en población de 10 a 19 años}

Porcentaje de la población de 10 a 19 años y más que consume de alcohol por sexo 2012 - 2018

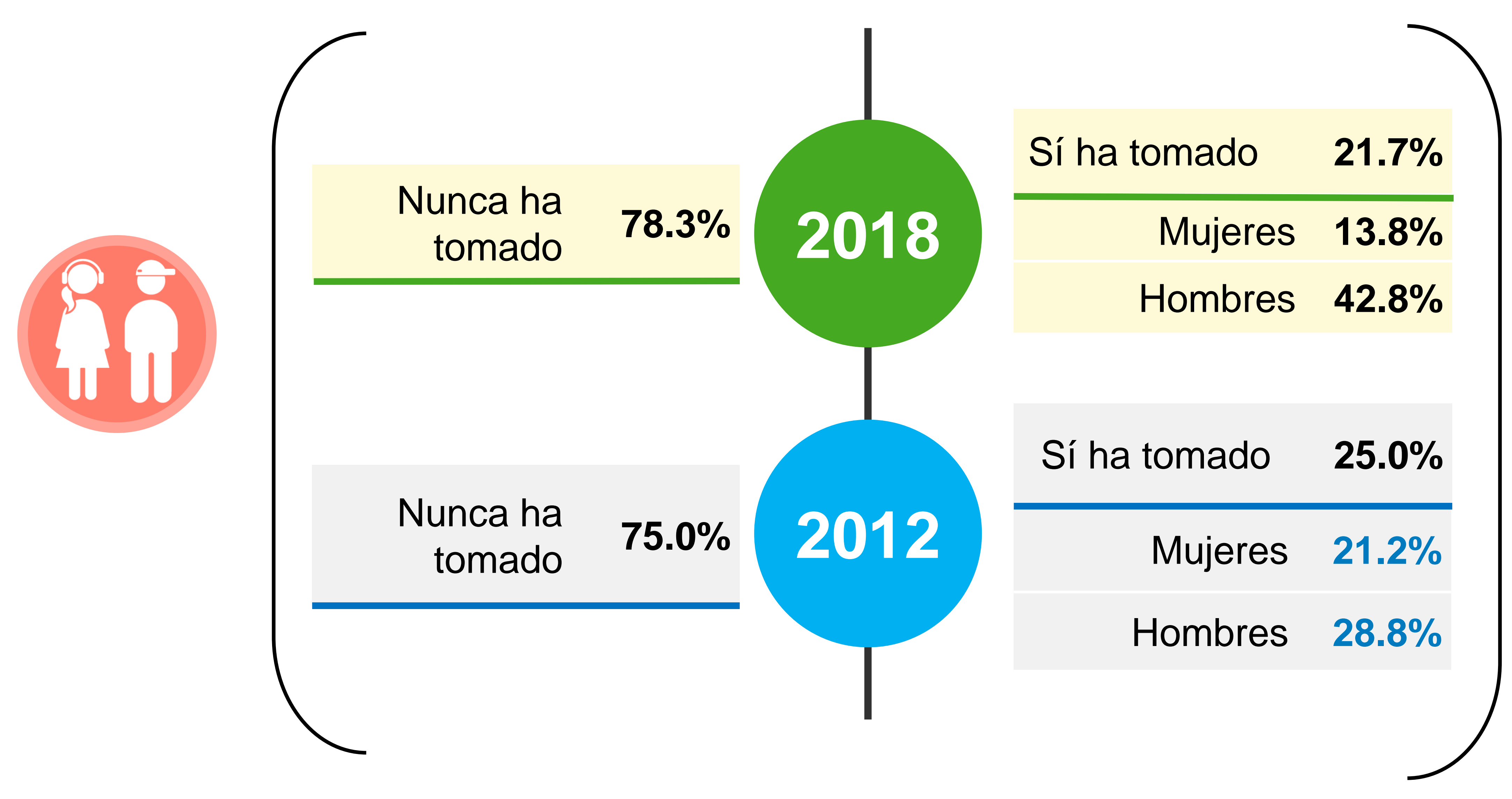




\section{Consumo de alcohol en población de 10 a 19 años}

Porcentaje de la población de 10 a 19 años y más que consume de alcohol por entidad federativa
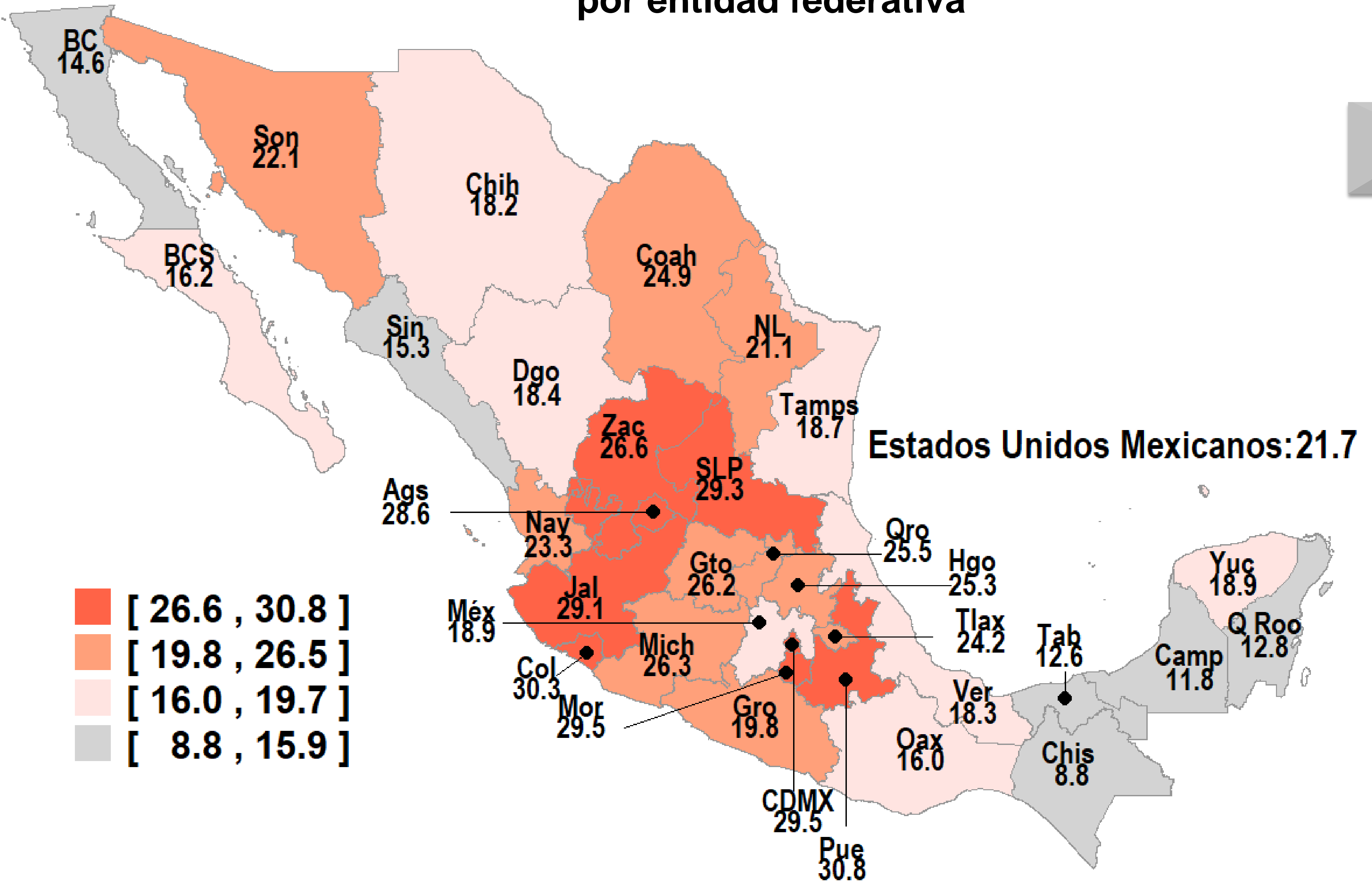

Entidades con porcentajes más altos: Puebla, Colima, CDMX, San Luis Potosí, Jalisco 


\section{Consumo de alcohol en población de 20 y más años}

Distribución porcentual de la población de 20 años y más por condición de consumo de alcohol y frecuencia de consumo

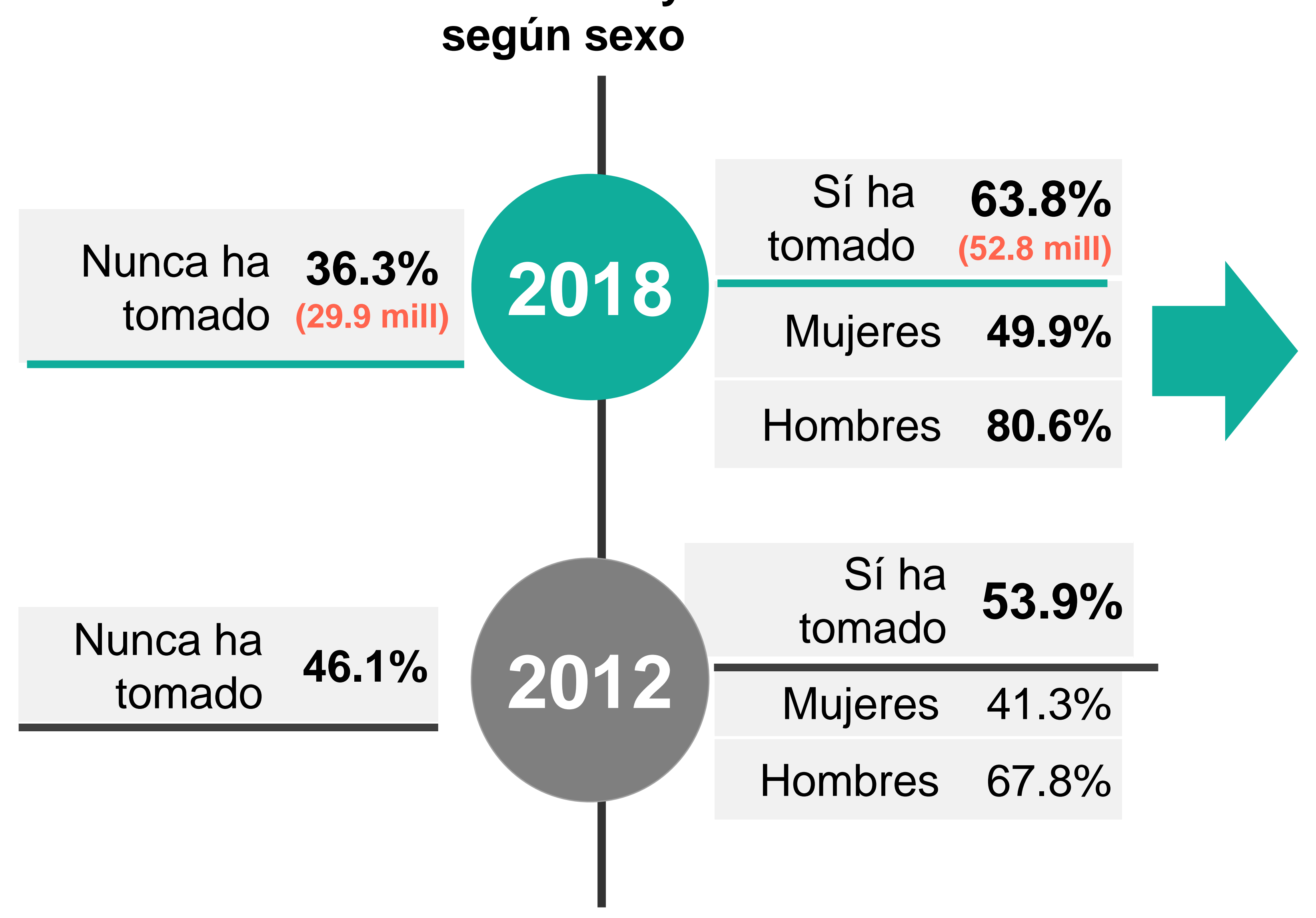

Diario

Semanal

Mensual

Ocasionalmente

No responde

\section{Frecuencia de consumo por sexo, 2018}

\begin{tabular}{|r|r|}
\hline $\mathbf{1 . 0} \%$ & $\mathbf{5 . 7} \%$ \\
\hline $\mathbf{9 . 5} \%$ & $\mathbf{3 0 . 2} \%$ \\
\hline $8.1 \%$ & $14.8 \%$ \\
\hline $75.9 \%$ & $47.0 \%$ \\
\hline $5.5 \%$ & $2.3 \%$ \\
\hline
\end{tabular}




\section{Consumo de alcohol en población de 20 y más años}

Porcentaje de la población de $\mathbf{2 0}$ años y más que ha consumido alcohol diaria o semanalmente por entidad federativa

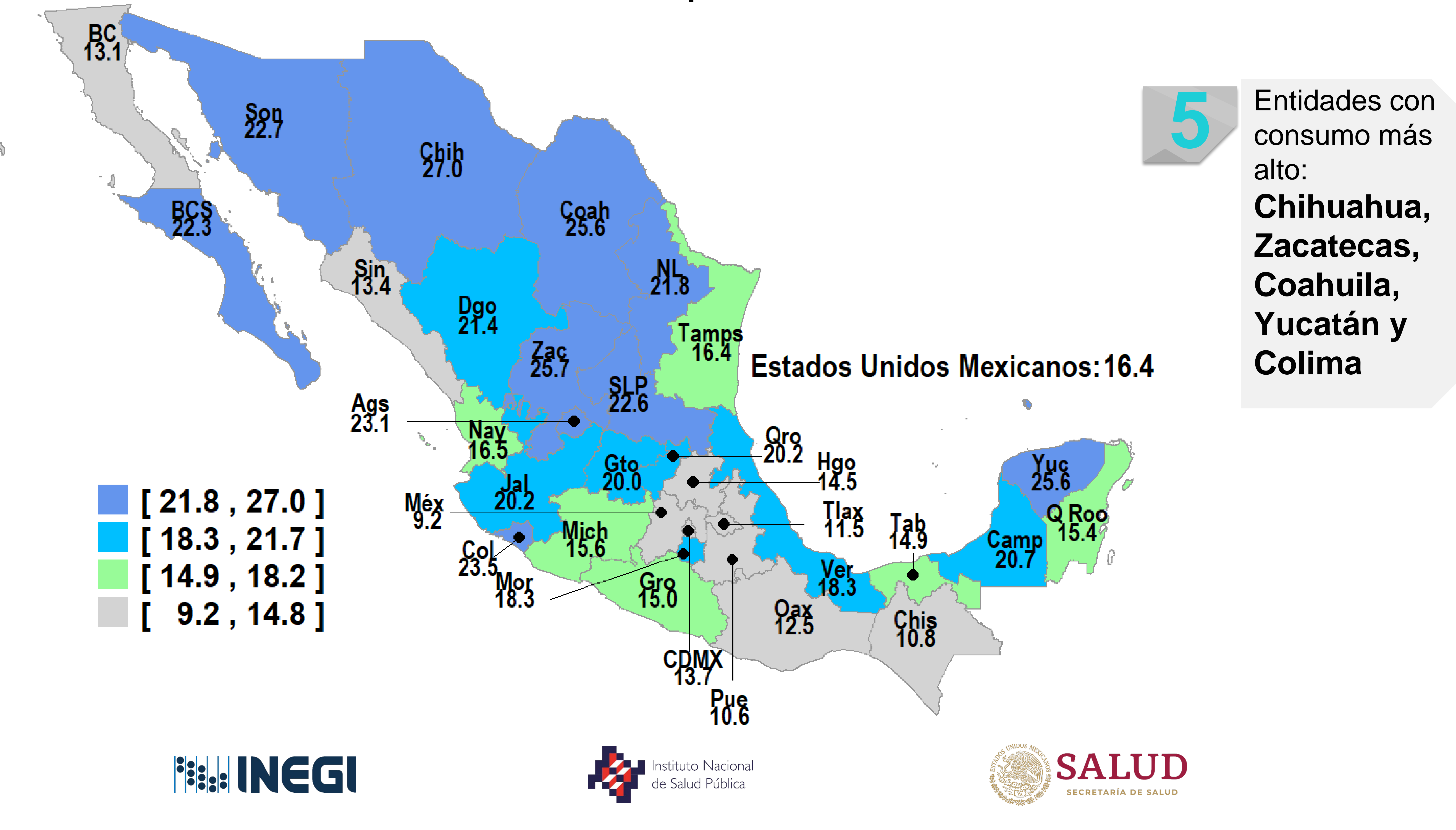




\section{Consumo de tabaco en población de 10 a 19 años}

En 2018 el porcentaje de personas de 10 a 19 años que consume tabaco fue de $\mathbf{5 . 1}$ por ciento.

Porcentaje de población de 10 a 19 años de edad que consume tabaco, por entidad $9.5 \%$ federativa

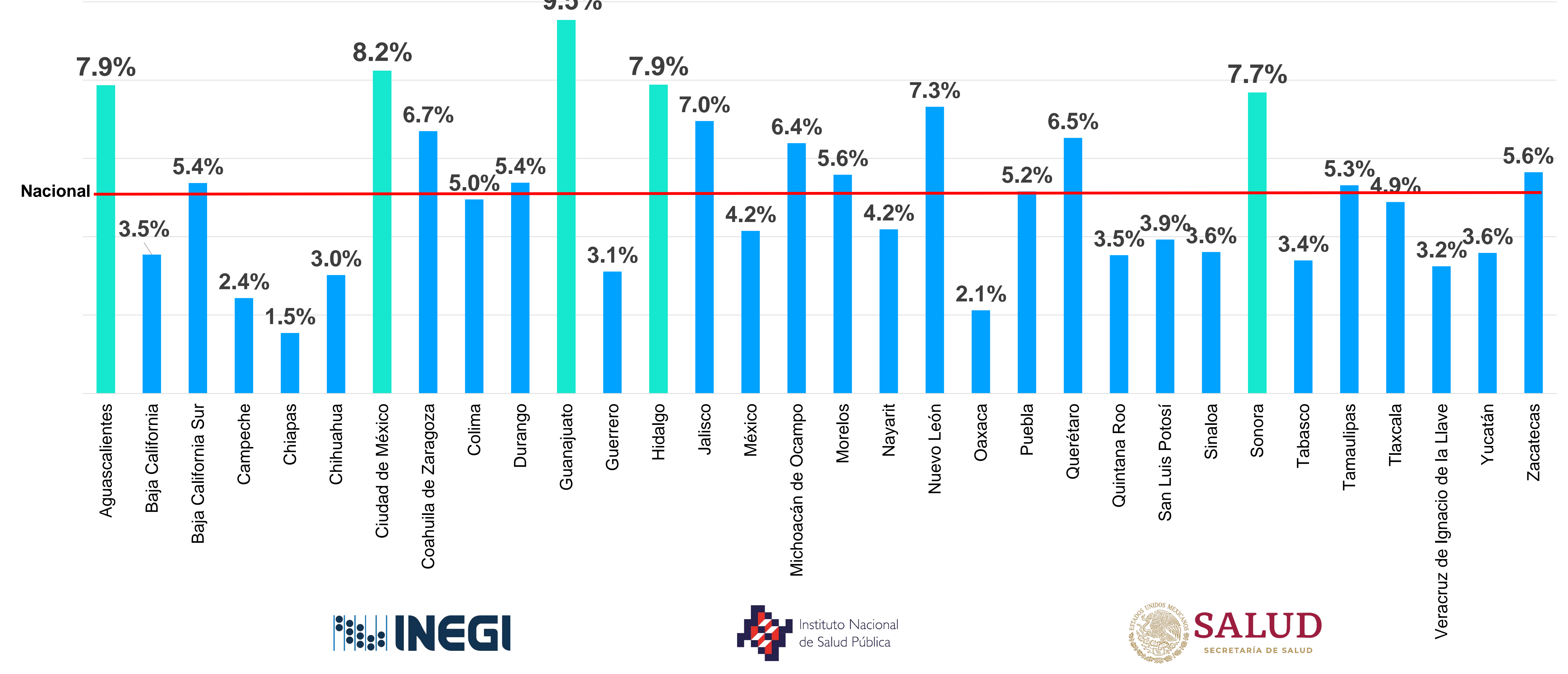




\section{Consumo de tabaco en población de 20 y más años}

En 2012 el porcentaje de consumo de tabaco entre la población de 20 años y más fue de 19.9\%, y en el 2018 se reduce al 11.4 por ciento.

Porcentaje de la población de 20 años y más de edad que consume tabaco, por entidad

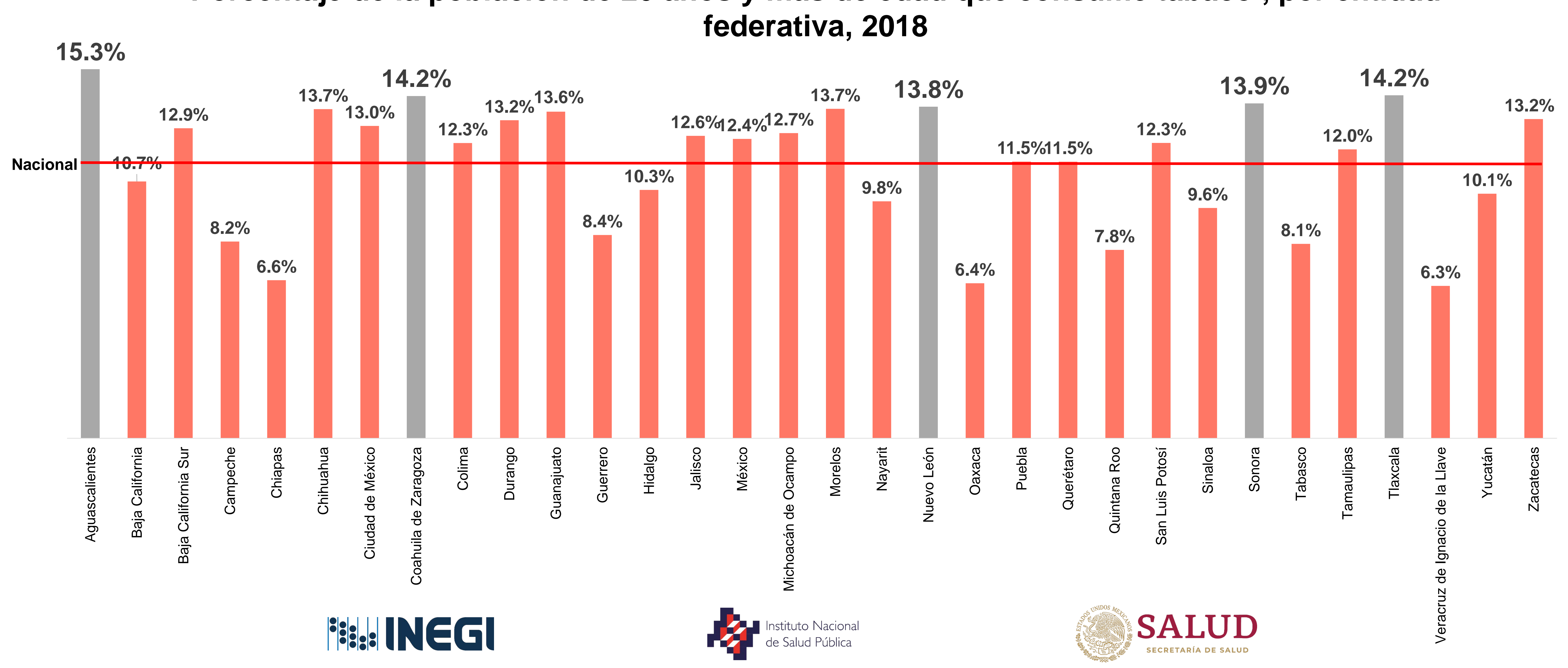




\section{Consumo de tabaco en población de 20 años y más}

Para los adultos de 20 años y más, el promedio de cigarros consumidos diarios fue de 7.5 en 2006 y 6.3 en 2012.

Promedio de cigarros fumados al día de la población de 20 años y más, por sexo y tipo de localidad
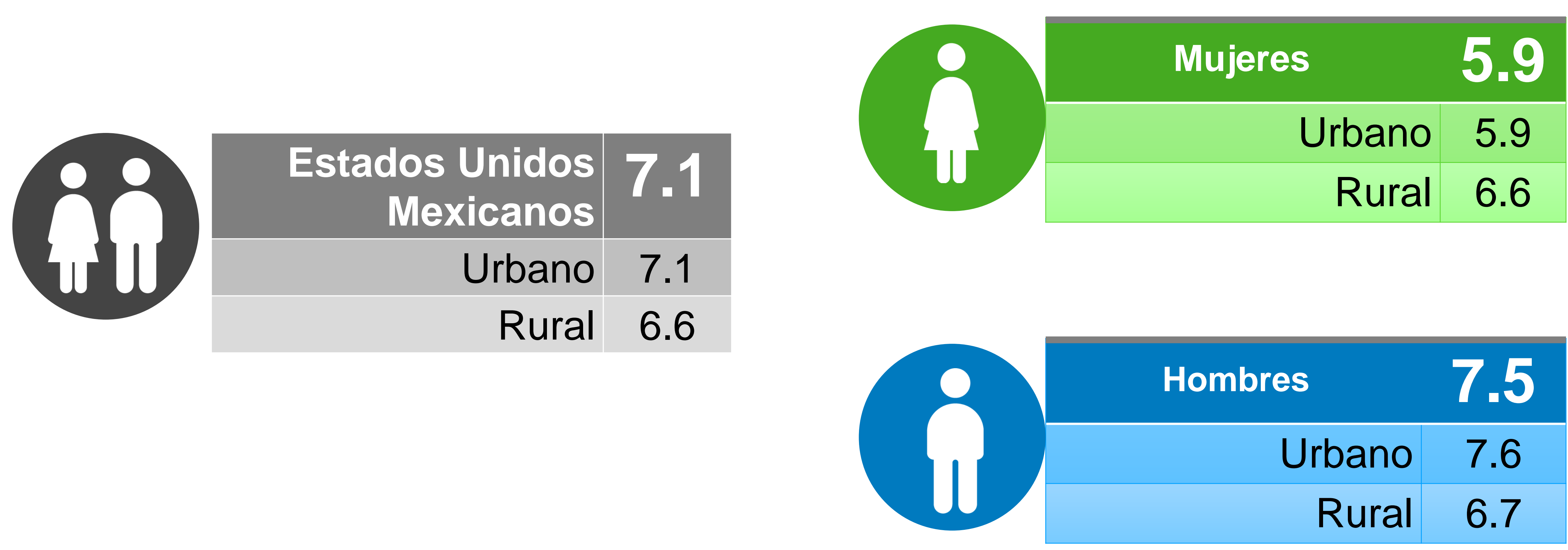


\section{Actividad física en población de 20 a 69 años}

Porcentaje de población de 20 a 69 años según tiempo de actividad física por semana

35

$$
32.5
$$

30

25

29.0

24.8

20

15

10

5

0

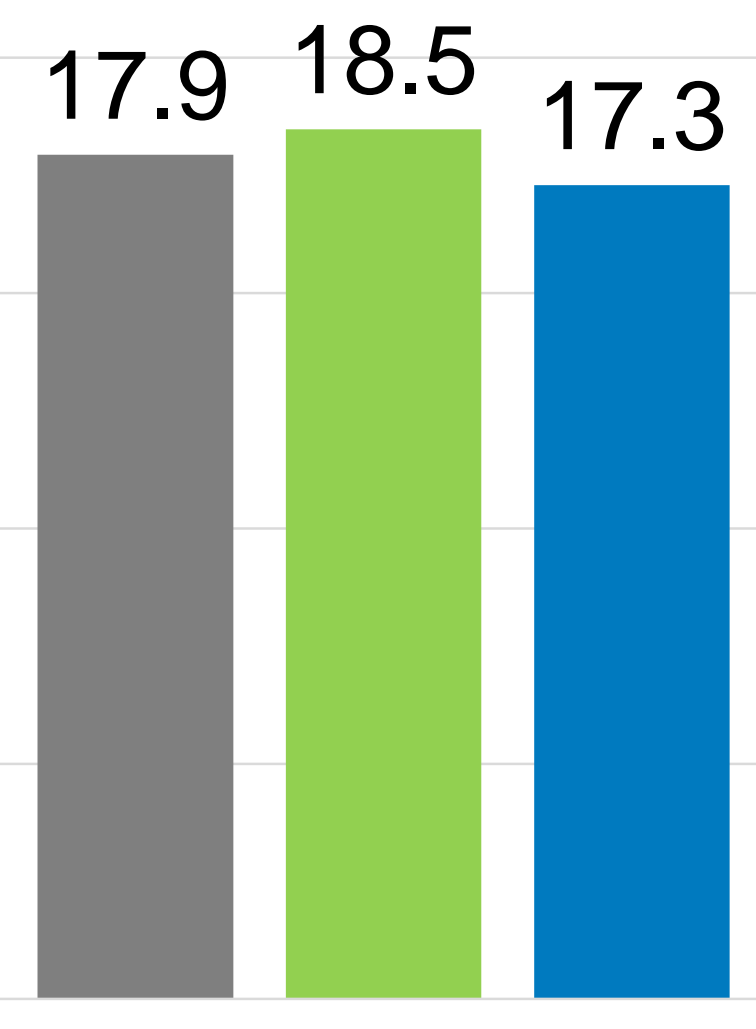

Menos de 420 minutos por semana

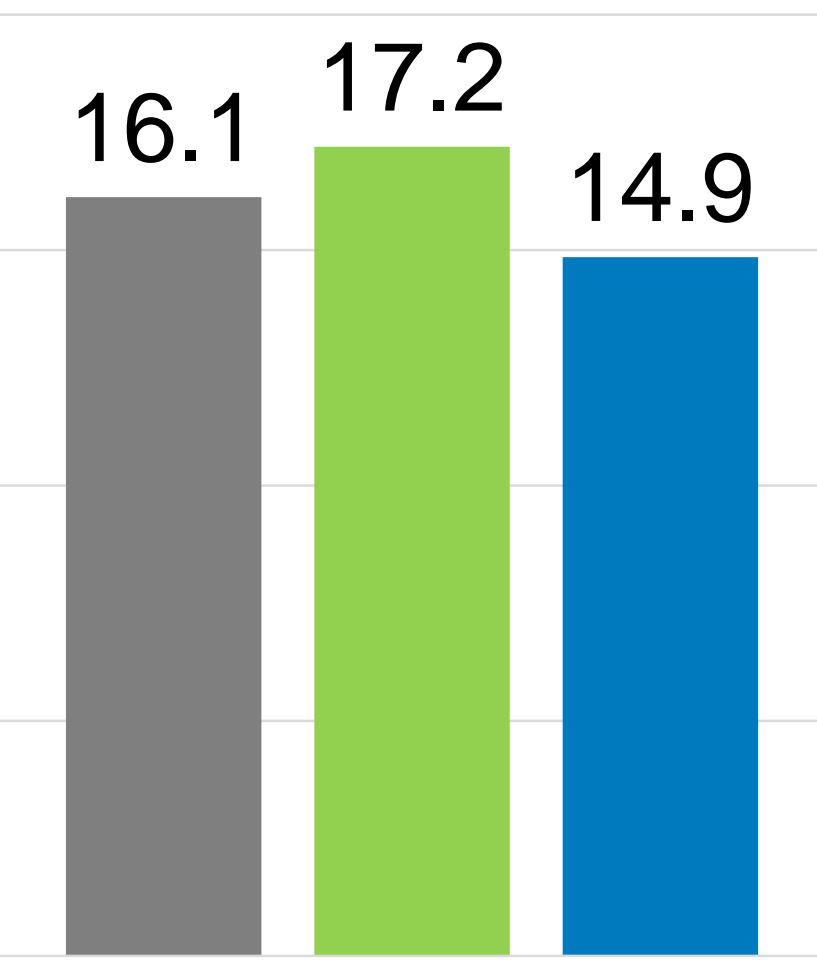

Menos de 840 minutos por semana

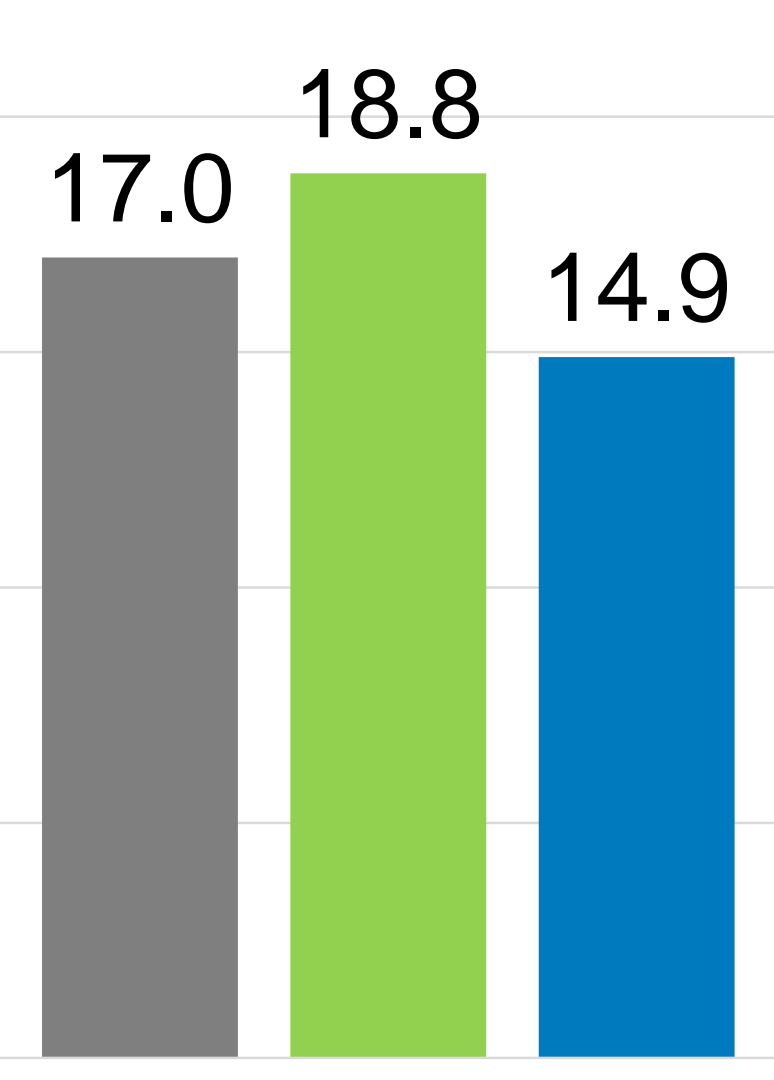

Menos de 1680 minutos por semana
20.0

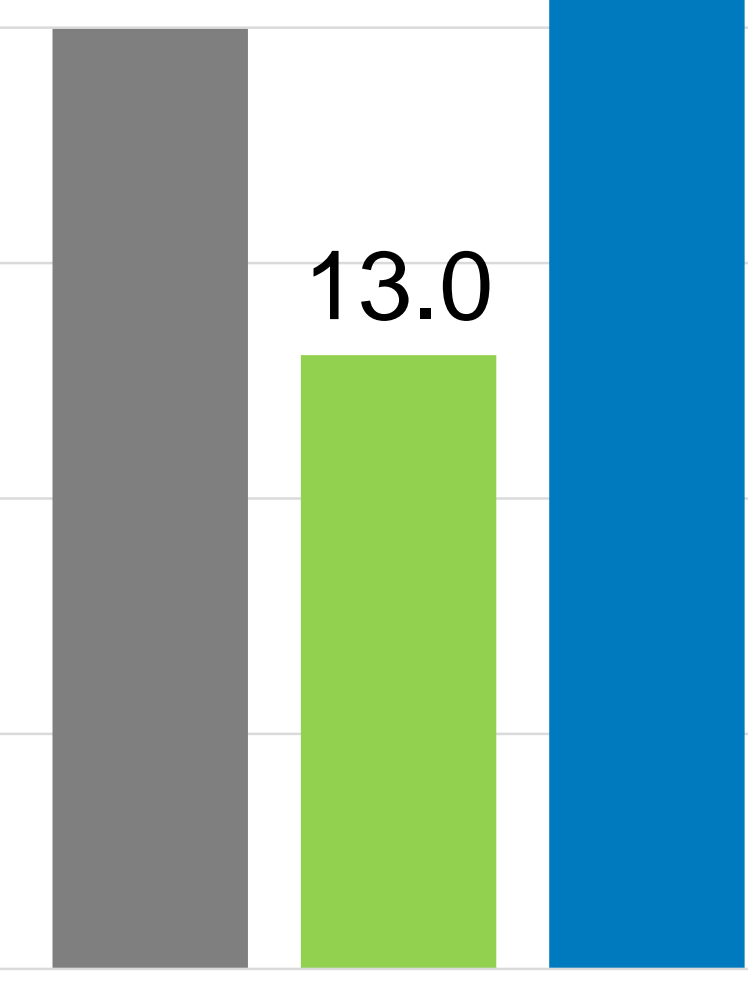

1680 minutos o más por semana

- Población adulta de 20 a 69 años

$\square$ Mujeres

- Hombres

150 minutos $=2.5$ hrs $\times$ semana

420 minutos $=7$ hrs $x$ semana 840 minutos $=14$ hrs $x$ semana 1680 minutos $=28$ hrs $\times$ semana 


\section{Seguridad alimentaria}

En 2018, el $\mathbf{4 4 . 5 \%}$ de los hogares en México se identificaron con seguridad alimentaria. En contraparte, el $22.6 \%$ presenta inseguridad alimentaria moderada y severa, el $32.9 \%$ restante inseguridad leve.

Hogares por tipo de localidad, según condición de seguridad alimentaria y nivel

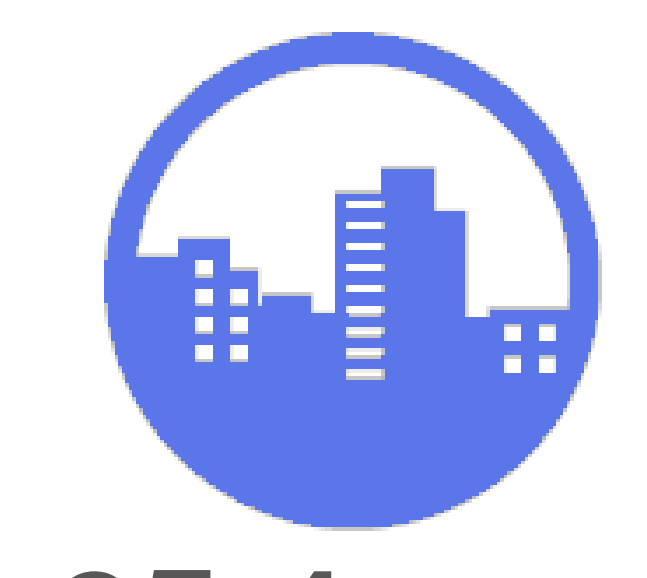

25.4 Millones 2018

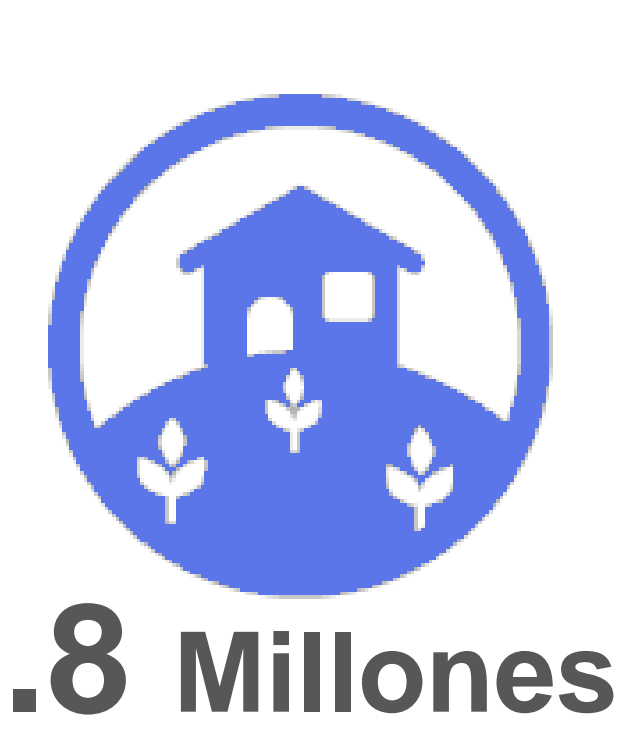

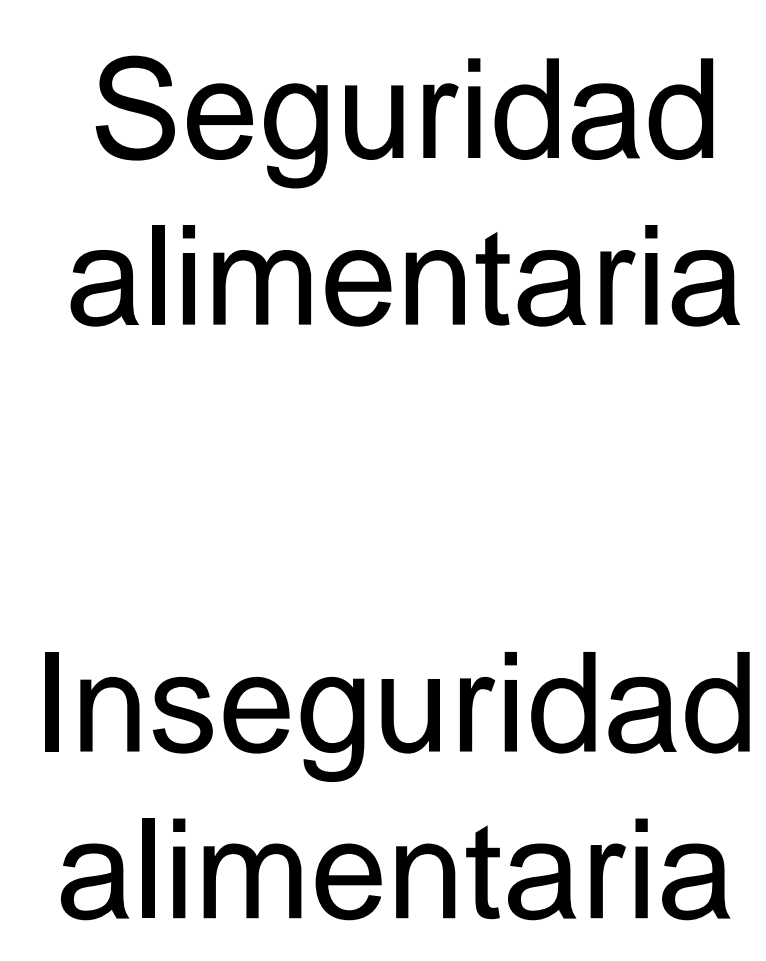

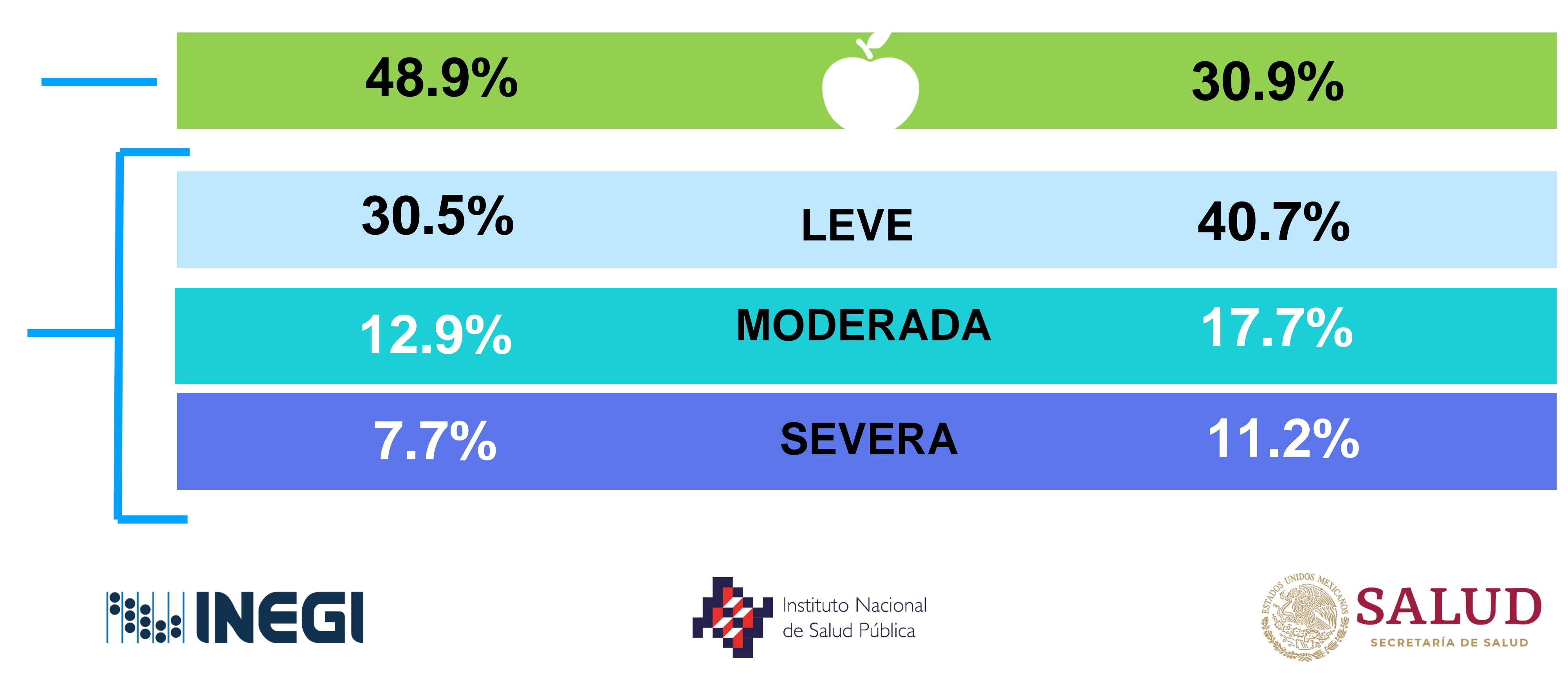




\section{Lactancia materna menores de 2 años}

Indicadores de Lactancia Materna (LM) en menores de 2 años

2012 - 2018

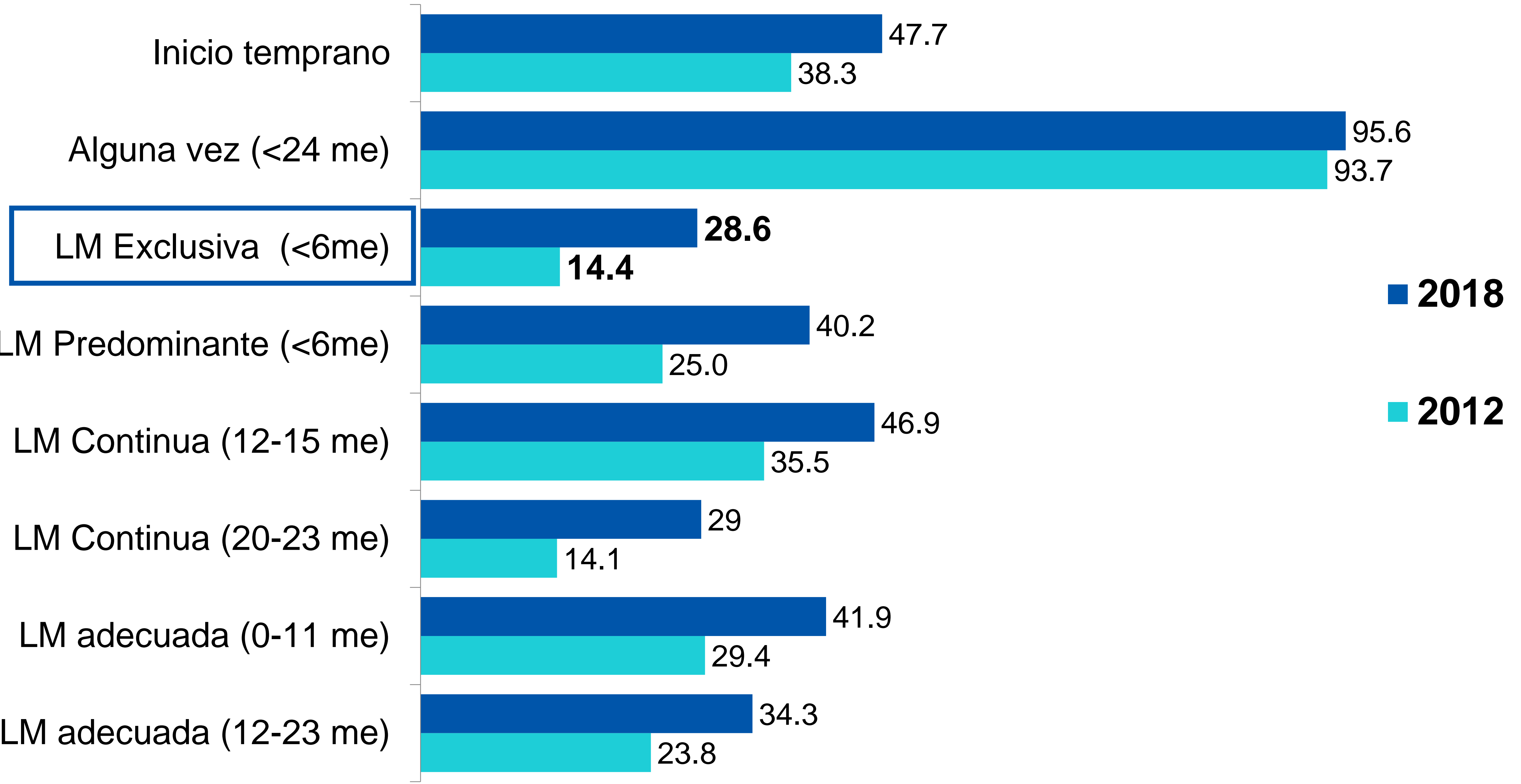

*me=meses 


\section{Lactancia materna}

Indicadores de Lactancia Materna en menores de 2 años según tipo de localidad, 2018

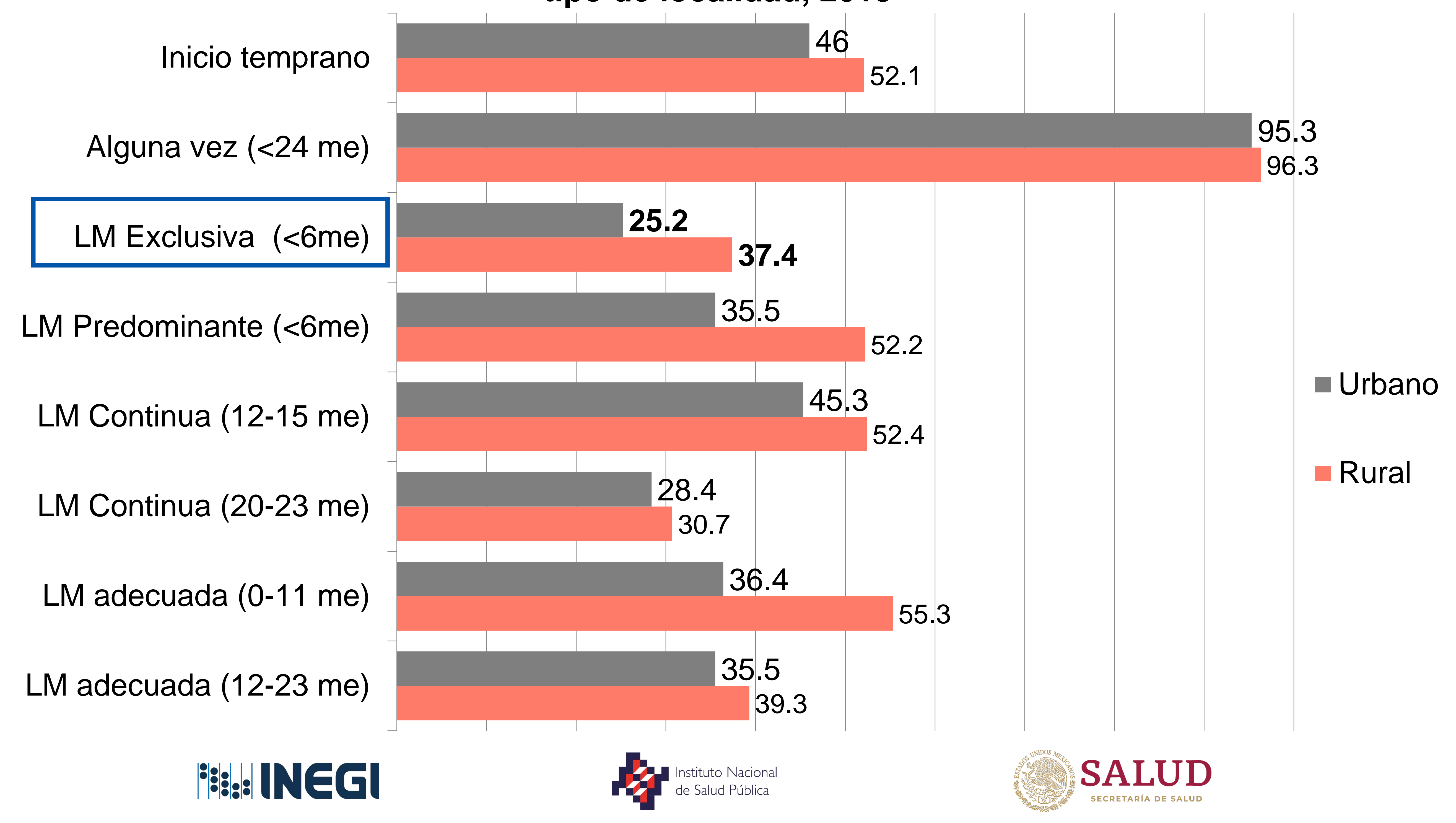




\section{Consumo de alimentos Recomendables}

\section{Porcentaje de población que consume alimentos Recomendables para}

consumo cotidiano, por grupos de edad

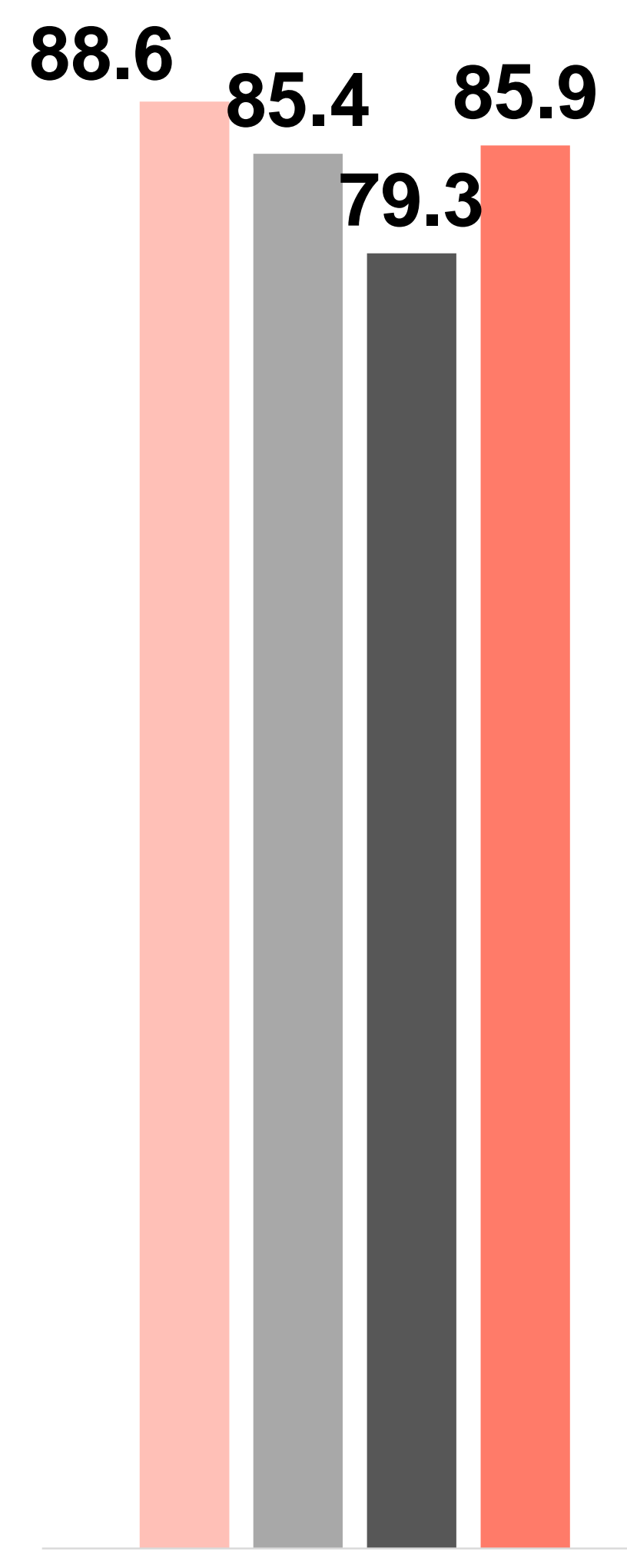

Agua
65.7

56.5

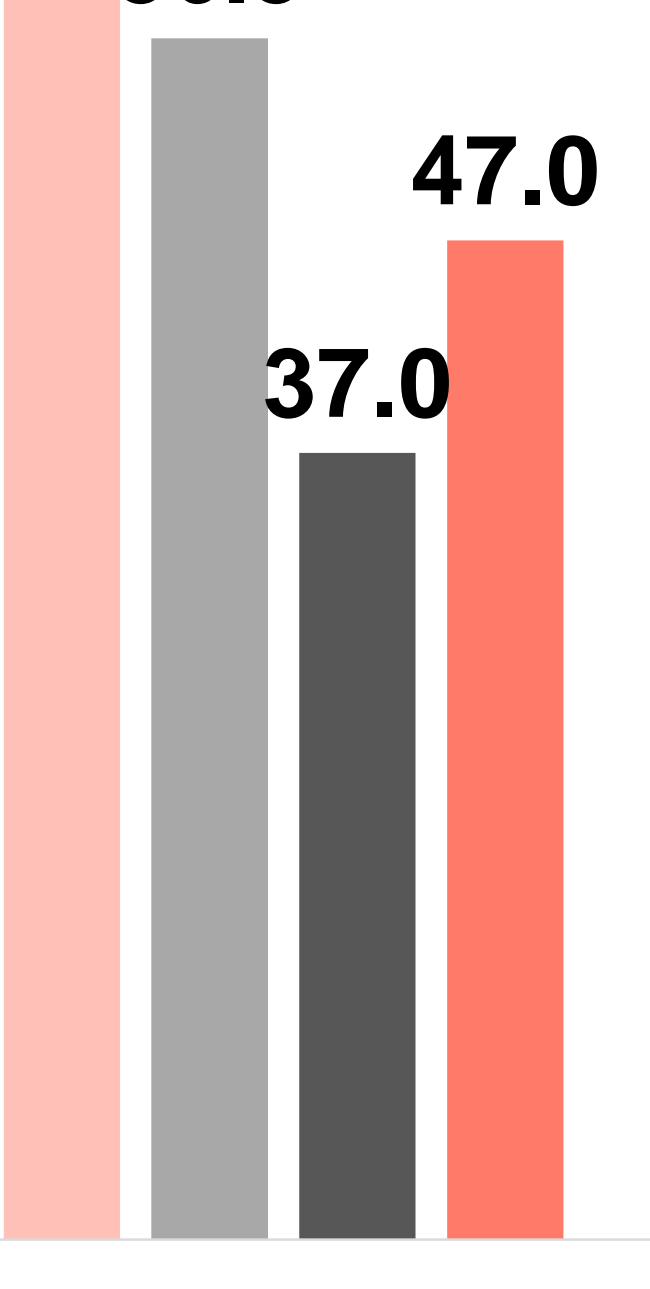

Lácteos
De 1 a 4 años

De 5 a 11 años
2018

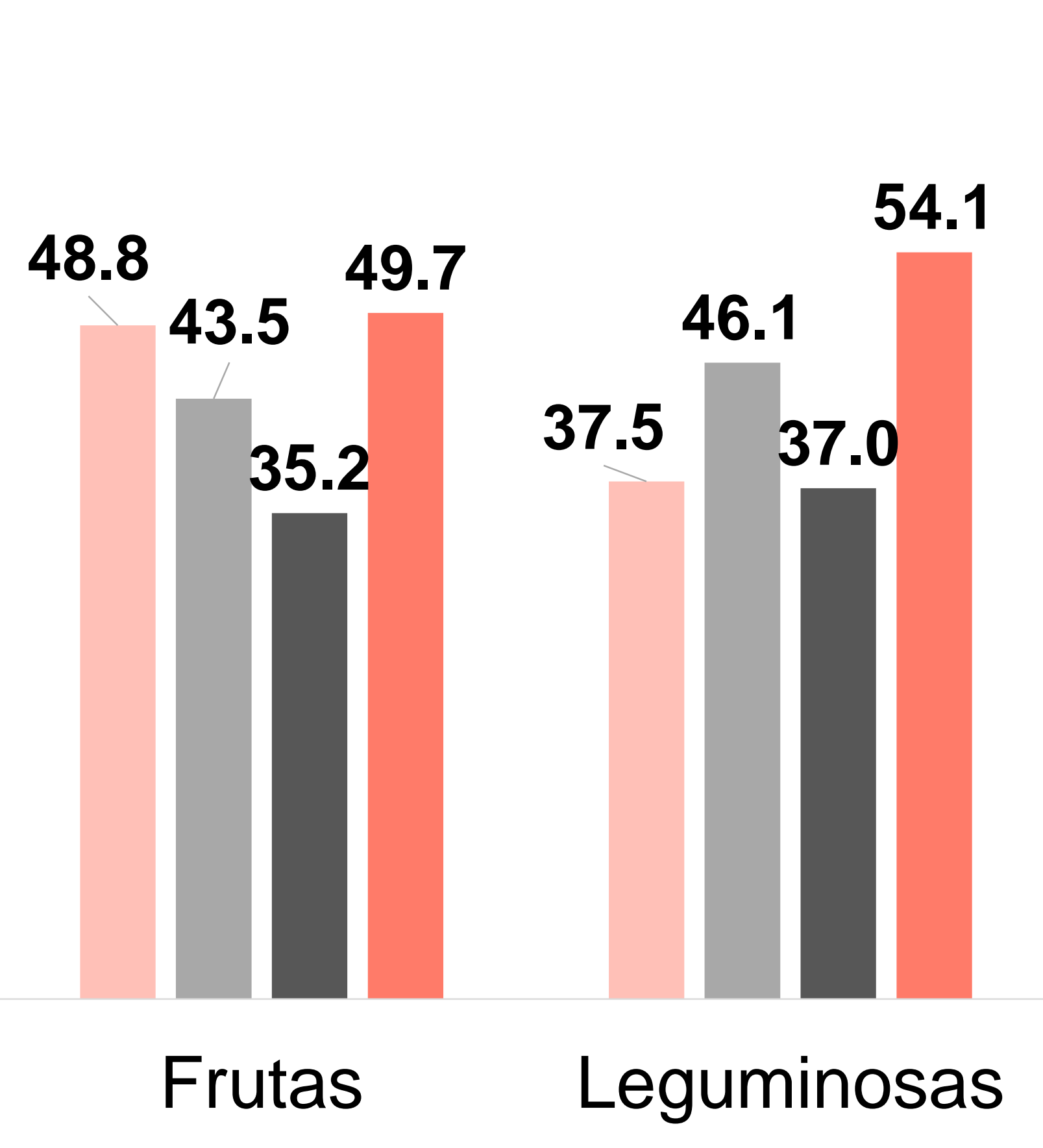

64.6

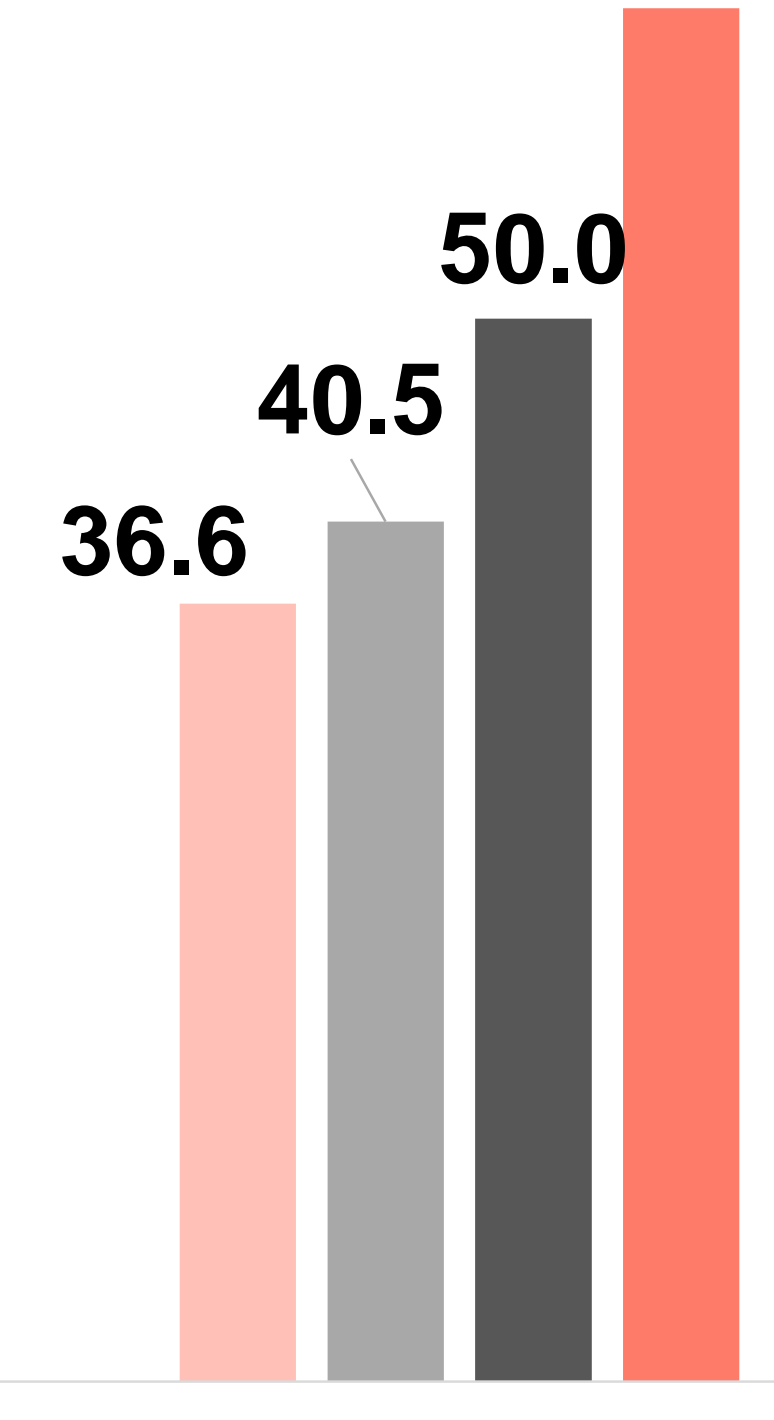

Carnes

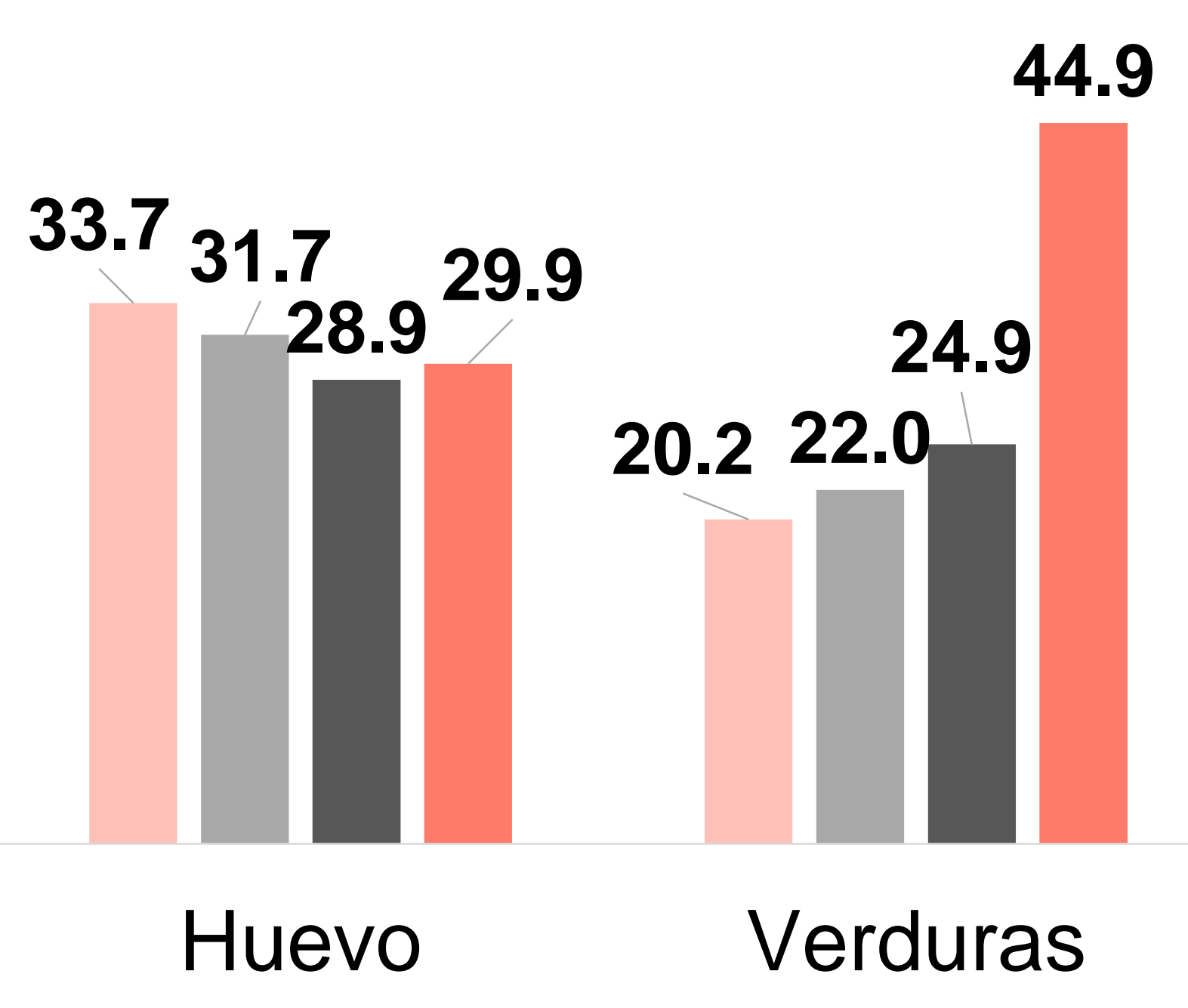

- De 12 a 19 años $\quad$ De 20 años y más 


\section{Consumo de alimentos No Recomendables}

Porcentaje de población que consume alimentos No Recomendables para consumo cotidiano, por grupos de edad

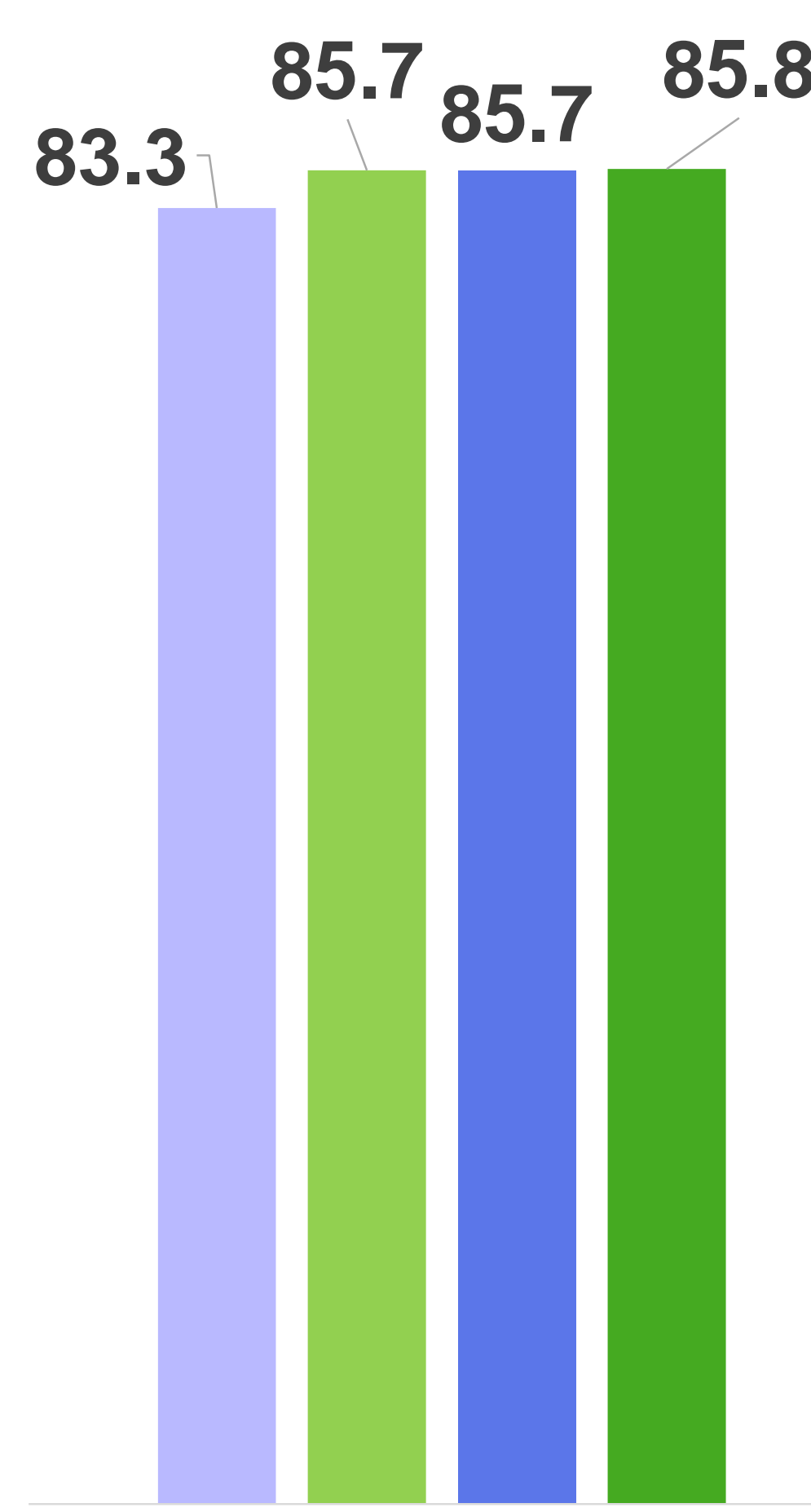

Bebidas no-lácteas endulzadas

\subsection{4 .6}

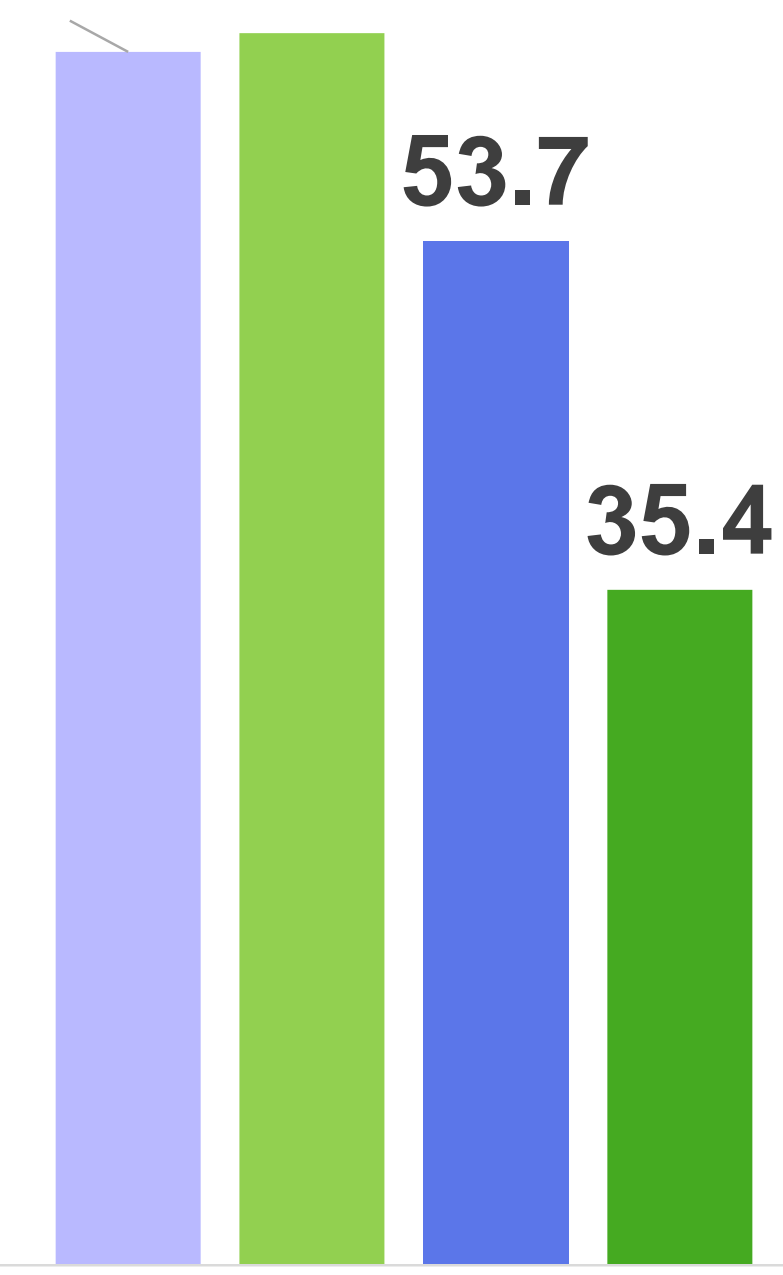

Botanas, dulces y postres

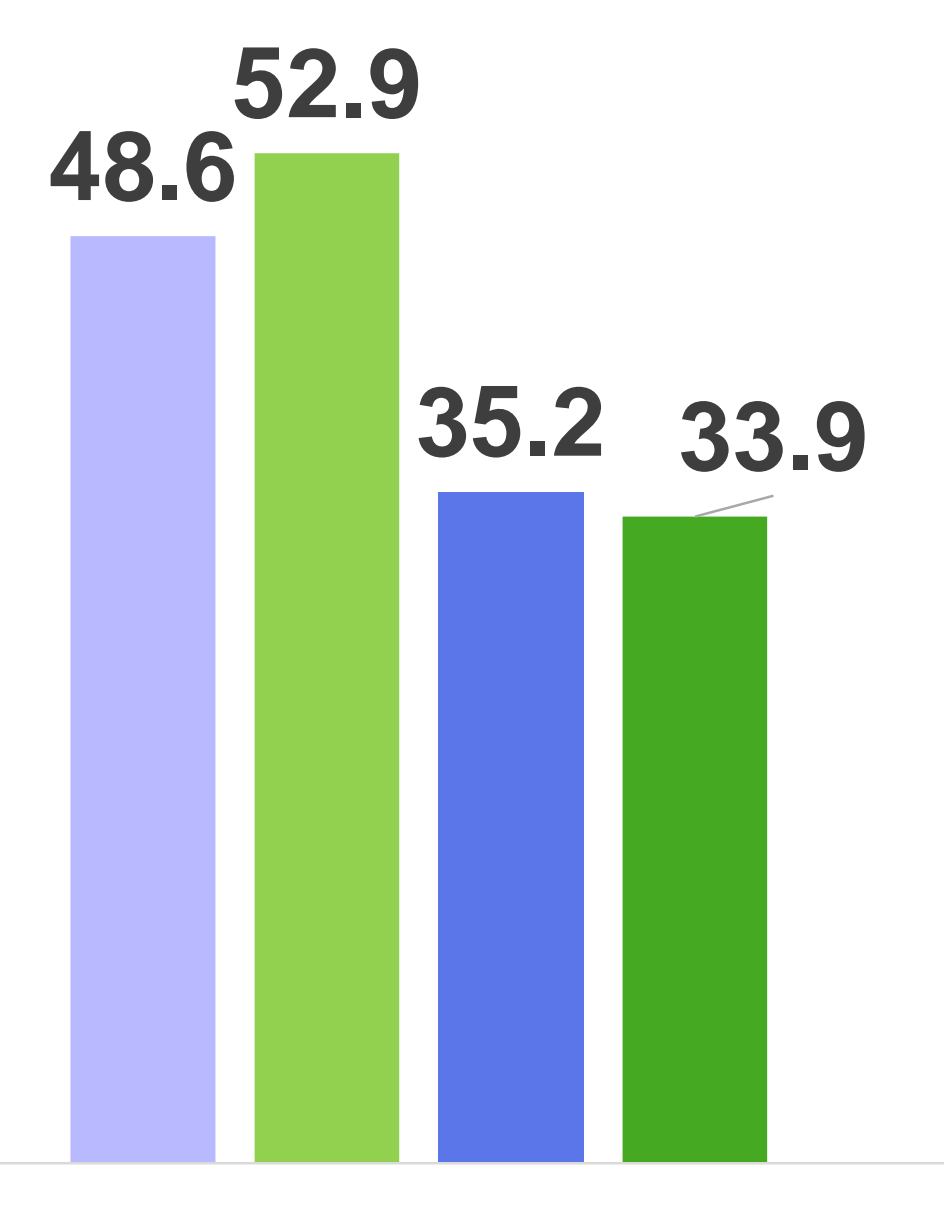

Cereales dulces
De 1 a 4 años De 5 a 11 años
2018

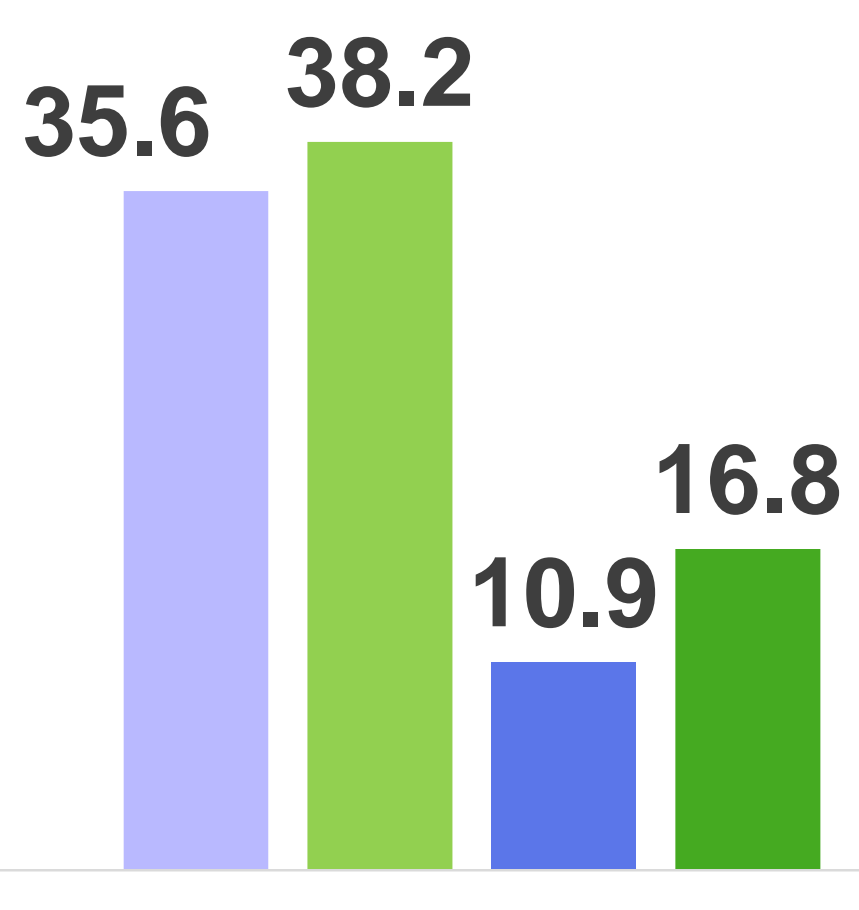

Bebidas lácteas endulzadas
- De 12 a 19 años

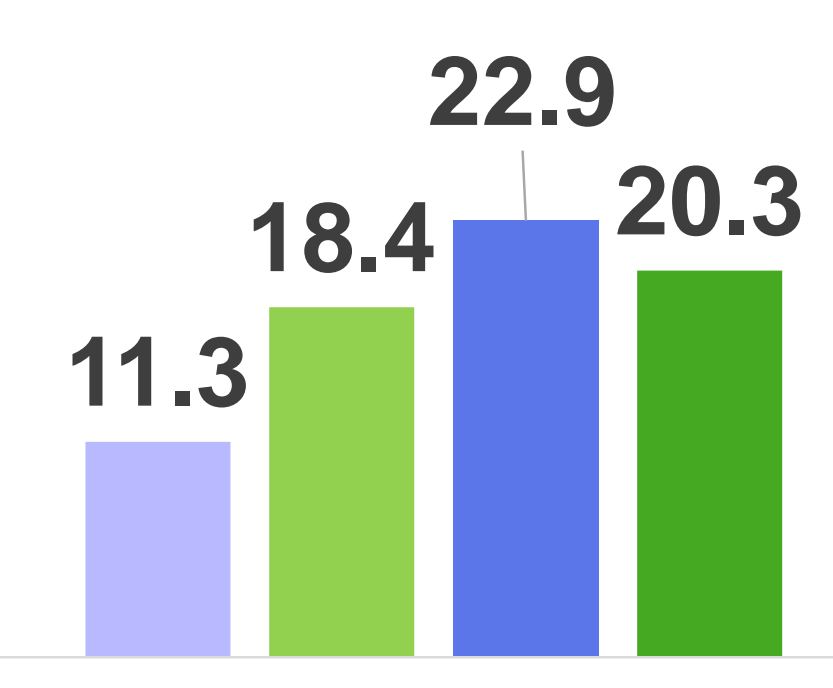

Comida rápida y antojitos mexicanos

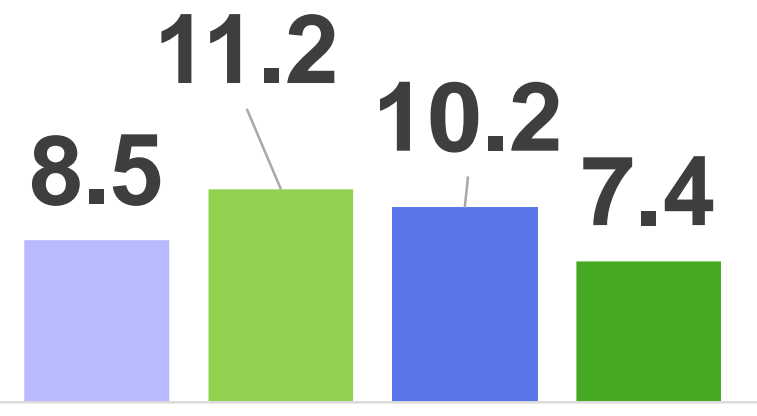

Carnes procesadas 


\section{Sobrepeso en población de 0 a 4 años}

Porcentaje de población de 0 a 4 años de edad con sobrepeso 2006-2018

\section{7}

8.3

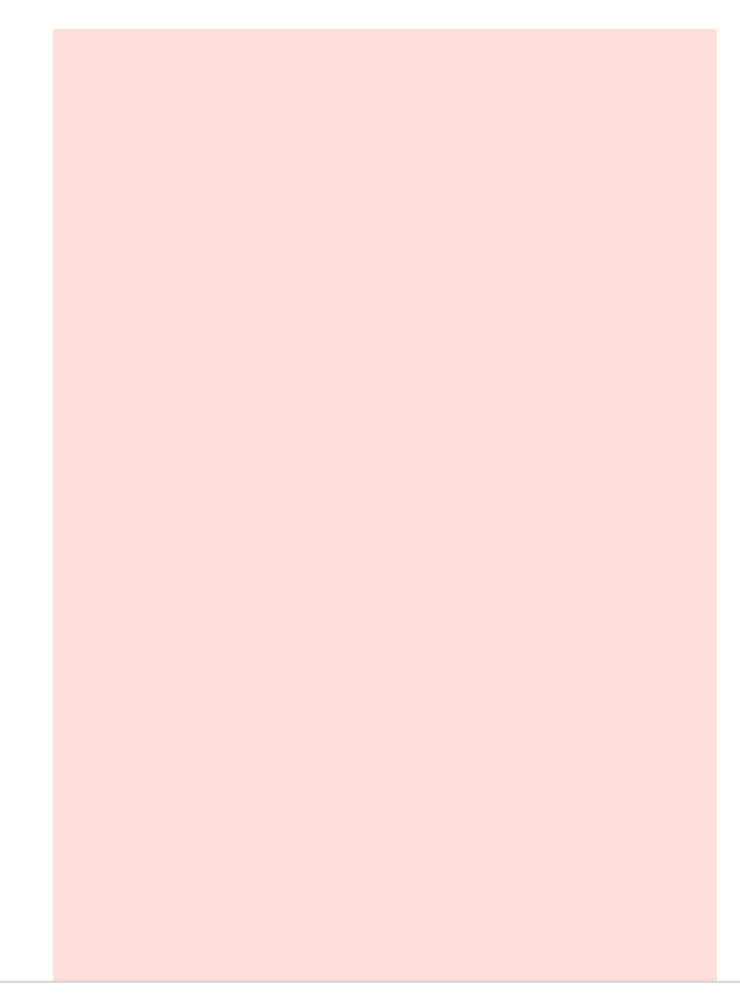

2006

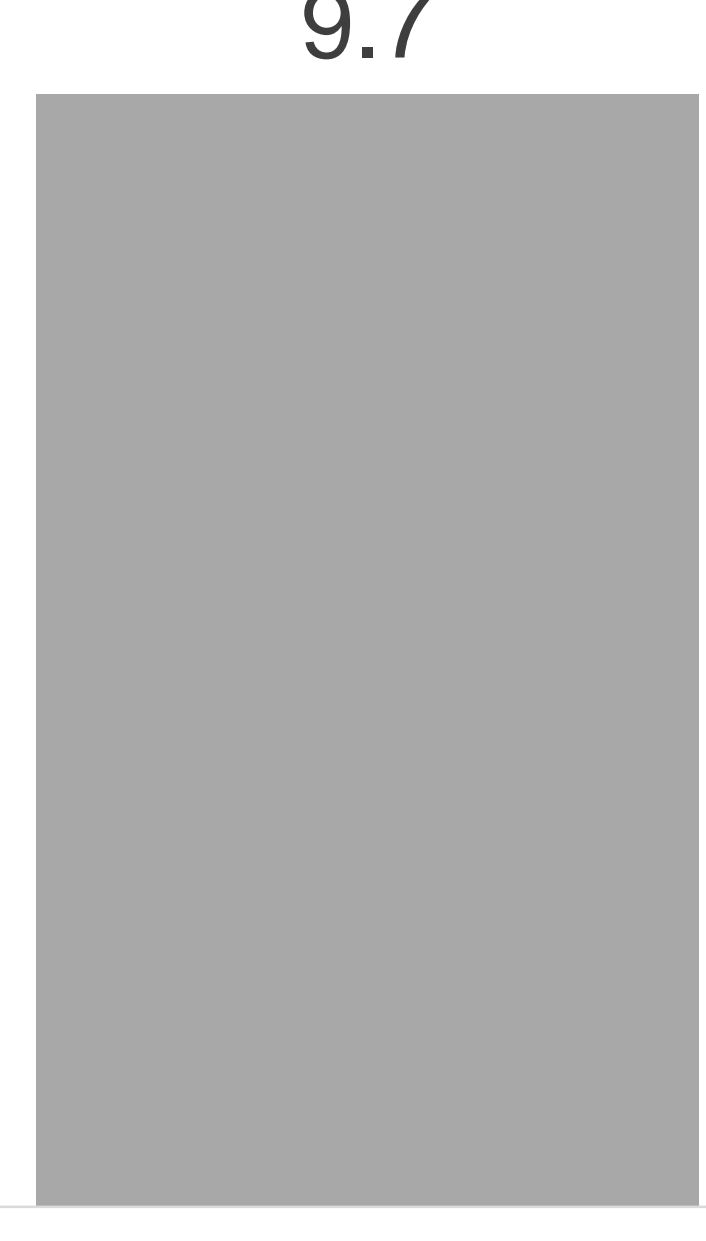

2012

\section{2}

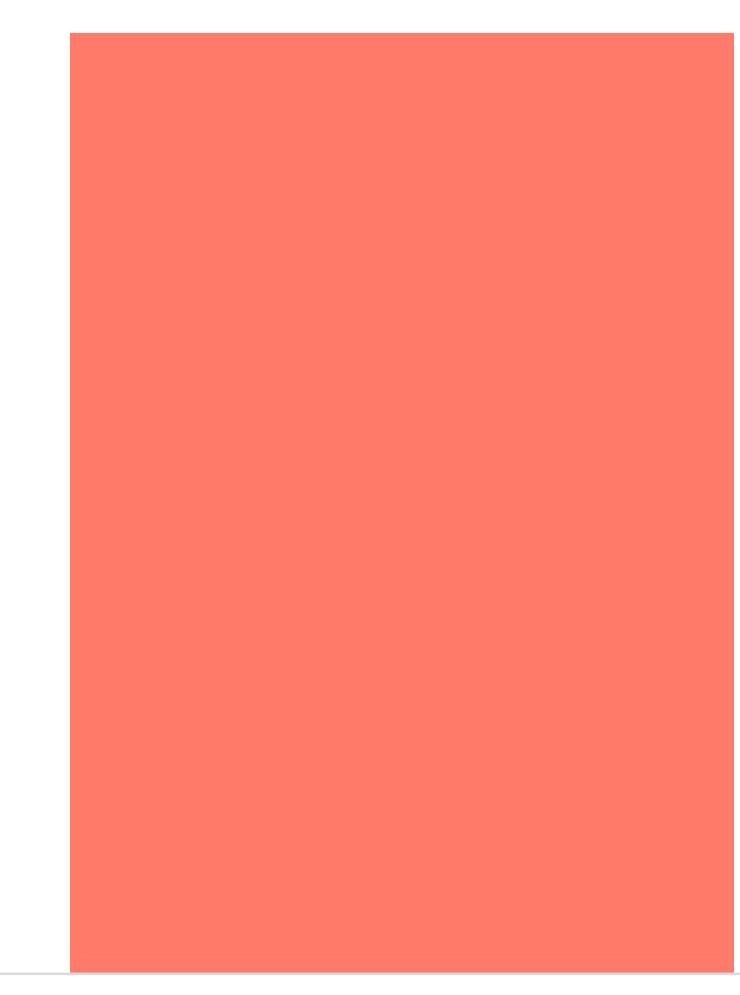

2018
Porcentaje de población de 0 a 4 años de edad con riesgo de sobrepeso y sobrepeso, por tipo de localidad, 2018

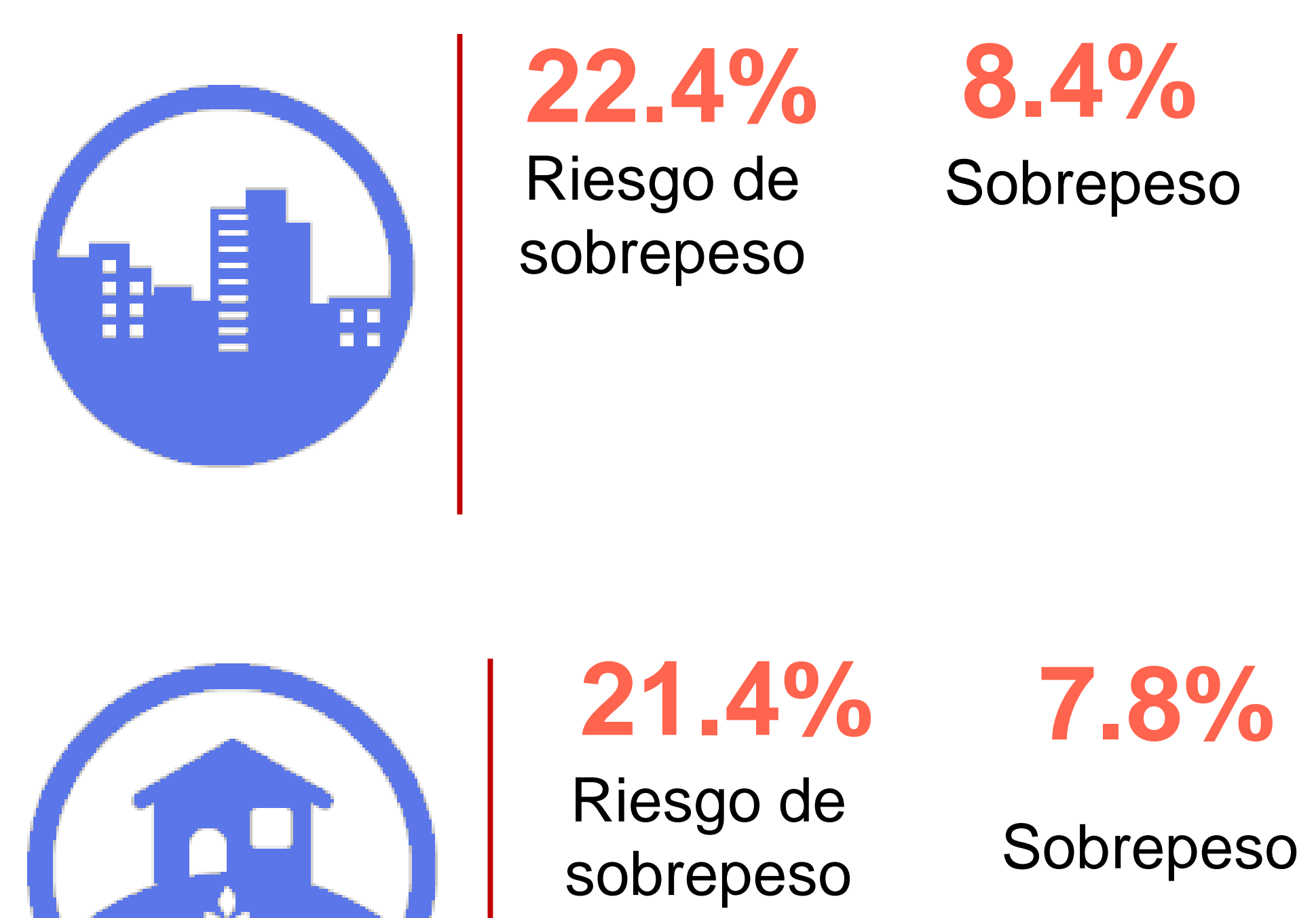

En 2018, el 22.2\% de la población de 0 a 4 años se identifica con riesgo de sobrepeso. 


\section{Sobrepeso y obesidad en población de 5 a 11 años}

Prevalencia de sobrepeso y obesidad en la población de 5 a 11 años de edad 2006 - 2018

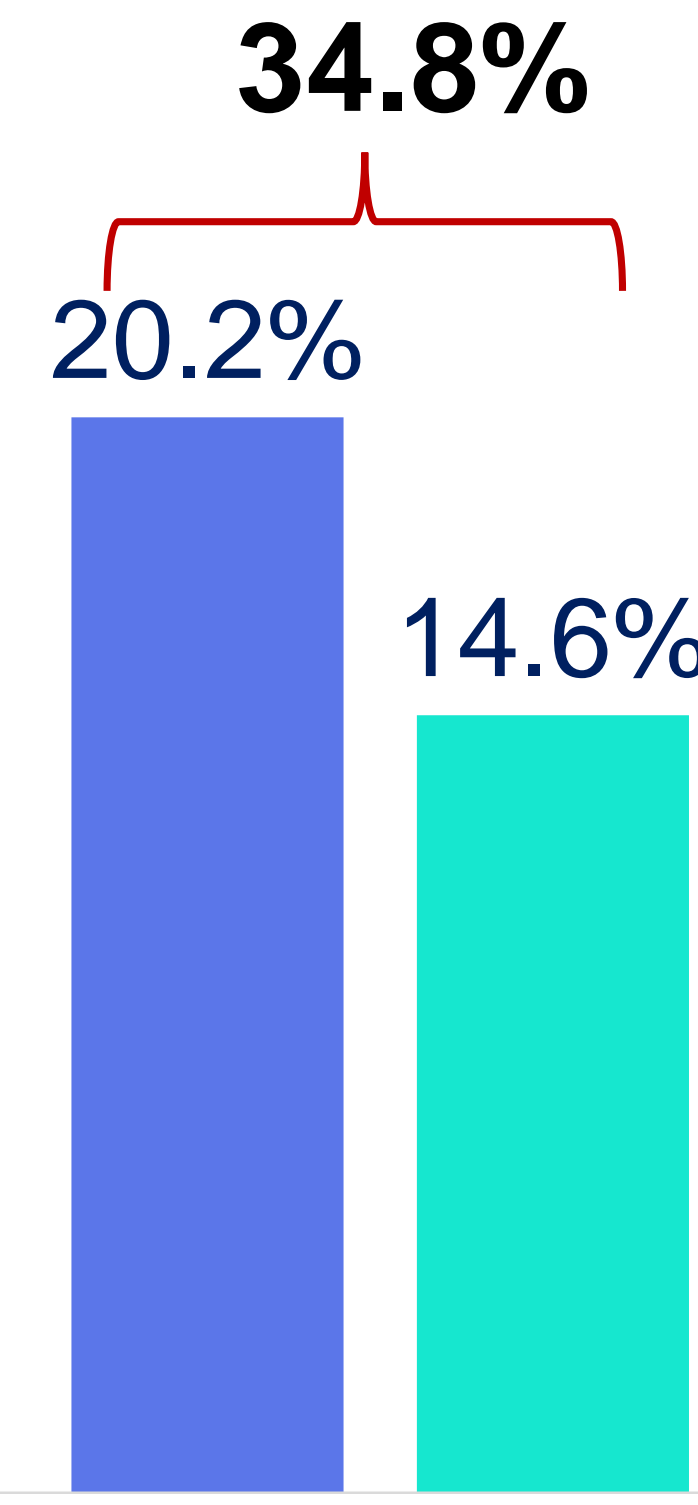

2006

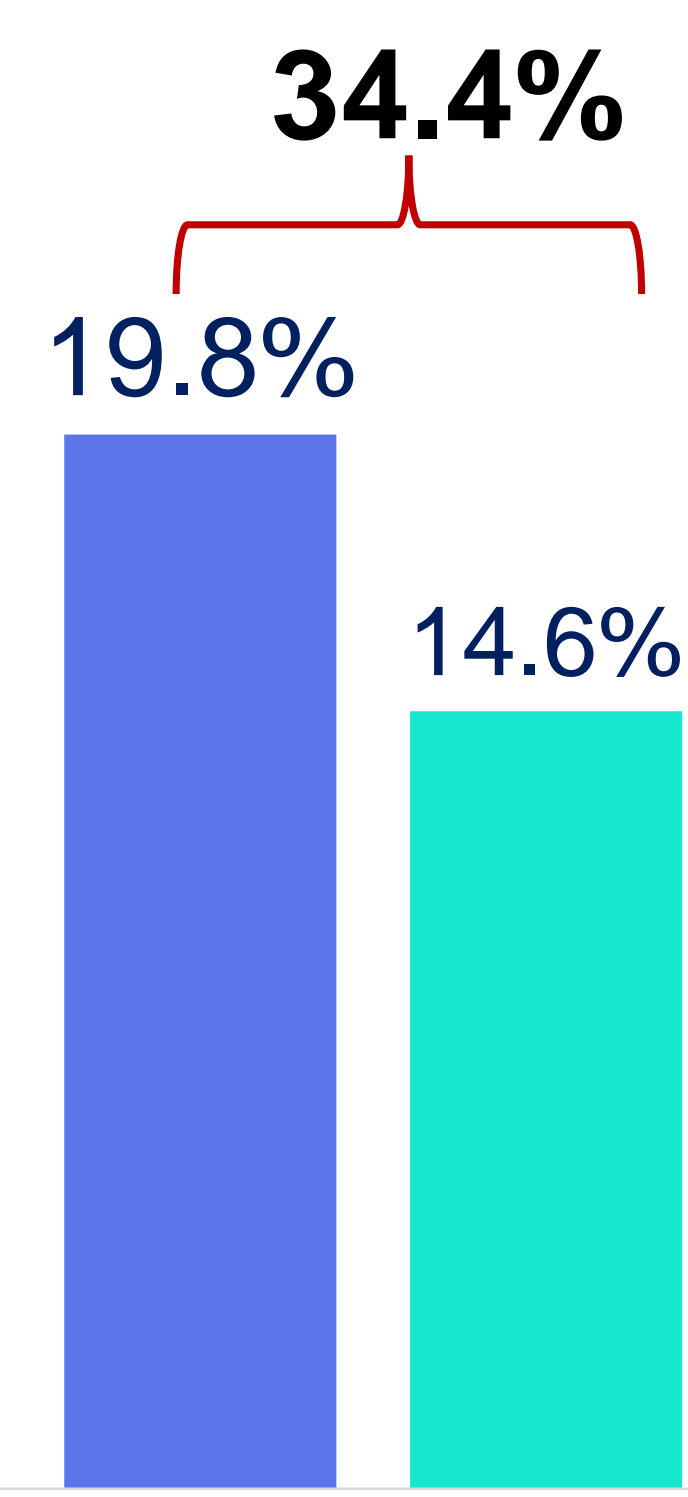

2012

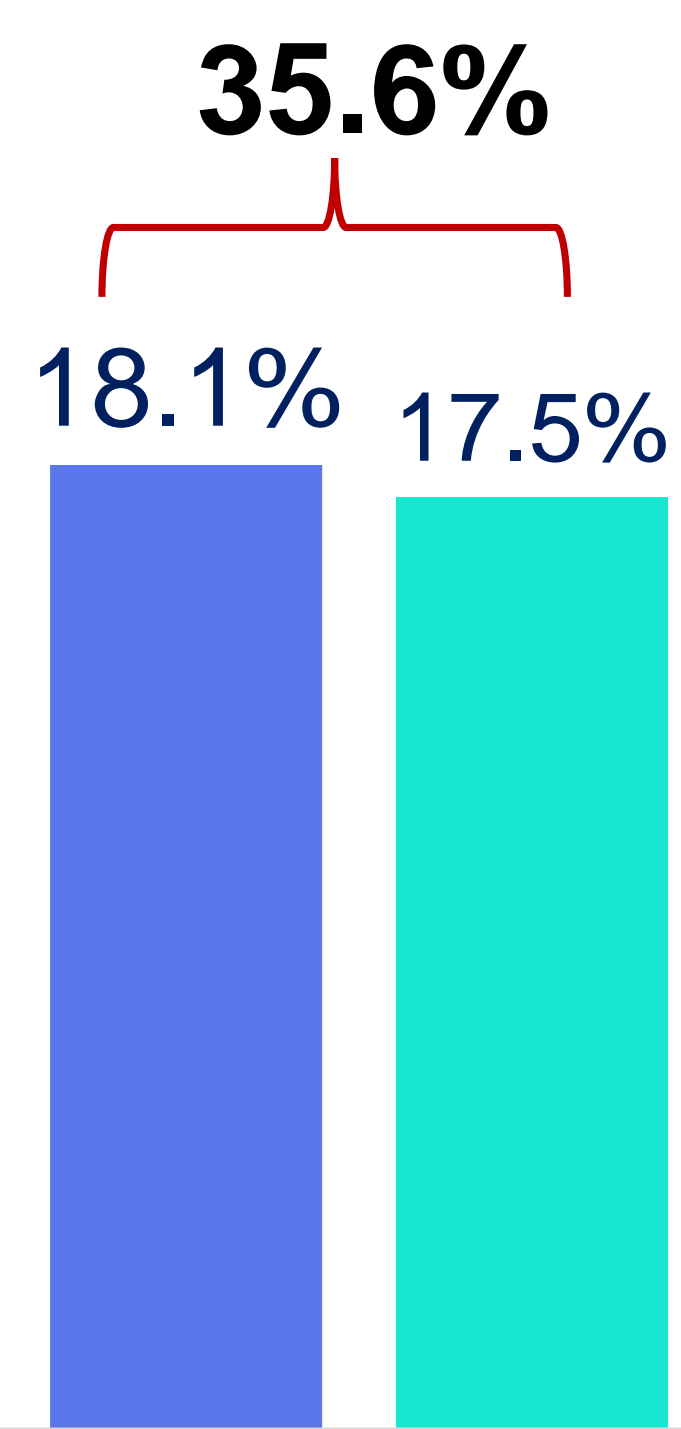

2018
Porcentaje de población de 5 a 11 años de edad con sobrepeso y obesidad, por tipo de localidad, 2018
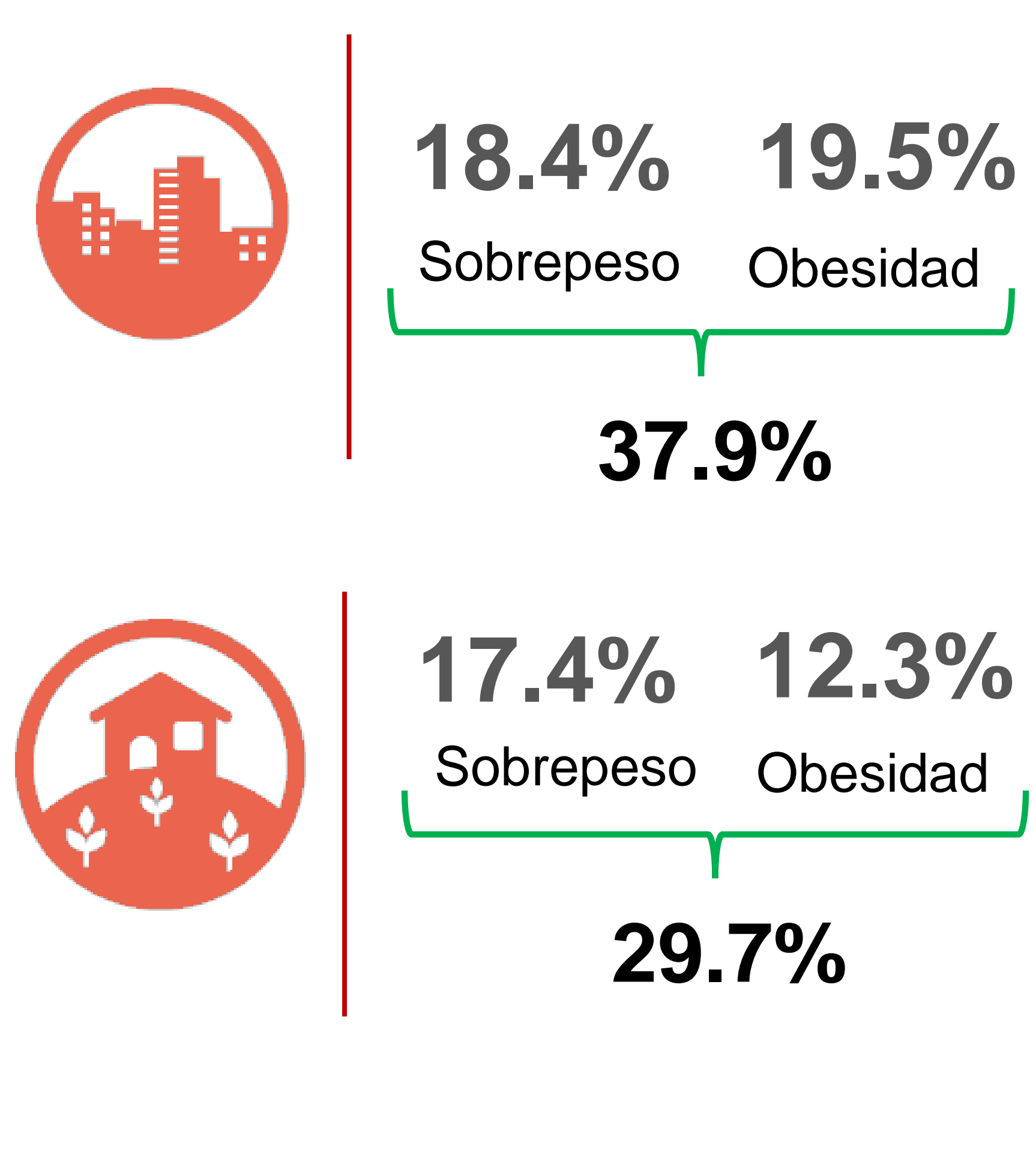

$17.4 \% \quad 12.3 \%$

Sobrepeso Obesidad

$29.7 \%$

- Sobrepeso $\quad$ Obesidad 


\section{Sobrepeso y obesidad en población de 12 a 19 años}

Porcentaje de población de 12 a 19 años de edad con sobrepeso y obesidad por sexo 2012 - 2018

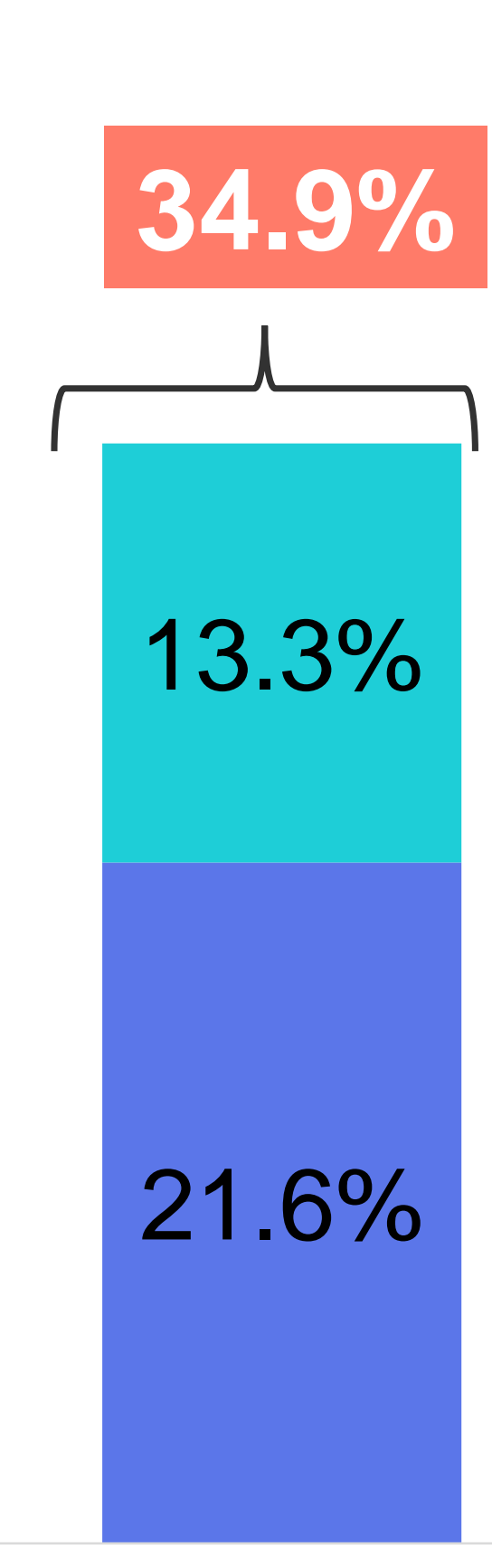

2012

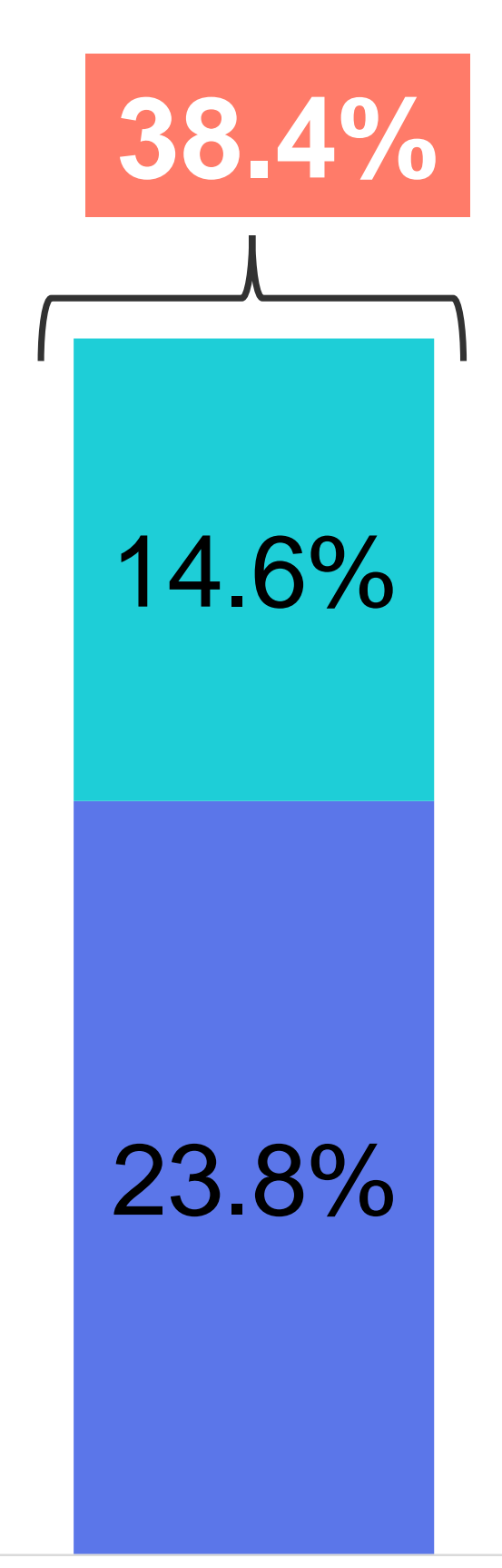

2018

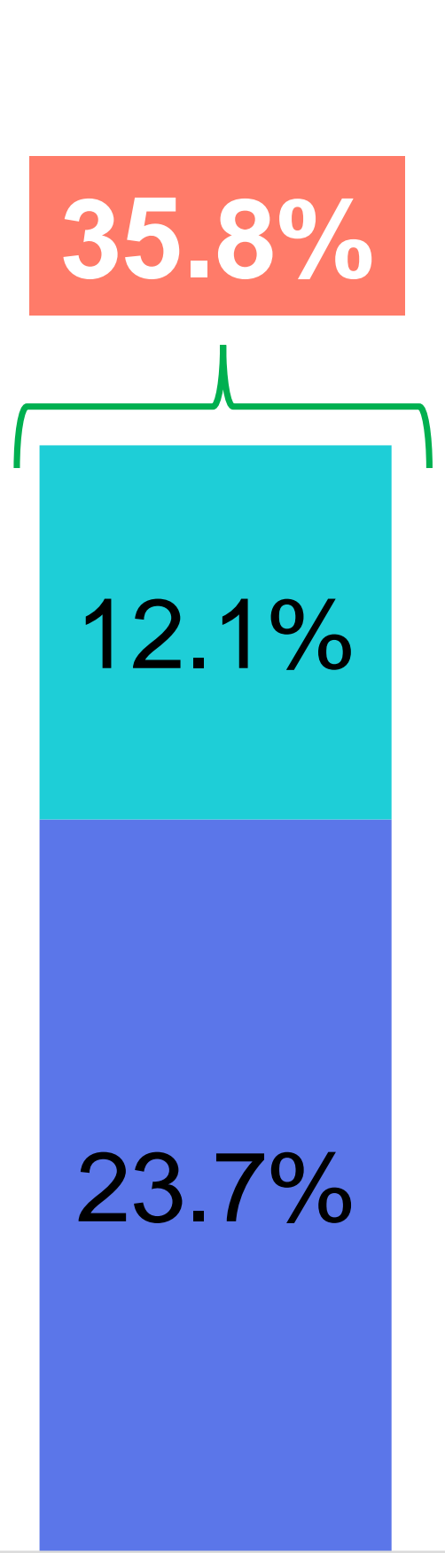

2012

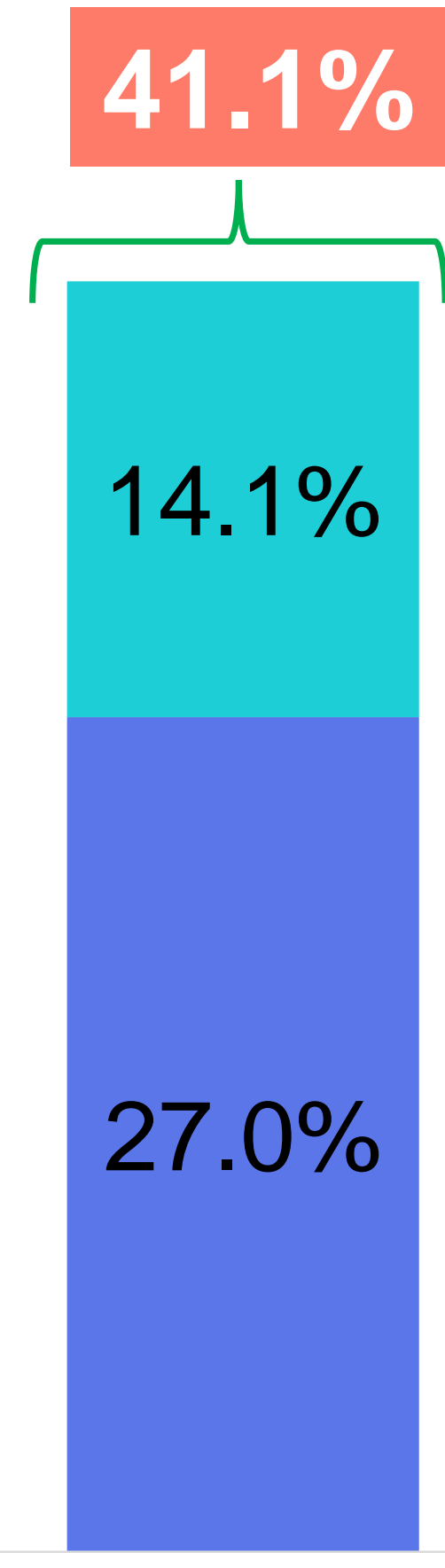

2018

Total

Porcentaje de población de 12 a 19 años con sobrepeso y obesidad por tipo de localidad, 2018

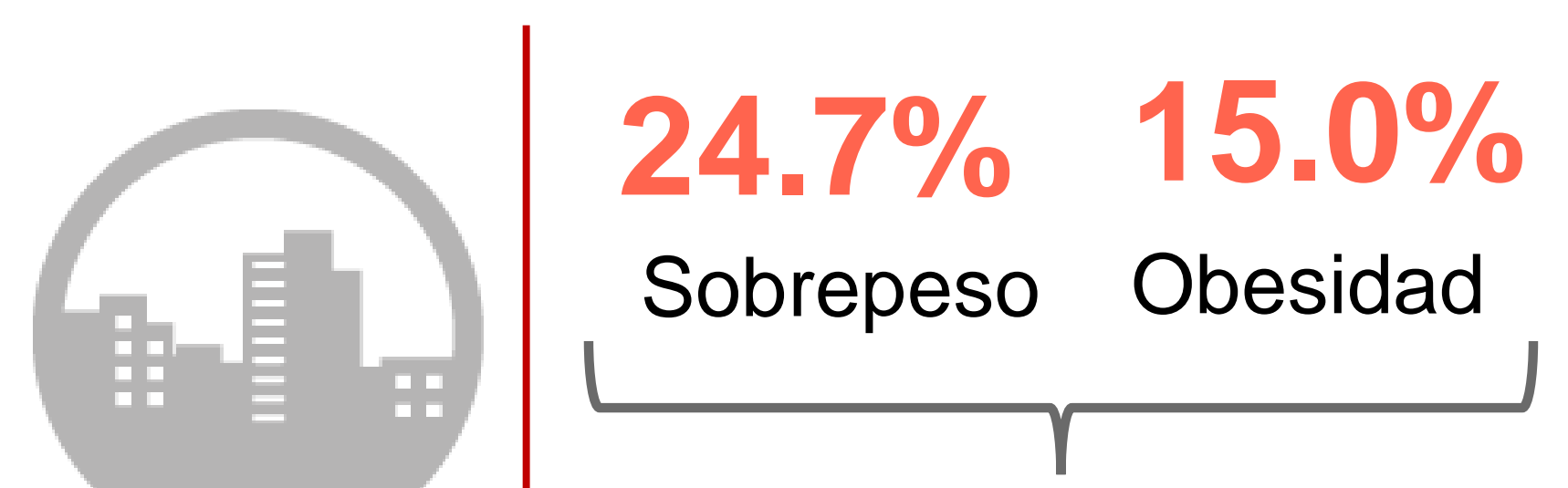

$39.7 \%$

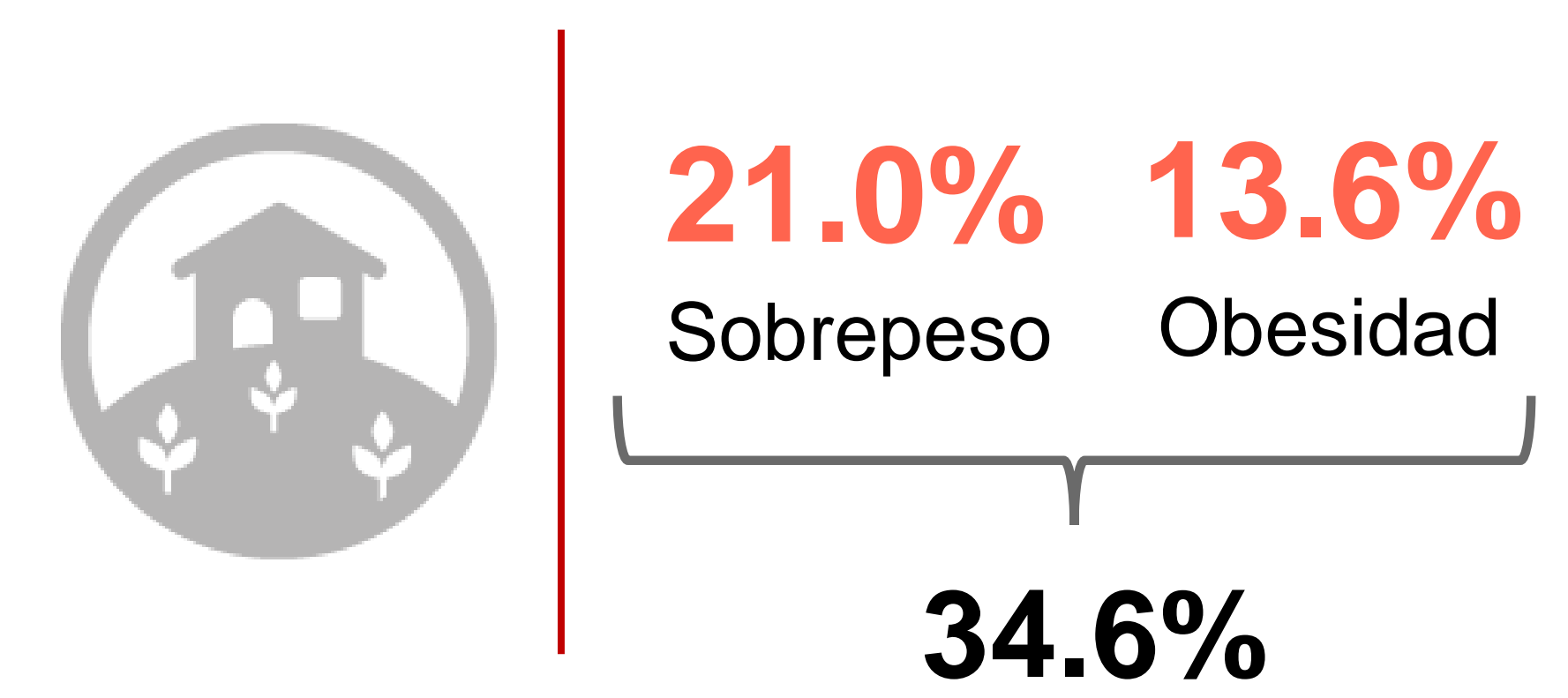

- Sobrepeso Obesidad 


\section{Obesidad en población de 12 a 19 años}

Porcentaje de población de 12 a 19 años de edad con obesidad, por entidad federativa

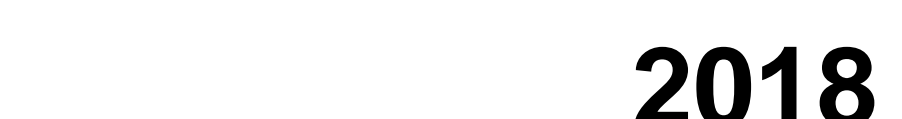

$[19.9,24.9]$

$[15.8,19.8]$

$[12.0,15.7]$

[ $6.3,11.9]$

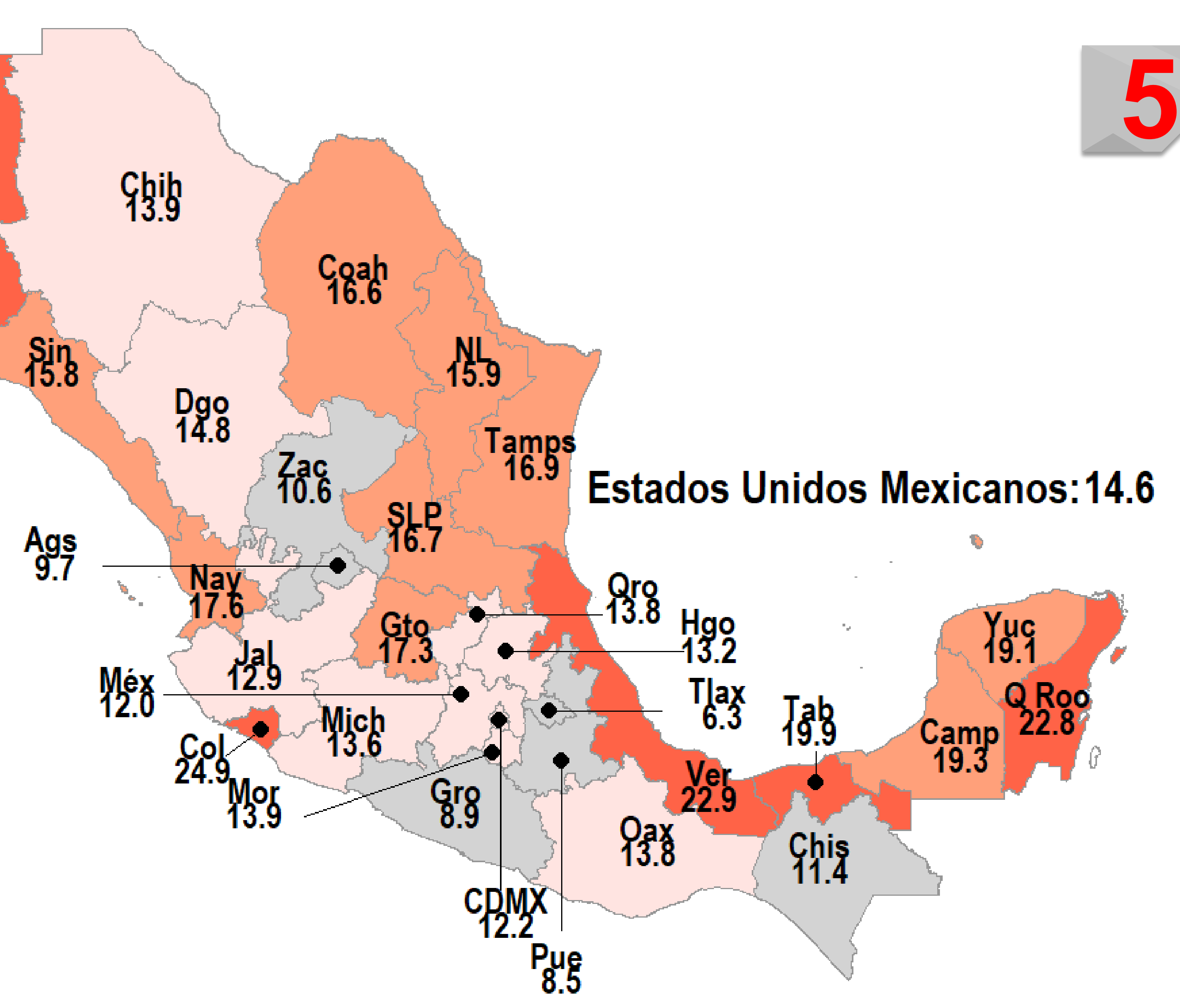

Entidades con porcentajes más altos: Veracruz, Quintana Roo, Colima, Sonora y Tabasco 


\section{Sobrepeso y obesidad en población de 20 y más años}

A nivel nacional, en 2018, el porcentaje de adultos de 20 años y más con sobrepeso y obesidad es de $\mathbf{7 5 . 2} \%$ (39.1\% sobrepeso y $36.1 \%$ obesidad), porcentaje que en 2012 fue de $\mathbf{7 1 . 3}$ por ciento.

Porcentaje de población de 20 años y más de edad con sobrepeso y obesidad, por sexo

2012 - 2018

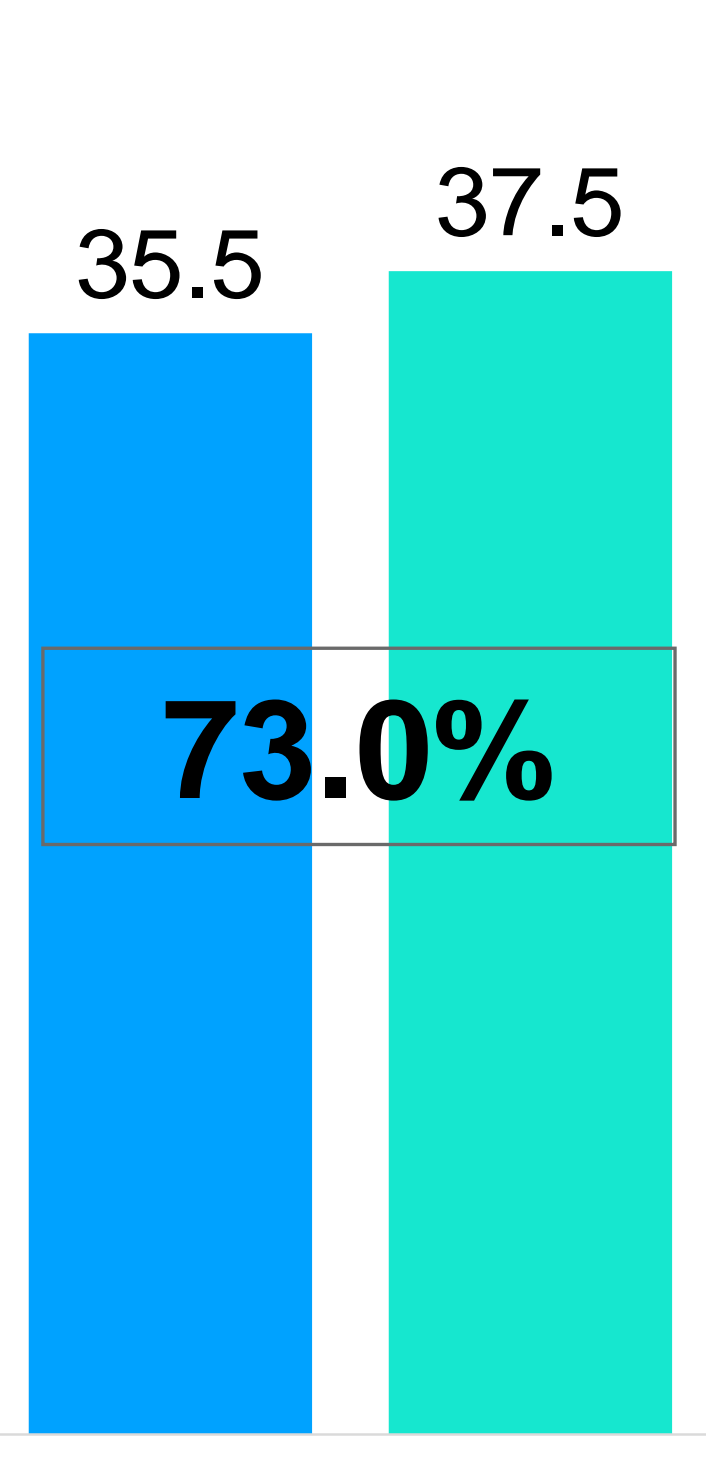

Mujeres

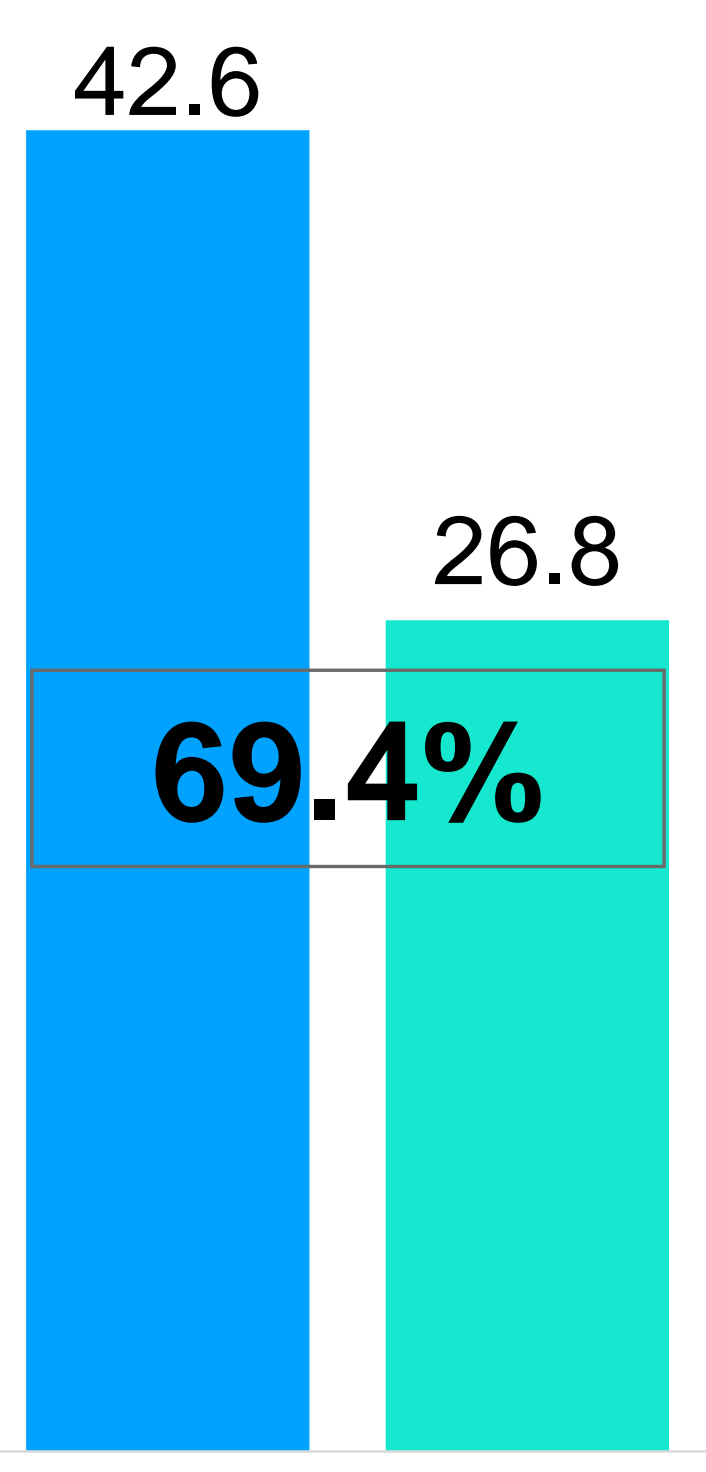

Hombres

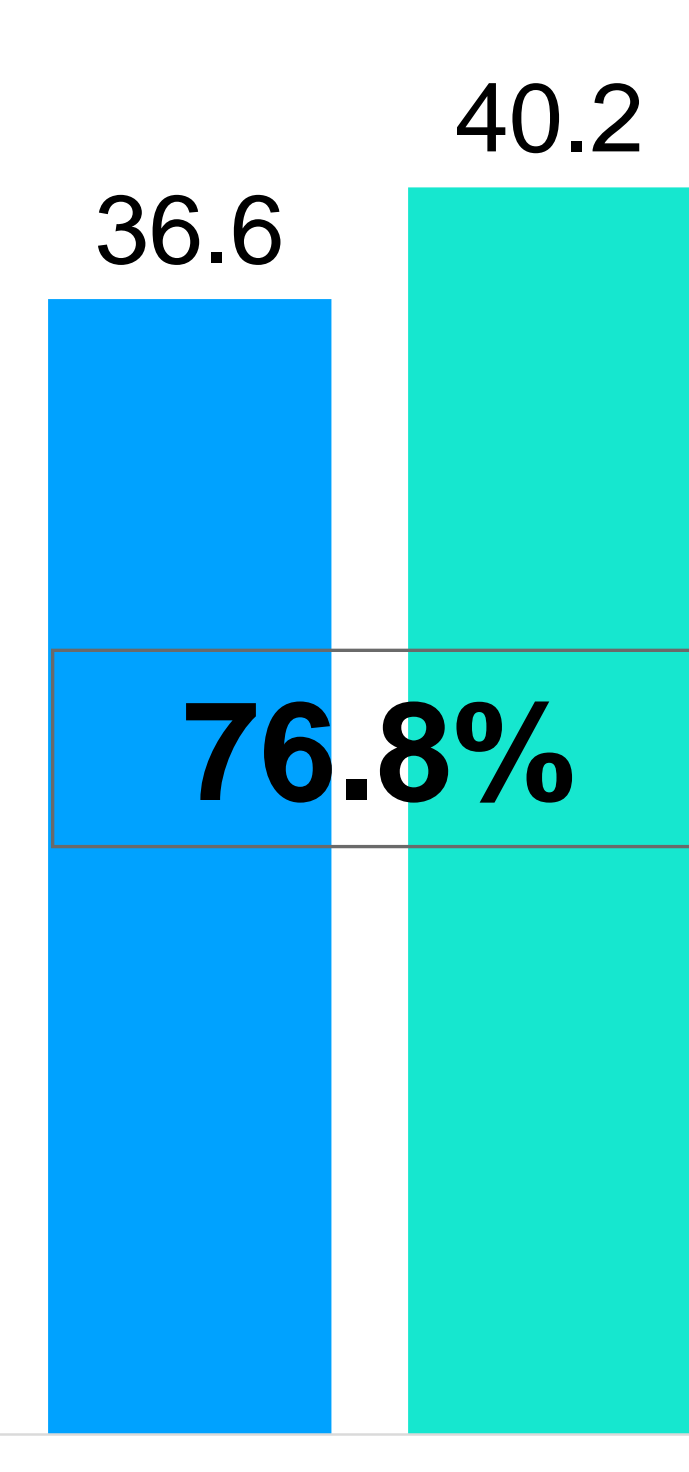

Mujeres

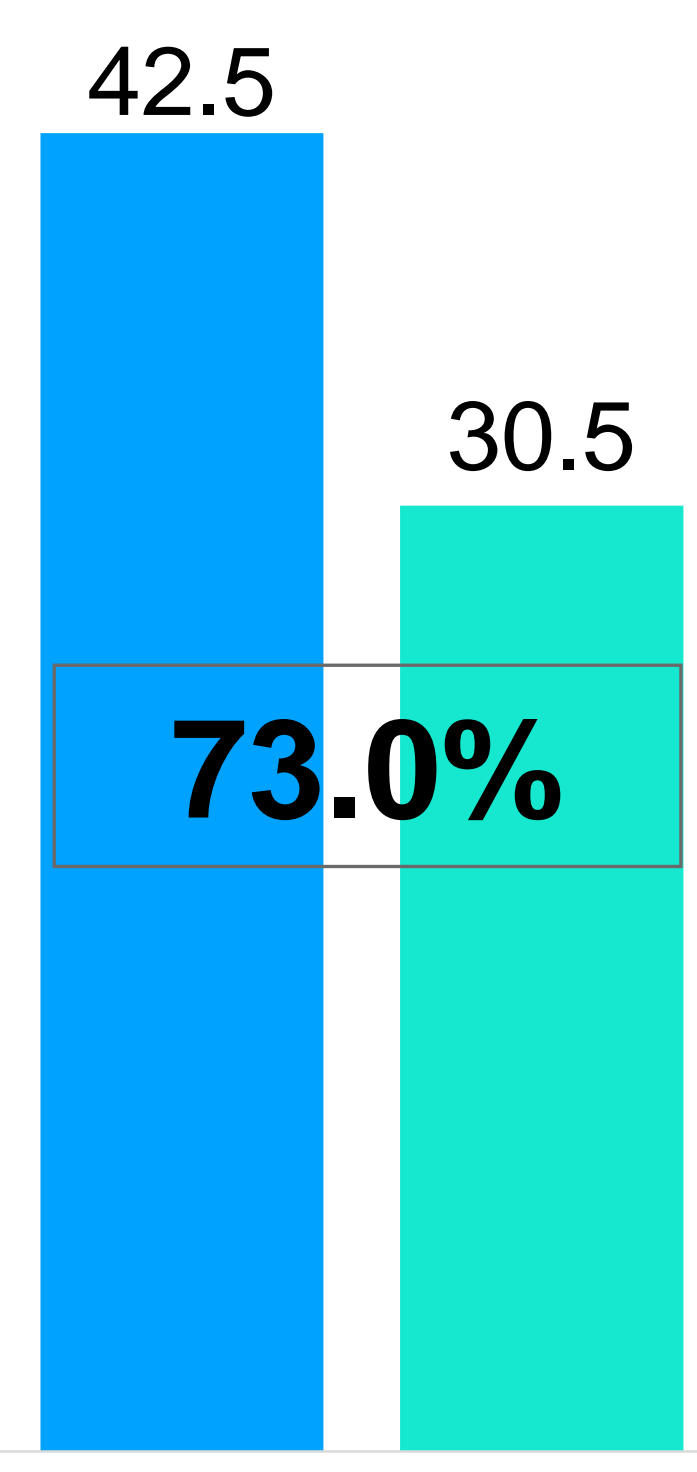

Hombres

2012 2018

- Sobrepeso $\quad$ Obesidad 


\title{
Conociendo México
}

\author{
018001114634 \\ www.inegi.org.mx \\ atencion.usuarios@inegi.org.mx \\ f 0 y 0 INECIInforma
}

